\title{
Isotopic and Fuel Lattice Parameter Trends in Extended Enrichment and Higher Burnup LWR Fuel
}

\section{Volume II: BWR Fuel}

\section{Approved for public release.} Distribution is unlimited.

Riley Cumberland Ryan Sweet Ugur Mertyurek Robert Hall William A. Wieselquist

March 2021 


\title{
DOCUMENT AVAILABILITY
}

Reports produced after January 1, 1996, are generally available free via US Department of Energy (DOE) SciTech Connect.

Website www.osti.gov

Reports produced before January 1, 1996, may be purchased by members of the public from the following source:

\author{
National Technical Information Service \\ 5285 Port Royal Road \\ Springfield, VA 22161 \\ Telephone 703-605-6000 (1-800-553-6847) \\ TDD 703-487-4639 \\ Fax 703-605-6900 \\ E-mail info@ntis.gov \\ Website http://classic.ntis.gov/
}

Reports are available to DOE employees, DOE contractors, Energy Technology Data Exchange representatives, and International Nuclear Information System representatives from the following source:

Office of Scientific and Technical Information

PO Box 62

Oak Ridge, TN 37831

Telephone 865-576-8401

Fax 865-576-5728

E-mail reports@osti.gov

Website http://www.osti.gov/contact.html

This report was prepared as an account of work sponsored by an agency of the United States Government. Neither the United States Government nor any agency thereof, nor any of their employees, makes any warranty, express or implied, or assumes any legal liability or responsibility for the accuracy, completeness, or usefulness of any information, apparatus, product, or process disclosed, or represents that its use would not infringe privately owned rights. Reference herein to any specific commercial product, process, or service by trade name, trademark, manufacturer, or otherwise, does not necessarily constitute or imply its endorsement, recommendation, or favoring by the United States Government or any agency thereof. The views and opinions of authors expressed herein do not necessarily state or reflect those of the United States Government or any agency thereof. 
Nuclear Energy Fuel Cycle Division

\section{ISOTOPIC AND FUEL LATTICE PARAMETER TRENDS IN EXTENDED ENRICHMENT AND HIGHER BURNUP LWR FUEL}

\section{VOLUME II: BWR FUEL}

Riley Cumberland, Ryan Sweet, Ugur Mertyurek, Robert Hall, William A. Wieselquist

Date Published: March 2021

Prepared by

OAK RIDGE NATIONAL LABORATORY

Oak Ridge, TN 37831-6283

managed by

UT-BATTELLE, LLC

for the

US DEPARTMENT OF ENERGY

under contract DE-AC05-00OR22725 



\section{CONTENTS}

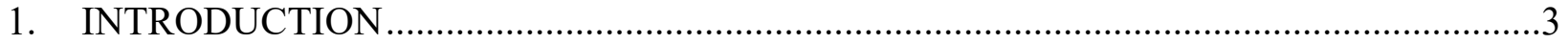

1.1 EXPECTED EFFECTS OF HBU AND EE ON FUEL MANAGEMENT ..................4

2. LATTICE PHYSICS MODEL DESCRIPTION ..........................................................

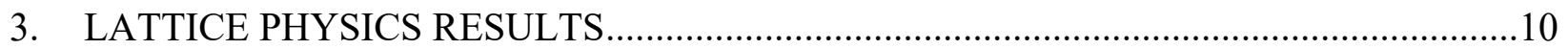

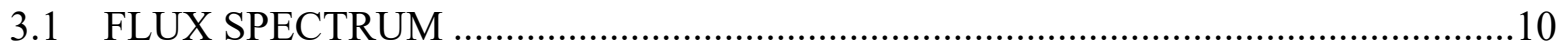

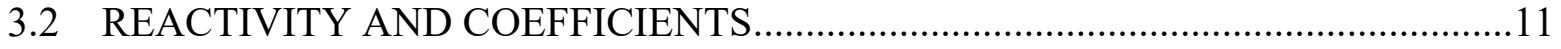

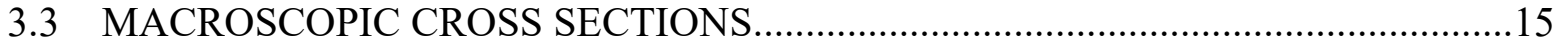

3.3.1 Lattice Cross Sections .......................................................................... 15

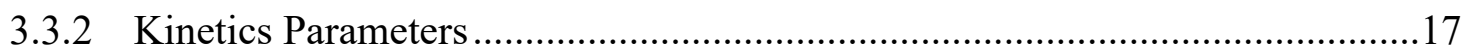

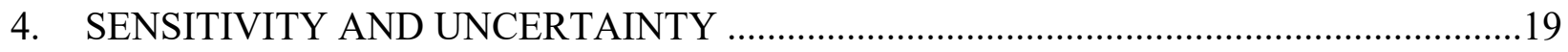

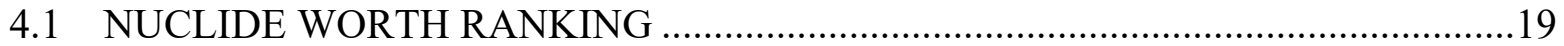

4.2 SAMPLER/POLARIS DEPLETION UNCERTAINTY ........................................21

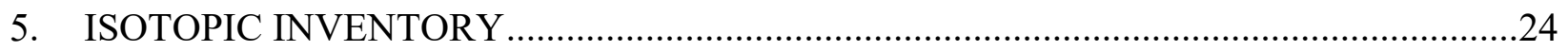

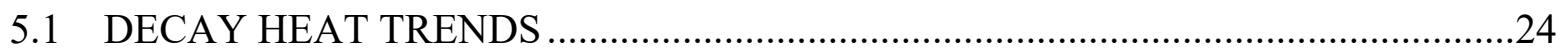

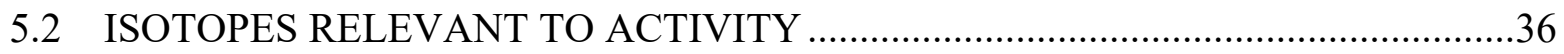

5.3 ISOTOPES RELEVANT TO ACCIDENT RELEASE SOURCE TERM .................41

5.4 ISOTOPES RELEVANT TO RADIATION SHIELDING SOURCE TERM ............43

5.5 ISOTOPES FOR CRITICALITY ......................................................................49

5.6 COMPARISON OF 252g AND 56g MULTIGROUP LIBRARIES .........................53

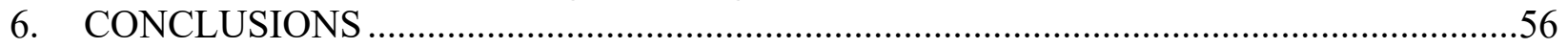

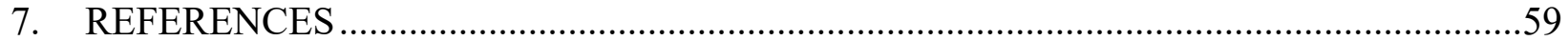

APPENDIX A. EFFECT OF CROSS SECTION LIBRARY …......................................... A-1

APPENDIX B. ARCHIVE FILE CONTENT ................................................................. 


\section{LIST OF FIGURES}

Figure 1. Layout of 5max-4.5av wt\% DOM (left) and 5max-4.5av wt\% VAN lattices

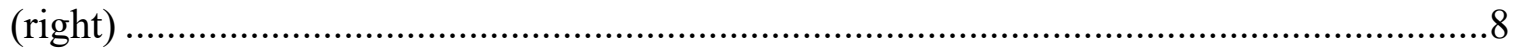

Figure 2. Layout of 8.5max-6.5av wt\% DOM (left) and 8.5max-5.9av wt\% VAN lattices

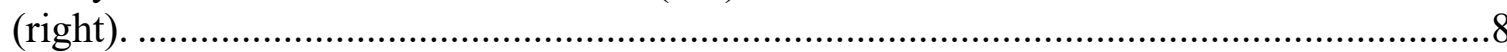

Figure 3. Layout of 10max-7.4av wt\% DOM (left) and 10max-7.4av wt\% VAN lattices

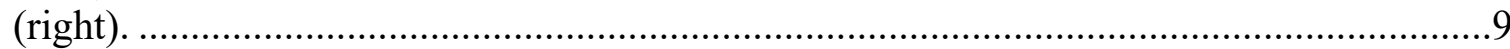

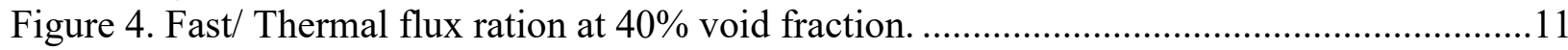

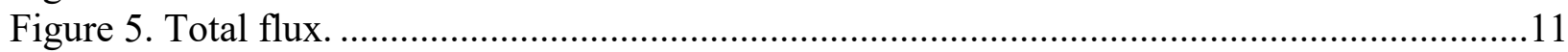

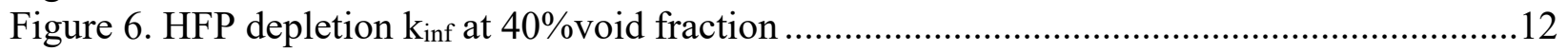

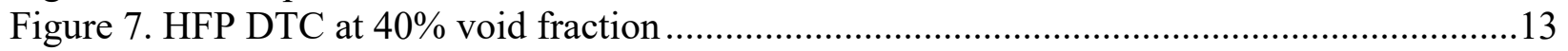

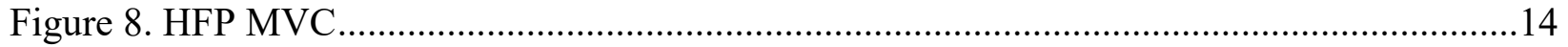

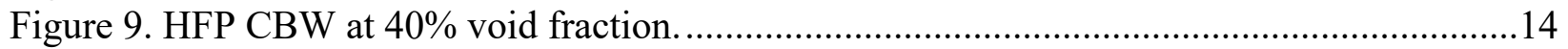

Figure 10. HFP macroscopic thermal absorption cross section ..........................................15

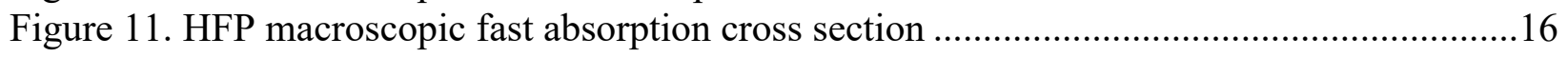

Figure 12. HFP macroscopic thermal fission cross section ..................................................16

Figure 13. HFP macroscopic fast fission cross section................................................ 17

Figure 14. Effective delayed neutron fraction ................................................................. 18

Figure 15. Uncertainty in $\mathrm{k}_{\text {inf }}$ at $40 \%$ void fraction due to nuclear data uncertainties.................23

Figure 16. Decay heat as a function of cooling time for all cases ........................................25

Figure 17. Decay heat as a function of cooling time (effect of enrichment and burnup) ............26

Figure 18. Decay heats as a fraction of full power vs cooling time.......................................26

Figure 19. Decay heat relative to $60 \mathrm{GWd} / \mathrm{MTU} 5 \mathrm{max}-4.5 \mathrm{av} 40 \%$ DOM case ..........................27

Figure 20. Decay heat difference with to $60 \mathrm{GWd}$ /MTU 5max-4.5av 40\% DOM case...............28

Figure 21. In-core abundances of ${ }^{144} \mathrm{Pr}$ beta chain isotopes for $10 \mathrm{max}-7.4 \mathrm{av} \mathrm{wt} \%$ initial

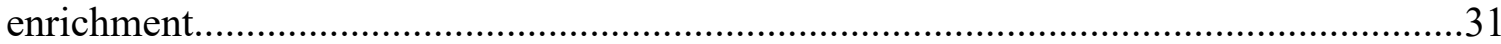

Figure 22. Activity as a function of cooling time for all 16 lattices.....................................36

Figure 23. Relative difference in activity with the reference case a function of cooling

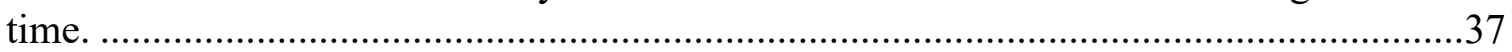

Figure 24. Difference in activity with the reference case a function of cooling time..................37

Figure 25. In-core abundances for isotopes in the activation chain for ${ }^{244} \mathrm{Cm}$ and ${ }^{246} \mathrm{Cm}$............48

Figure 26. Relative difference in SF neutron emission on total SF neutron emission basis for time point $80 \mathrm{GWd} / \mathrm{MTU} 10 \mathrm{max}-7.4 \mathrm{av} \mathrm{wt} \%$ vs the reference case for $40 \%$ void fraction.

Figure 27. Difference in reactivity between the 252 and $56 \mathrm{~g}$ cross section libraries for the $10 \%$ limit dominant and vanished lattices.

Figure 28. Comparison of the Doppler temperature coefficient (DTC) for the 252 and 56 $\mathrm{g}$ cross section libraries for the $10 \%$ limit dominant and vanished lattices.

Figure 29. Comparison of the moderator void coefficient (MVC) for the 252 and $56 \mathrm{~g}$ cross section libraries for the $10 \%$ limit dominant and vanished lattices. 


\section{LIST OF TABLES}

Table 1. GE14 BWR fuel lattice modeling parameters .......................................................6

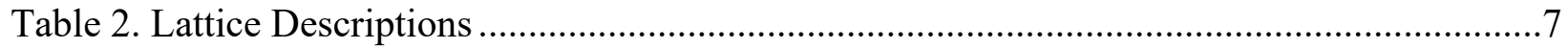

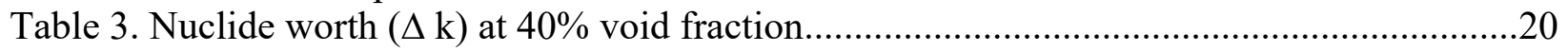

Table 4. Predictions and relative standard deviations in isotope inventories ............................22

Table 5. Contributions of each isotope to total percent change in decay heat from

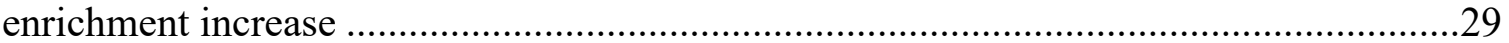

Table 6. Contributions of each isotope to total percent change in decay heat from burnup

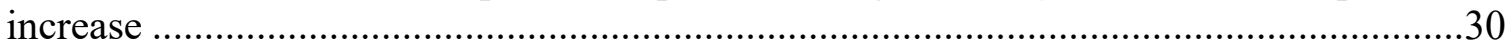

Table 7. Contributions of each isotope to total percent change in decay heat from

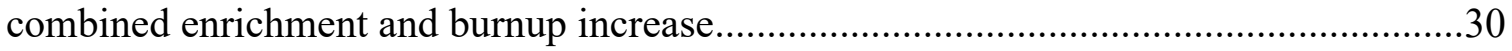

Table 8. Difference in isotopic decay heats resulting from enrichment increase at various cooling times

Table 9. Difference in isotopic decay heats resulting from burnup increase at various

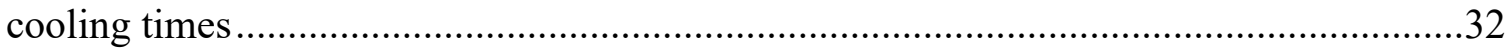

Table 10. Difference in isotopic decay heats resulting from burnup and enrichment

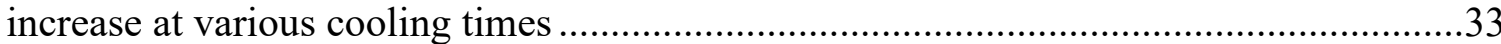

Table 11. Signed RMS change in isotope decay heat relative to total for enrichment

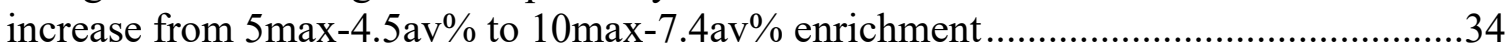

Table 12. Signed RMS change in isotope decay heat relative to total for burnup increase from 60 to $80 \mathrm{GWd} / \mathrm{MTU}$ at $10 \mathrm{max}-7.4 \mathrm{av} \%$ enrichment.

Table 13. Signed RMS change in isotope decay heat relative to total for enrichment and burnup increase from 5 max-4.5av wt $\% 60 \mathrm{GWd} / \mathrm{MTU}$ to $10 \mathrm{max}-7.4 \mathrm{av}$ wt $\%$ enrichment at $80 \mathrm{GWd} / \mathrm{MTU}$

Table 14. Signed RMS change in isotopic decay heat due to changes in lattice design and void fraction for $10 \mathrm{max}-7.4 \mathrm{av} \mathrm{wt} \%$ DOM lattice at $80 \mathrm{GWd} / \mathrm{MTU}$

Table 15. Contributions of each isotope to total percent change in activity from enrichment increase

Table 16. Contributions of each isotope to total percent change in activity from burnup increase

Table 17. Contributions of each isotope to total percent change in activity from combined enrichment and burnup increase

Table 18. Signed RMS change in isotopic activity due to changes in lattice design and void fraction for 10 max-7.4av wt $\%$ DOM lattice at $80 \mathrm{GWd} / \mathrm{MTU}$

Table 19. Relative differences of selected release isotopes activities due to enrichment increase

Table 20. Relative differences of selected release isotopes activities due to burnup increase

Table 21. Relative differences of selected release isotopes activities due to both enrichment and burnup increase

Table 22. Signed RMS relative differences in abundance of selected release isotopes due to changes in lattice design and void fraction for $10 \mathrm{max}-7.4 \mathrm{av} \mathrm{wt} \% \mathrm{DOM}$ lattice at $80 \mathrm{GWd} / \mathrm{MTU}$

Table 23. Relative differences of selected shielding isotopes activities due to enrichment increase 
Table 24. Relative differences of selected shielding isotopes activities due to burnup increase

Table 25. Relative differences of selected shielding isotopes activities due to both enrichment and burnup increase

Table 26. Signed RMS relative differences in abundance of selected shielding isotopes vs the dominant lattice with $10 \%$ void for $10 \%$ maximum enriched lattices burned to $80 \mathrm{GWd} / \mathrm{MTU}$

Table 27. Relative differences of criticality isotope masses due to enrichment increase

Table 28. Relative differences of criticality isotope masses due to burnup increase

Table 29. Relative differences of criticality isotope masses due to both enrichment and burnup increase

Table 30. Relative differences of criticality isotope masses due to changes in lattice design and void fraction for 10max-7.4av wt\% DOM lattice at $80 \mathrm{GWd} / \mathrm{MTU}$

Table 31. Relative difference between 252- and 56-group cross section structures on isotope results (other comparisons shown for reference) 


\section{ACRONYMS}

$\begin{array}{ll}\text { ATF } & \text { accident-tolerant fuel } \\ \text { BOC } & \text { beginning of cycle } \\ \text { BW } & \text { [soluble] boron worth } \\ \text { BWR } & \text { Boiling Water Reactor } \\ \text { control rod worth } & \text { dominant } \\ \text { DOM } & \text { Doppler temperature coefficient } \\ \text { DTC } & \text { extended enrichment } \\ \text { EE } & \text { Evaluated Nuclear Data File } \\ \text { ENDF } & \text { end of cycle } \\ \text { EOC } & \text { gigawatt-days per metric ton of uranium } \\ \text { GWd/MTU } & \text { high assay low-enriched uranium } \\ \text { HALEU } & \text { hot full power } \\ \text { HFP } & \text { International Atomic Energy Agency } \\ \text { IAEA } & \text { integral fuel burnable absorber } \\ \text { IFBA } & \text { Joint Evaluated Fission and Fusion File } \\ \text { JEFF } & \text { light water reactor } \\ \text { LWR } & \text { moderator temperature coefficient } \\ \text { MTC } & \text { moderator void coefficient } \\ \text { MVC } & \text { pressurized water reactor } \\ \text { PWR } & \text { root mean square } \\ \text { RMS } & \text { spent fuel pool } \\ \text { SFP } & \text { sensitivity and uncertainty } \\ \text { S/U } & \text { vanished } \\ \text { VAN } & \end{array}$





\section{SUMMARY}

Commercial light water reactor (LWR) operators and fuel vendors in the United States are pursuing changes to nuclear fuel that include extended enrichment (EE) and accident-tolerant fuel (ATF) designs to further improve reactor safety and plant economics. Extended fuel enrichments above $5 \%{ }^{235} \mathrm{U}$ pin enrichment and up to $10 \%{ }^{235} \mathrm{U}$ are a subset of high assay lowenriched uranium (HALEU) that may be deployed in commercial US LWRs in the near term. ATF features, such as cladding coatings or alternative cladding materials, are designed to improve fuel system performance under accident conditions. One goal of EE is to improve fuel cycle economy by enabling fuel to be depleted to higher burnup than the typical current limits (62 gigawatt-days per metric ton of uranium [GWd/MTU]). Adoption of EE, ATF, and high burnup (HBU) fuels in the US commercial fleet requires a clear understanding of the effects on core physics parameters and used fuel isotopic content, as well as confidence in the accuracy of computer code predictions over an expanded range of materials, enrichment, and burnup. A thorough understanding of the applicability and adequacy of benchmark data (e.g., criticality, decay heat, isotopic content) for computer code validation is necessary to ensure that appropriate safety margins are maintained.

As part of the US Nuclear Regulatory Commission (NRC) agreement number 31310019N0008, "SCALE Code Development, Assessment and Maintenance," the effects of EE, ATF, and HBU are being assessed for selected representative LWR fuel designs. The project is divided into phases, and this report summarizes the findings of the Phase 1 work, which focuses on lattice physics parameter and used fuel isotopic changes for a conventional GE14 10 $\times 10$ boiling water reactor (BWR) design with GNF-2 part length rod patterns to model a modern BWR assembly design.

This activity is part of Phase 1 of HALEU/HBU/ATF SCALE code preparedness activities beginning in

Q2 FY20 and ending in Q2 FY21. This report addresses the following NRC user needs within the Nuclear Reactor Regulation (NRR) and Nuclear Material Safety and Safeguards offices.

- Identify data needs for high burnup and enrichment $>5 \%$ in SCALE.

- Compare isotopics from baseline ( $\sim 62 \mathrm{GWD} / \mathrm{MTU}$ rod average) to $75 \mathrm{GWD} / \mathrm{MTU}$ rodaverage and quantify impact on reactivity, decay heat, and radioactive source terms in prototypical applications in each area.

- Compare isotopics from baseline (5\%) to $8 \%$, and quantify impact on reactivity, decay heat, and radioactive source terms in prototypical applications in each area.

- These NRC user needs are expected to change and adapt to the ever-changing commercial nuclear landscape. Phase 2 HALEU/HBU/ATF SCALE activities are expected to focus on core level (PARCS) assessments as well as code development efforts recommended by Phase 1 activities. If new user needs are available, activities identified for Phase 2 will be re-mapped and re-prioritized according to the updated user needs.

Calculations were performed using Polaris and ORIGEN sequences in SCALE to evaluate the effects of EE and HBU fuels on depletion characteristics of a representative commercial BWR fuel assembly. Uncertainties in Polaris calculations due to nuclear data uncertainties were 
calculated Sampler sequence. All calculations were performed using a pre-release version of SCALE 6.3 with the 56 -group ENDF/B-VII.1 cross section library. The investigation focused on differences between depletions of better-understood LWR fuel (5 wt $\%{ }^{235} \mathrm{U}$ maximum pin enrichment with lattices depleted to $60 \mathrm{GWd} / \mathrm{MTU}$ ) and depletion for maximum pin enrichments up to $10 \mathrm{wt} \%$ and lattice burnup up to $80 \mathrm{GWd} / \mathrm{MTU}$.

Key quantities of interest include (1) lattice physics parameters (reactivity, reactivity coefficients, cross sections, and kinetics parameters), (2) isotopic inventory at various decay times, (3) uncertainty in $k_{\text {inf }}$ arising directly from cross section uncertainties and indirectly from uncertainties in the discharged isotopic content. Limited comparisons between predictions using SCALE 56-group ENDF/B-VII.1 cross sections and SCALE 252-group ENDF/B-VII.1 cross sections are also presented. No unexpected or anomalous trends were found that would call into question the accuracy of the Polaris code using SCALE 56-group ENDF/B-VII.1 cross sections for depletion, lattice physics, and isotopic content calculations of the analyzed BWR fuel with enrichments up to $8 \mathrm{wt} \%$ and burnup up to $80 \mathrm{GWd} / \mathrm{MTU}$. For multiple physical quantities of interest, increases in enrichment and increases in burnup had opposing and offsetting effects. 


\section{INTRODUCTION}

Commercial light water reactor (LWR) operators and fuel vendors in the United States are pursuing evolutionary changes to nuclear fuel that include extended enrichment (EE) fuel $\left({ }^{235} \mathrm{U}\right.$ maximum pin enrichment within 5-10 wt $\%$ ) and accident-tolerant fuel (ATF) designs intended to improve fuel and cladding performance under accident conditions [1,2]. One goal of this effort is to improve fuel cycle economy by enabling fuel to be depleted to higher burnup than presently possible. Adoption of these changes in the US commercial fleet requires a clear understanding of the effects on core physics parameters and used fuel isotopic content, as well as confidence in the accuracy of computer code predictions over an expanded range of materials, enrichment, and burnup. A thorough understanding of the applicability and adequacy of benchmark data (e.g., criticality, decay heat, isotopic content) for computer code validation is necessary to ensure that appropriate safety margins are maintained.

To prepare for and support these potential changes, the effects of EE, ATF, and high burnup (HBU) fuels are being assessed for selected representative LWR fuel designs. This Volume II report focuses on changes to lattice physics parameters and used fuel isotopic compositions for a conventional GNF-2 $10 \times 10$ boiling water reactor (BWR) design [3]. The SCALE Polaris lattice physics code and the ORIGEN depletion and decay code are the primary investigation tools [4].

To aid in understanding the best-estimate effects of $\mathrm{EE}$ and $\mathrm{HBU}$, various quantities of interest for $\mathrm{UO}_{2}$ fuel ${ }^{235} \mathrm{U}$ enrichments are evaluated at $5,8.5$, and $10 \mathrm{wt} \%$ up to $80 \mathrm{GWd} / \mathrm{MTU}$ latticeaverage burnup, with a focus on differences relative to $5 \mathrm{wt} \%$ enrichment up to $60 \mathrm{GWd} / \mathrm{MTU}$.

Specific power was not varied in this study because it is implicitly included in burnup. Furthermore, specific power is not expected to change with EE and HBU due to its being set by thermal hydraulic limits. Therefore, power is not a parameter being varied in this study.

The quantities of interest include:

- Lattice physics behavior (modeled with Polaris)

- Neutron flux and flux spectrum

○ Reactivity ( $k_{\text {inf }}$, reactivity coefficients)

- Trends and contributing isotopic inventory of importance in four categories

$\circ$ Decay heat (short- and long-term decay times)

- Shielding (activity at short- and long-term decay times)

- Severe accident (important nuclides at short and long decay times)

$\circ$ Criticality (during decay)

These calculations are 2D, representing assembly average quantities and equilibrium cycles. 5 $\mathrm{wt} \%$ is the current enrichment limit for commercial LWRs, $10 \mathrm{wt} \%$ bounds the maximum envisioned near-term enrichment increase, and $8.5 \mathrm{wt} \%$ is included as a midpoint to improve confidence in observed trends. Evaluation of 3D parameters such as axial burnup shapes will be performed in later work. 
In addition to identifying the best-estimate effects of EE and HBU on quantities of interest, it is important to understand the uncertainty of EE and HBU models relative to conventional fuel models. Preliminary results of limited sensitivity and uncertainty $(\mathrm{S} / \mathrm{U})$ analyses are presented, comparing $80 \mathrm{GWd} / \mathrm{MTU}$ lattices with $10 \mathrm{wt} \%$ maximum pin enrichment to $60 \mathrm{GWd} / \mathrm{MTU}$ lattices with $10 \mathrm{wt} \%$ maximum pin enrichment and $60 \mathrm{GWd} / \mathrm{MTU}$ lattices with $5 \mathrm{wt} \%$ maximum pin enrichment. The primary tools for $\mathrm{S} / \mathrm{U}$ analysis is Sampler/Polaris [4]. These analyses quantify uncertainty in $k_{\text {inf }}$ and in depleted fuel isotopic content due to nuclear data uncertainty using the cross section covariance data included in pre-release version of SCALE 6.3. The following preliminary $\mathrm{S} / \mathrm{U}$ data for $5 \mathrm{wt} \% 60 \mathrm{GWd} / \mathrm{MTU}^{1}$ and $80 \mathrm{GWd} / \mathrm{MTU}$ fuel are presented.

- Sampler/Polaris perturbed cross section depletions (isotopic content and $\mathrm{k}_{\text {inf }}$ uncertainty at in-reactor hot full power [HFP] conditions)

- Isotope worth ranking by importance to $k_{\text {inf }}$ (in-reactor HFP conditions)

Polaris models are described in Section 2. Lattice physics comparisons are presented in Section 3. Section 4 describes and summarizes the preliminary $\mathrm{S} / \mathrm{U}$ analysis. Isotopic inventory comparisons are presented in Section 5.

All calculations were performed using a pre-release version of SCALE 6.3 with the 56 -group ENDF/B-VII.1 cross section library.

This volume discusses the lattice physics models (not the codes) in more detail in Section 2 . The physics of the BWR system are discussed in Section 3. That foundation is then used to explore lattice physics (Section 4), S/U (Section 5) and isotopic inventories (Section 6) relevant to various analyses.

\subsection{EXPECTED EFFECTS OF HBU AND EE ON FUEL MANAGEMENT}

This evaluation of EE and HBU fuel is focused on existing commercial BWR fuel designs. As in the PWR case, the driving force for use of higher enrichment fuel is to achieve reduced fuel cycle costs. Again, higher enrichment without higher burnup would result in increased cost without the benefit of more energy produced. Higher burnup without increased enrichment cannot be achieved due to the requirement for sufficient fuel reactivity at the end of cycle (EOC). As is consistent with prior experience, increased enrichment results in increased achievable burnup, and the effects should be evaluated in combination.

There are at least two ways that EE may affect fuel cycle management. First, cycle length could be maintained, and the size of the reload fuel batch could be reduced. This approach would result in higher core average burnup throughout a cycle, and higher discharge fuel assembly burnup. It is also possible that increased enrichment could be used to increase cycle length (perhaps from 18 to 24 months). This strategy would increase EOC core average burnup and discharge burnup. The net effect on beginning of cycle (BOC) core average burnup would depend in part on batch

\footnotetext{
${ }^{1}$ Note that unless otherwise stated, enrichments in this volume refer to maximum pin enrichments, and burnups refer to lattice average burnups.
} 
size. From a fuel cycle management perspective, EE and HBU are expected to be positively correlated for at least part of a reload cycle.

Regardless of whether increased enrichment is used to achieve smaller batch size or longer cycles, higher core average burnup is expected, as well as higher assembly discharge burnup. When combined with results from lattice physics calculations, this approximation is used to better understand some of the expected core average effects of EE and HBU. 


\section{LATTICE PHYSICS MODEL DESCRIPTION}

The 2D lattice physics code Polaris was used to assess how the reactivity and local power across a fuel assembly changes from extended burnup and increased enrichment. For these calculations, design parameters were selected to approximate the GNF-2 10×10 BWR fuel lattice by using GE14 lattice parameters with GNF-2 vanished rod positions. Modeling parameters for the GE-14 lattice are provided in Table 1. In addition to the dominant (DOM) region of the assembly, the vanished (VAN) region was used in the analysis due to expected variation in neutronic behavior.

Table 1. GE14 BWR fuel lattice modeling parameters

\begin{tabular}{|c|c|}
\hline Parameter & Value \\
\hline Lattice size & $10 \times 10$ \\
\hline Assembly pitch & $15.24 \mathrm{~cm}[12]$ \\
\hline Fuel rod pitch & $1.295 \mathrm{~cm} \mathrm{[12]}$ \\
\hline Clad material & Zirc-2 \\
\hline $\mathrm{UO}_{2}$ pellet radius & $0.4380 \mathrm{~cm} \mathrm{[12]}$ \\
\hline Clad inner radius & $0.4470 \mathrm{~cm} \mathrm{[12]}$ \\
\hline Clad outer radius & $0.5130 \mathrm{~cm} \mathrm{[12]}$ \\
\hline Water tube inner radius & $1.20 \mathrm{~cm}[12]$ \\
\hline Water tube outer radius & $1.28 \mathrm{~cm}[12]$ \\
\hline Channel width (inside) & $13.406 \mathrm{~cm} \mathrm{[12]}$ \\
\hline Channel box thickness1 & $0.2032 \mathrm{~cm} \mathrm{[13]}$ \\
\hline Channel radius $^{2}$ & $0.9652 \mathrm{~cm}$ \\
\hline Fuel temperature & $1100 \mathrm{~K}$ \\
\hline Clad temperature & $600 \mathrm{~K}$ \\
\hline Coolant temperature & $580 \mathrm{~K}$ \\
\hline $\mathrm{UO}_{2}$ effective density & $10.64 \mathrm{~g} / \mathrm{cm}^{3}[12]$ \\
\hline Coolant density & $0.7048 \mathrm{~g} / \mathrm{cm}^{3}$ \\
\hline
\end{tabular}

The fuel assembly layouts for the reference 5max-4.5av wt $\%$ DOM (5\% maximum and $4.5 \%$ lattice average enrichment) and VAN lattices are shown in Figure 1. The gadolinia rods are shown in green, with the $\mathrm{Gd}_{2} \mathrm{O}_{3}$ weight precents under the ${ }^{235} \mathrm{U}$ enrichments. Starting with GE14 enrichment maps in the literature [14], and vanished rod patterns for a GNF-2 VAN lattice region [12], ${ }^{235} \mathrm{U}$ enrichments, gadolinia weight percents and gadolinia locations were modified to meet the following criteria for a more realistic lattice design:

- Maximum fuel pin enrichment 5\%

- Depletion calculations starting with $\mathrm{k}_{\mathrm{inf}}$ at $\mathrm{BOC}$ to 1.1 and gad peaking near $10 \mathrm{GWd} / \mathrm{MTU}$

- Pin peaking factors below 1.3 
Unfortunately, there is no publicly available BWR lattice design with pin enrichments above 5\%. Increasing the maximum pin enrichments proportionally using the same 5\% reference design enrichment map causes large power peaking factors within pins around the periphery. As expected, the initial lattice reactivity is also much higher.

Therefore, a simple iterative optimization study was performed to have a realistic looking lattice design for this work. Assuming that the EE, HALEU lattices will be subjected to similar lattice design constraints, the target $\mathrm{k}_{\text {inf }}$ value was as selected 1.1 at BOC while the target maximum pin peak was kept below 1.3. To suppress the initial fuel assembly reactivity and power peaking across the assembly, number of gadolinia rods were increased. The lattice designs that are used in this report, descriptions and the selected naming convention are provided in Table 2.

Table 2. Lattice Descriptions

\begin{tabular}{|c|c|c|c|}
\hline Lattice Name & $\begin{array}{c}\text { Maximum Enrichment } \\
\left(\%{ }^{235} U\right)\end{array}$ & $\begin{array}{c}\text { Average Lattice } \\
\text { Enrichment } \\
\left(\%{ }^{235} \mathrm{U}\right)\end{array}$ & $\begin{array}{l}\text { Lattice } \\
\text { Region }\end{array}$ \\
\hline $\begin{array}{l}5 \mathrm{max}-4.5 \mathrm{av} w \mathrm{t} \% \text { DOM } \\
\text { 5max-4.5av wt } \% \text { VAN }\end{array}$ & $5.0 \%$ & $\begin{array}{l}4.33 \% \\
4.31 \%\end{array}$ & $\begin{array}{l}\text { DOM } \\
\text { VAN }\end{array}$ \\
\hline $\begin{array}{l}8.5 \mathrm{max}-6.5 \mathrm{av} \mathrm{wt} \% \mathrm{DOM} \\
8.5 \mathrm{max}-5.9 \mathrm{av} \mathrm{wt} \% \text { VAN }\end{array}$ & $8.5 \%$ & $\begin{array}{l}6.50 \% \\
5.92 \% \\
\end{array}$ & $\begin{array}{l}\text { DOM } \\
\text { VAN }\end{array}$ \\
\hline $\begin{array}{l}\text { 10max-7.4av wt\% DOM } \\
10 \mathrm{max}-7.4 \mathrm{av} \text { wt } \% \text { VAN }\end{array}$ & $10.0 \%$ & $\begin{array}{l}7.45 \% \\
7.47 \%\end{array}$ & $\begin{array}{l}\text { DOM } \\
\text { VAN }\end{array}$ \\
\hline
\end{tabular}

The enrichment maps calculated for the max 8.5 and max $10 \%$ enrichment cases are shown in Figure 2 and Figure 3, respectively. Both designs include 8 different UO2 fuel enrichments and 4 different $\mathrm{UO}_{2}-\mathrm{Gd}_{2} \mathrm{O}_{3}$ enrichment combinations. Although, the number of different enrichments can be reduced with use of gad rod in the periphery and more rigorous optimizations, the current design is satisfactory for this study.

For the reference lattice, the nominal moderator void fraction was set to $40 \%$. Depletion calculations were performed up to $80 \mathrm{GWd}$ /MTU. for both dominant and vanished lattices. No design changes to conventional fuel pellets were assumed. Considering typical void fraction history that a DOM and VAN lattices will experience during their life time in the core, $10 \%$ and $40 \%$ void fraction state points were modeled for DOM while $40 \%$ and $70 \%$ void fraction state points were modeled for VAN lattices.

Two SCALE cross section libraries are available for use with Polaris: 56- and 252-group ENDF/B-VII.1. Lattice physics parameters and fuel depletion isotopic content were calculated using the 56-group library. Some 252- and 56-group library depletion $\mathrm{k}$ and reactivity coefficient comparisons are also provided to help determine whether EE and HBU introduce challenges for the 56-group library. 

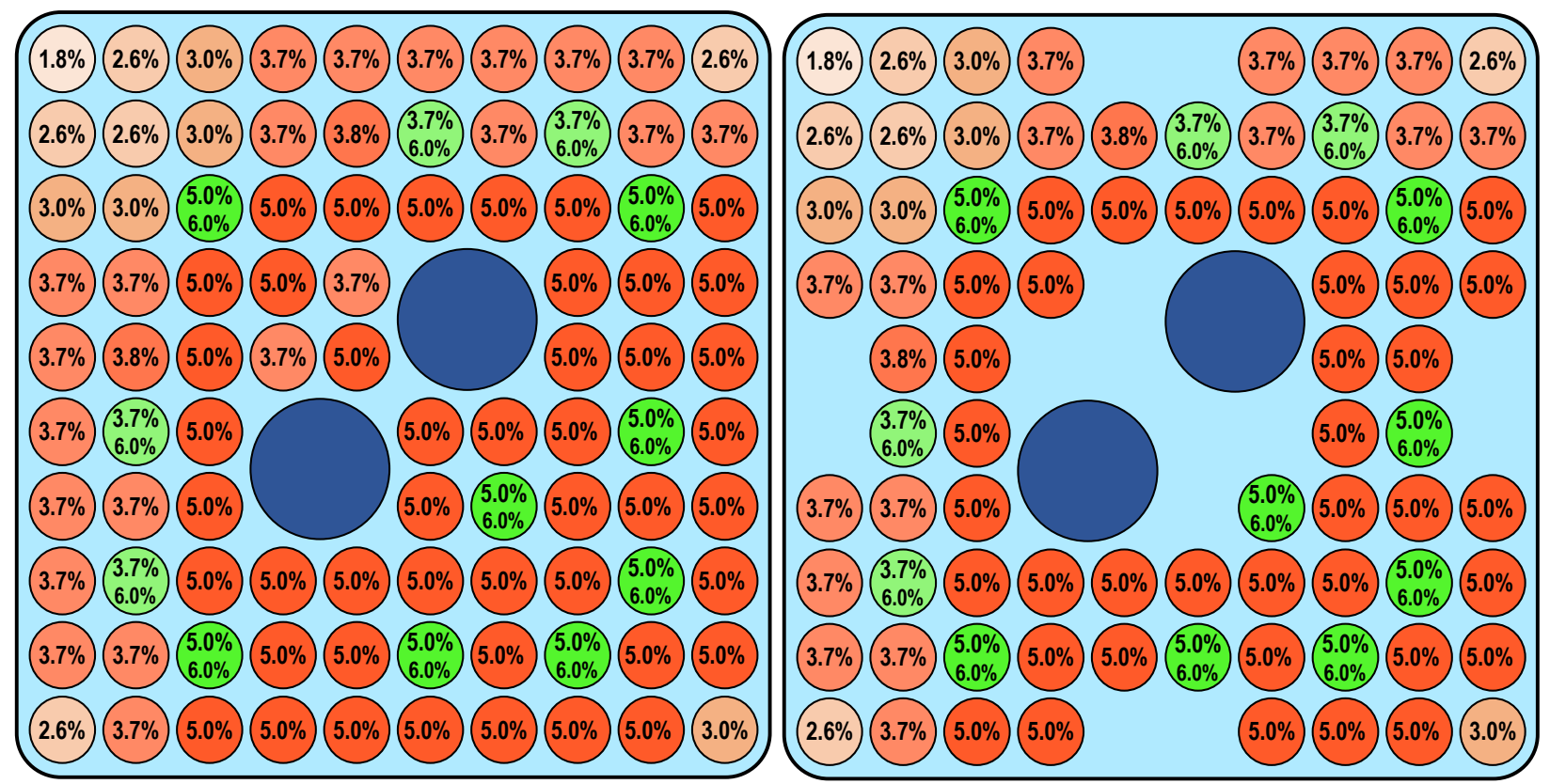

Figure 1. Layout of $5 \mathrm{max}-4.5 \mathrm{av}$ wt\% DOM (left) and $5 \mathrm{max}-4.5 \mathrm{av}$ wt\% VAN lattices (right)
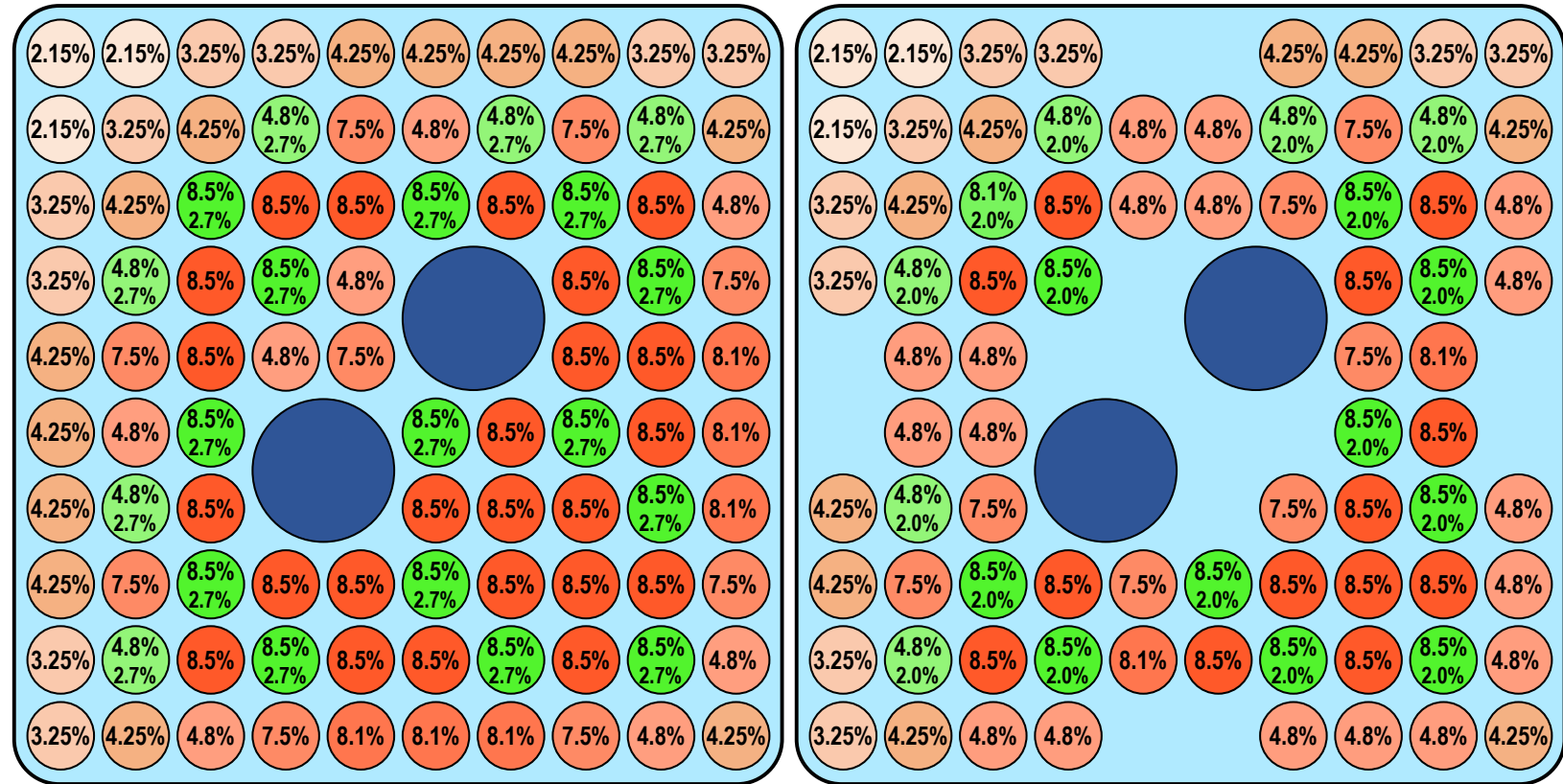

Figure 2. Layout of 8.5max-6.5av wt\% DOM (left) and 8.5max-5.9av wt\% VAN lattices (right). 

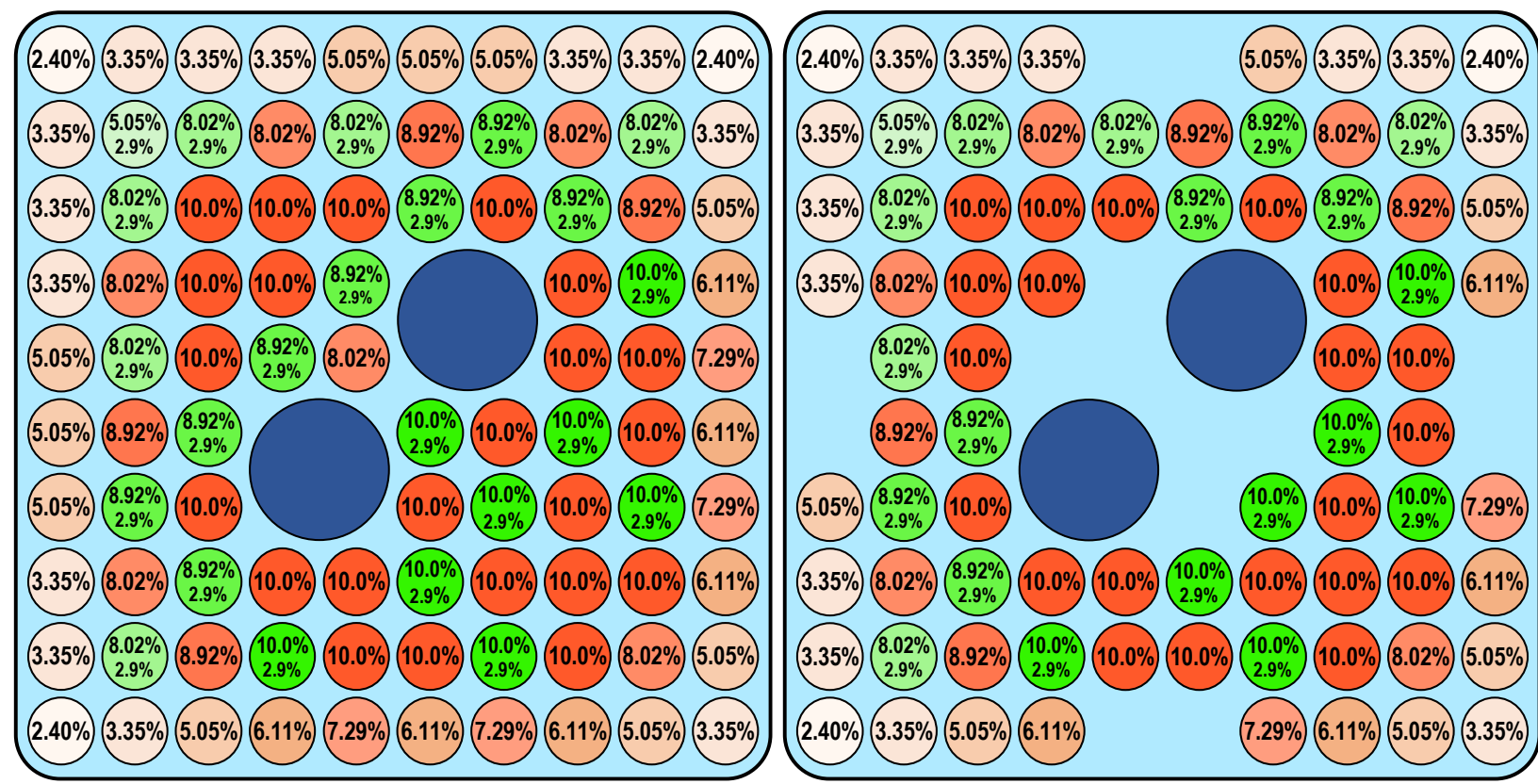

Figure 3. Layout of 10max-7.4av wt\% DOM (left) and 10max-7.4av wt\% VAN lattices (right). 


\section{LATTICE PHYSICS RESULTS}

This section compares general neutronics trends observed in depletion of reference and extended enriched fuel and discusses observed differences. Extended enrichment and high burnup HFP depletions were modeled using Polaris with the model parameters described in the previous section for all 6 lattices. Reactivity for the modeled lattices is compared, as well as the ratio of fast and thermal fluxes, and the Doppler temperature coefficient (DTC) and moderator void coefficients (MVC) of reactivity.

\subsection{FLUX SPECTRUM}

Change in flux provides insight to many neutronic behavior observed with depletion. The fraction of fast flux to thermal flux is shown in Figure 4 as a function of burnup. Increases in the fast to thermal flux ratio demonstrate the magnitude of spectrum hardening due to increased enrichment. Similar spectrum hardening is observed between DOM and VAN lattice regions for each enrichment. All three enrichment cases follow parallel trends until practical life time of $5 \mathrm{max}-4.5 \mathrm{av} \mathrm{wt} \%$ lattice. Although spectrum of all three lattices become more thermal with burnup, the relative difference in spectra due to increased enrichment remains constant. In other words, EE lattices always operate at a harder spectrum than the $5 \mathrm{max}-4.5 \mathrm{av} w \mathrm{wt} \%$ lattices throughout their lifetime.

The lattice average total flux for different lattice enrichments is also depicted in Figure 5. The observed trends in flux with burnup is mainly dominated by the gadolinia content of the lattices and gadolinia depletion until $15 \mathrm{GWd} / \mathrm{MTU}$. The differences in flux trends in this region is due to gadolinia loading differences between $5 \mathrm{max}-4.5 \mathrm{av} \mathrm{wt} \%$ and $10 \mathrm{max}-7.4 \mathrm{av} \mathrm{wt} \%$ enriched lattices. However, in general, the differences in magnitudes and trends with depletion are caused by the flux normalization to match constant power for the lattice depletion calculations. The flux increases as fissile isotope content decreases with burnup, compensating for the reduction in number of fissions. Similarly, the flux decreases as the fissile content increases with increasing enrichment. 


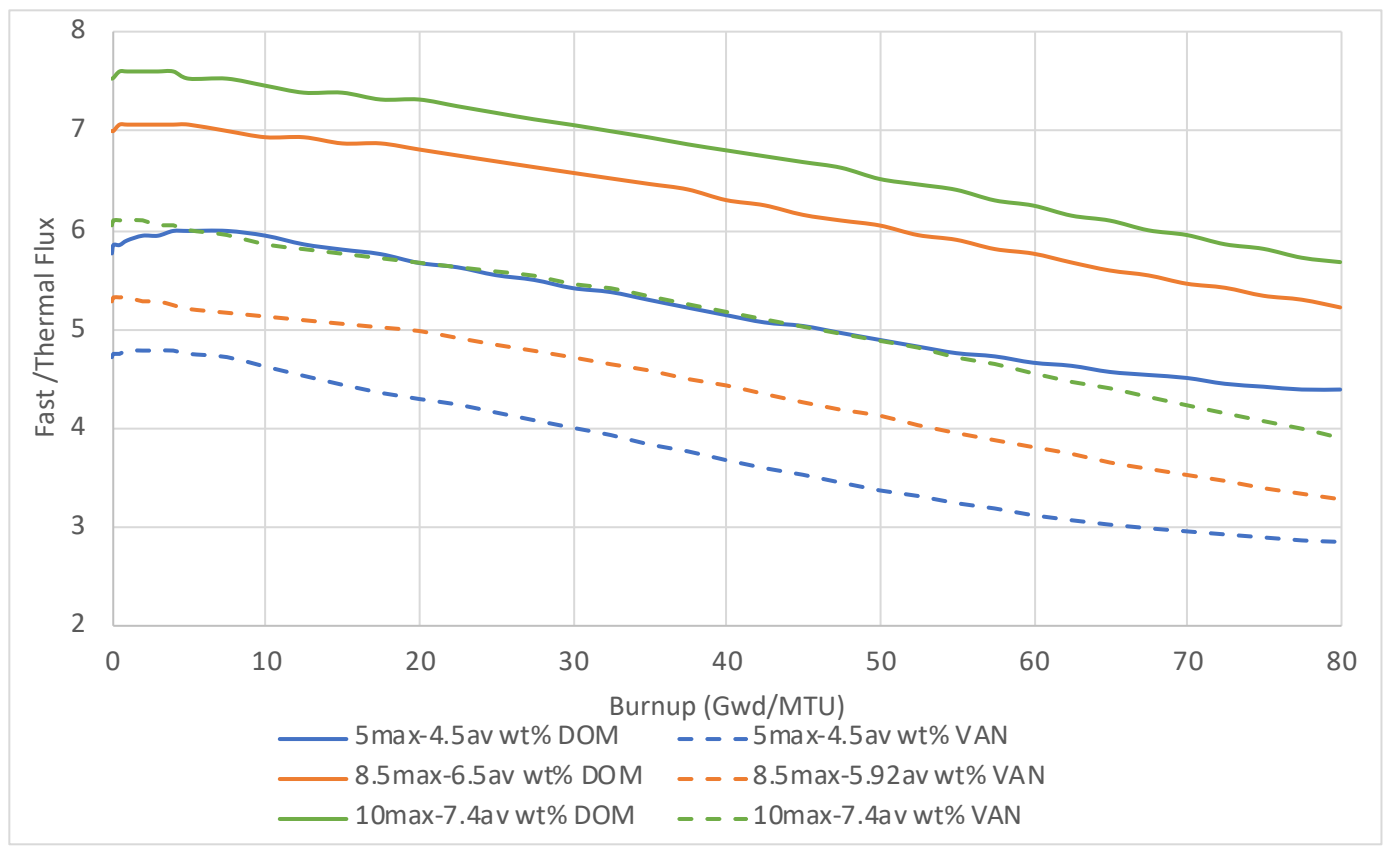

Figure 4. Fast/ Thermal flux ration at $40 \%$ void fraction.

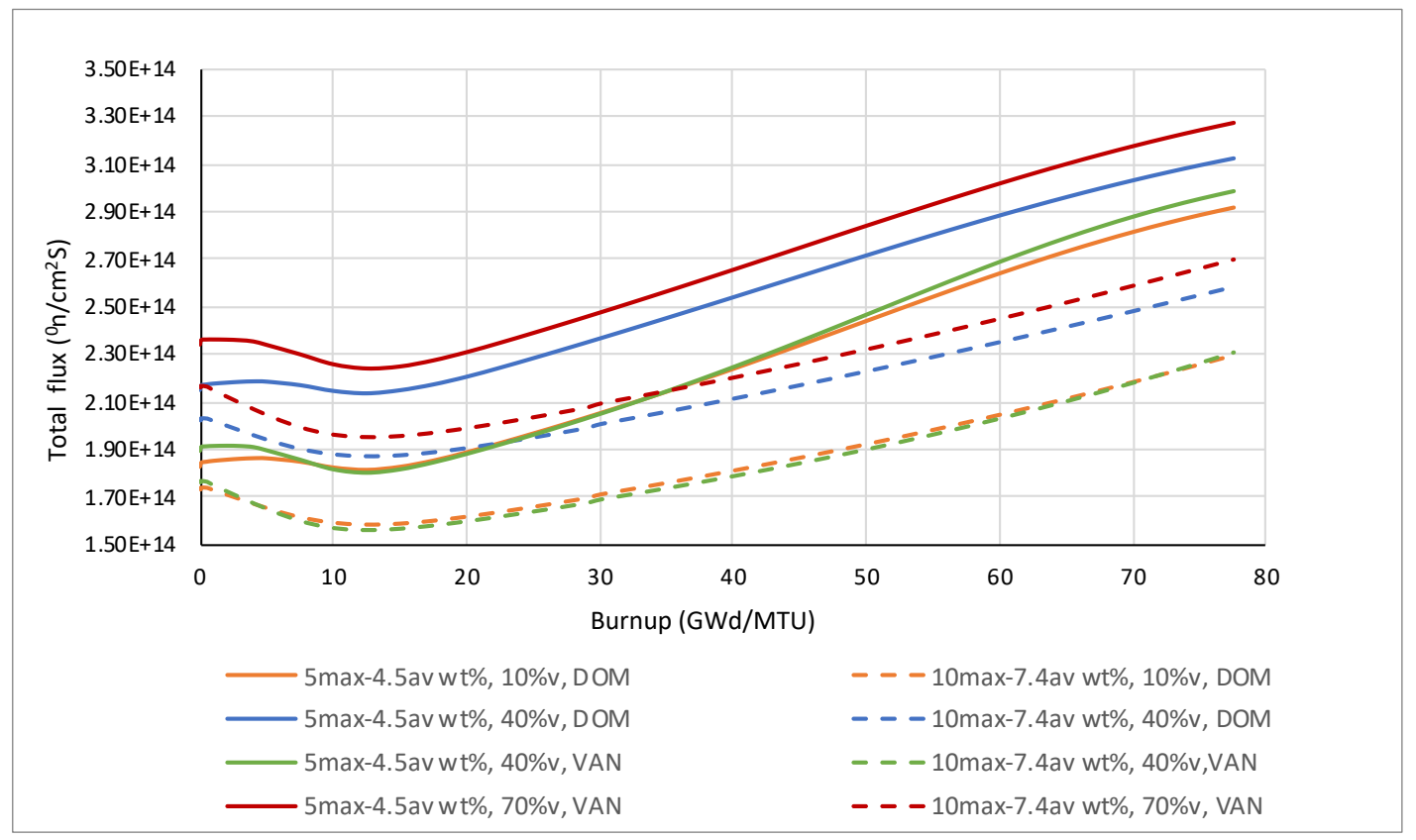

Figure 5. Total flux.

\subsection{REACTIVITY AND COEFFICIENTS}

Reactivity comparisons for EE/HBU depletions presented herein include HFP depletion $\mathrm{k}_{\text {inf, }}$ as well as reactivity coefficients and control blade worth (CBW). Coefficients and worths were calculated for each depletion step using the Polaris depletion $\mathrm{k}_{\text {inf }}$ at the nominal condition (1100 
$\mathrm{K}$ fuel temperature, $580 \mathrm{~K}$ moderator temperature at $40 \%$ void fraction). Branch cases were performed with fuel temperatures of $900 \mathrm{~K}$ and $1300 \mathrm{~K}$, and void fractions of $10 \%$ and $70 \%$, and control blades inserted.

The reactivity increase with increasing enrichment and fuel content (DOM vs VAN) can be seen in Figure 6. In general, when DOM and VAN lattice depletions are compared, lattices with different enrichments show similar trends. Higher gad worth at VAN lattices causes higher reactivity peaks due to burnup of gadolinia (gad peak) than DOM lattices, while gad peaks are at consistent burnups. The reactivity of $5 \mathrm{max}-4.5 \mathrm{av}$ wt $\%$ lattice at $45 \mathrm{GWD} / \mathrm{MTU}$ is similar to $8.5 \%$ max lattice at $65 \mathrm{GWd} / \mathrm{MTU}$ and $10 \mathrm{max}-7.4 \mathrm{av}$ wt $\%$ lattice at $73 \mathrm{GWd} / \mathrm{MTU}$ ( marked with a black line in the figure). If all lattices are expected have similar reactivities before they are discharged, about 20 to $30 \mathrm{GWd} / \mathrm{MTU}$ extension in lattice core lifetime can be assumed with extended enrichments.

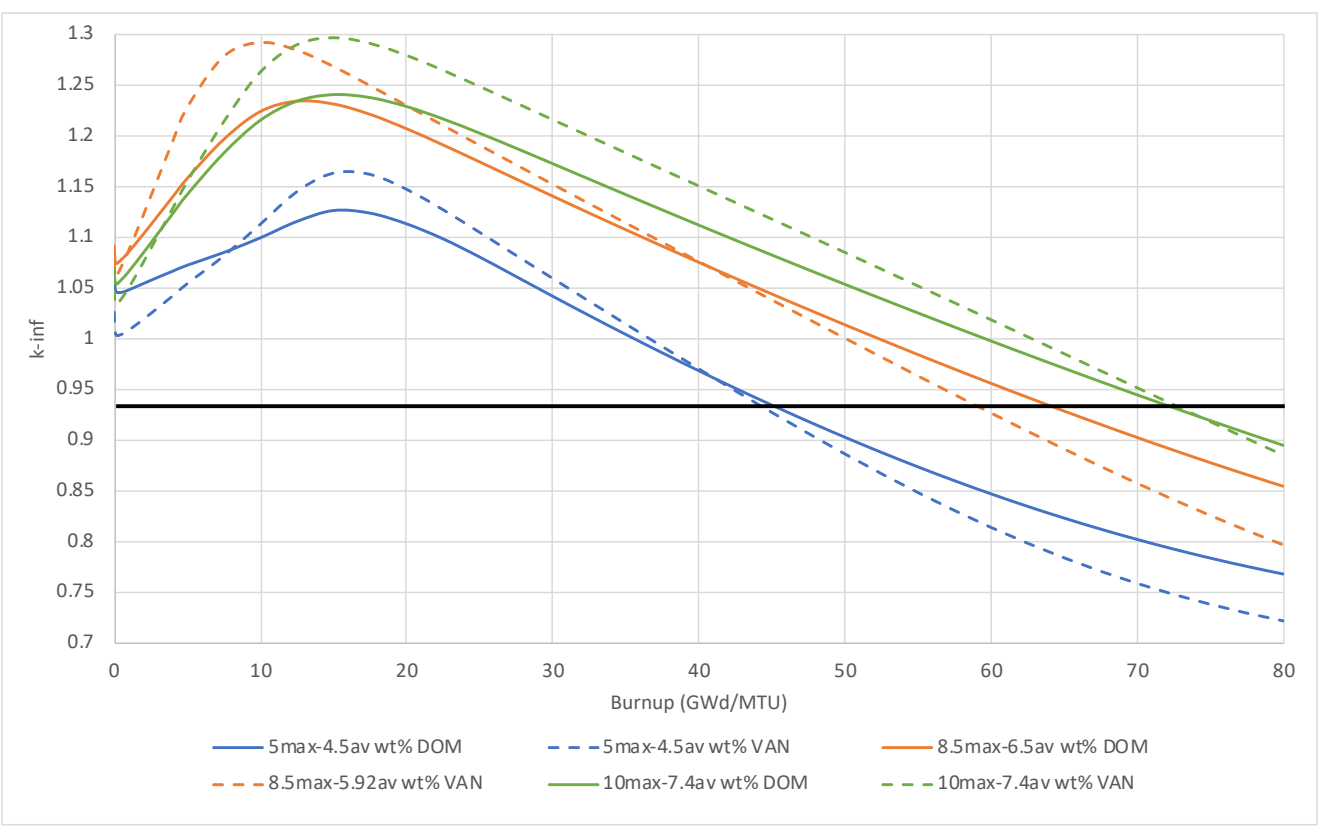

Figure 6. HFP depletion $k_{\text {inf }}$ at $40 \%$ void fraction

As illustrated in Figure 7, the effect of DTC becomes less pronounced with increased enrichment and more pronounced with increasing burnup. Doppler broadening in ${ }^{238} \mathrm{U}$ primarily results in neutron capture (negative DTC). In fissile materials such as ${ }^{235} \mathrm{U}$, Doppler broadening increases fission (positive DTC). Higher enrichment fuel increases the positive fissile contribution to DTC. Higher burnup reduces the positive fissile contribution to DTC. Based on the expected increase in core average burnup with increased enrichment (Figure 6) the estimated core average DTC (EOC estimate) is small due to offsetting effects of increased enrichment and increased burnup. A notable observation is the inflection in 5max-4.5av wt $\%$ VAN lattice DTC after 55 GWd/MTU. The similar behavior is observed in DTC of $8.5 \%$ enriched VAN lattice as it plateaus around $70 \mathrm{GWd} / \mathrm{MTU}$. 


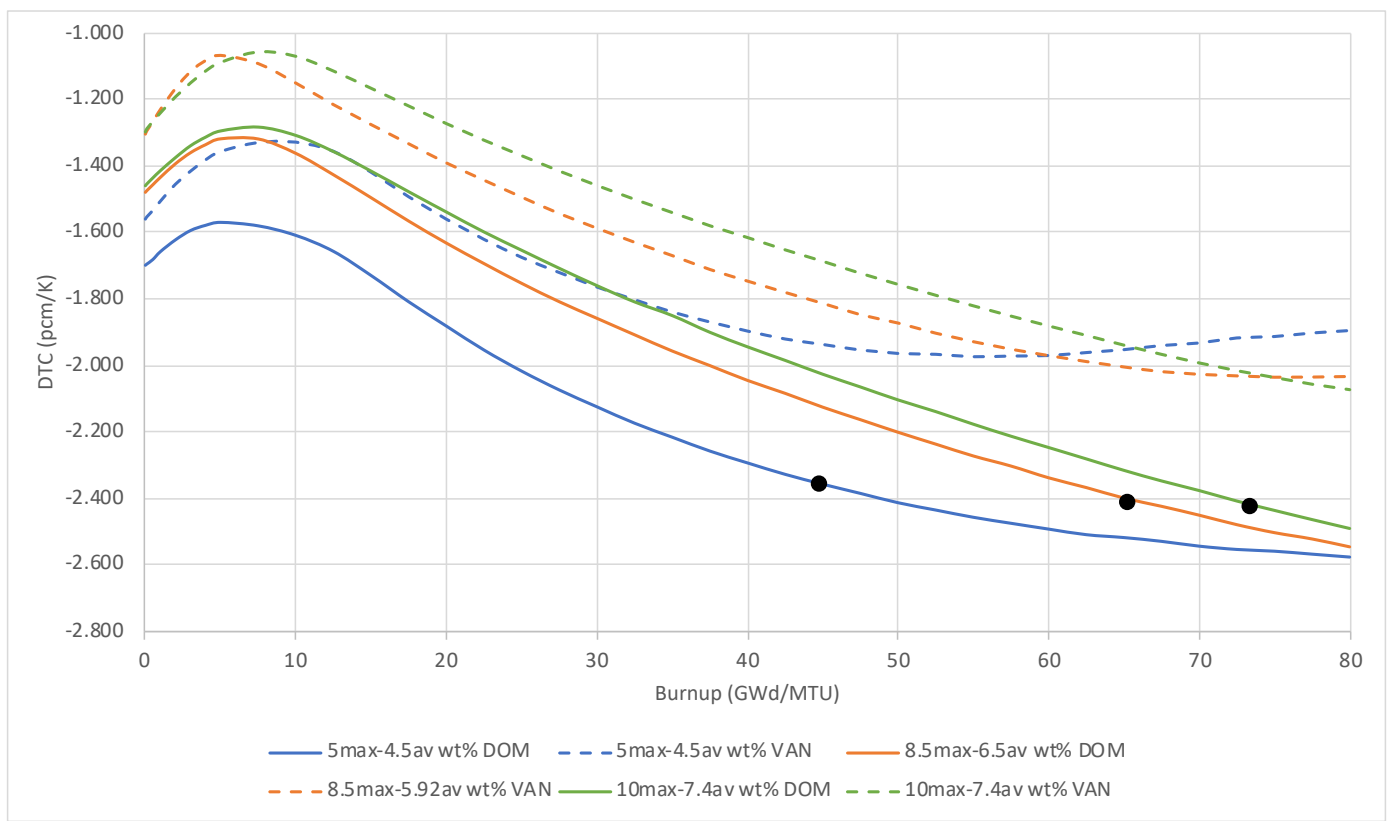

Figure 7. HFP DTC at $40 \%$ void fraction

The change in MVC with burnup and lattice enrichment is shown in Figure 8. In general, MVC becomes more positive with increased enrichment and more negative with increasing burnup. The effect of reduced moderator density on reactivity is less pronounced for VAN lattices compared DOM lattices. At BOC, a small, positive MVC with increasing enrichment beyond $7.4 \%$ average enrichment (10\% max) seems possible, however it should be noted that the actual cores are not expected to have all fresh fuel of this high enrichment and gadolinia loadings are less than expected for these lattices due to incomplete enrichment map optimization. At EOC, the offsetting effects of burnup and enrichment means a fairly minor change, e.g., compare the MVC at $10 \%$ max enrichment lattice at $73 \mathrm{GWd} / \mathrm{MTU}(-118 \mathrm{pcm} / \%$ Void) to $5 \%$ max lattice at 45 GWd/MTU (-115 pcm/\%Void). 


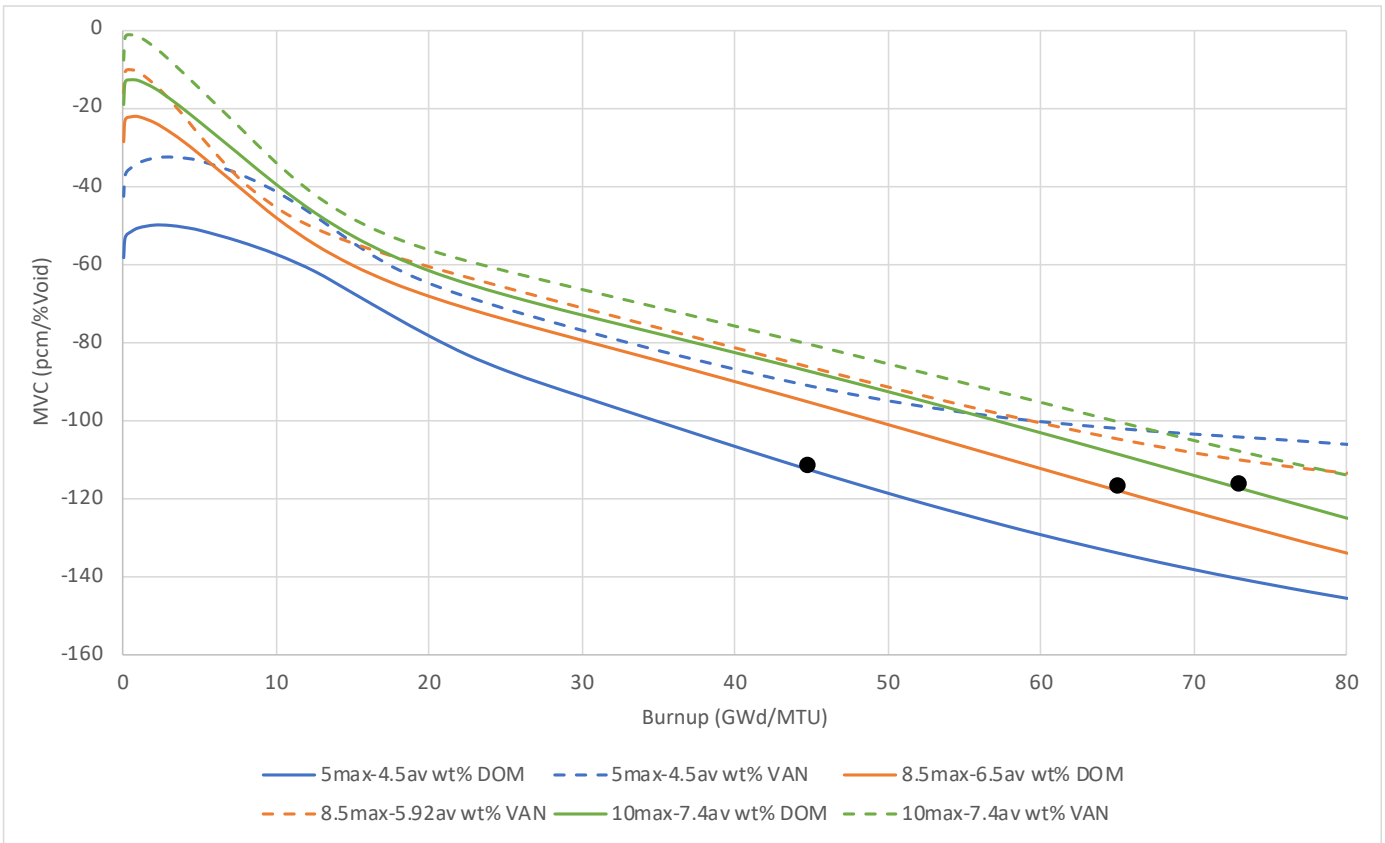

Figure 8. HFP MVC

A comparison of control blade rod worths for 5\%max, $8.5 \%$ max and $10 \%$ max enriched lattices at $40 \%$ void fraction is provided in Figure 9. All lattices show the same increasing rod worth trend with burnup as the spectrum for all lattices become more thermal. However, as enrichment increases, the blade worth decreases due to hardening in spectrum with increasing enrichment. The CBW at BOC is decreased by $7000 \mathrm{pcm}\left(\sim 9 \% / \mathrm{wt} \%{ }^{235} \mathrm{U}\right)$ for the $10 \%$ maximum enrichment lattice compared to the reference lattice. This difference drops to $2000 \mathrm{pcm}(\sim 2 \% /$ $\left.\mathrm{wt} \%{ }^{235} \mathrm{U}\right)$ at EOC for the two lattices.

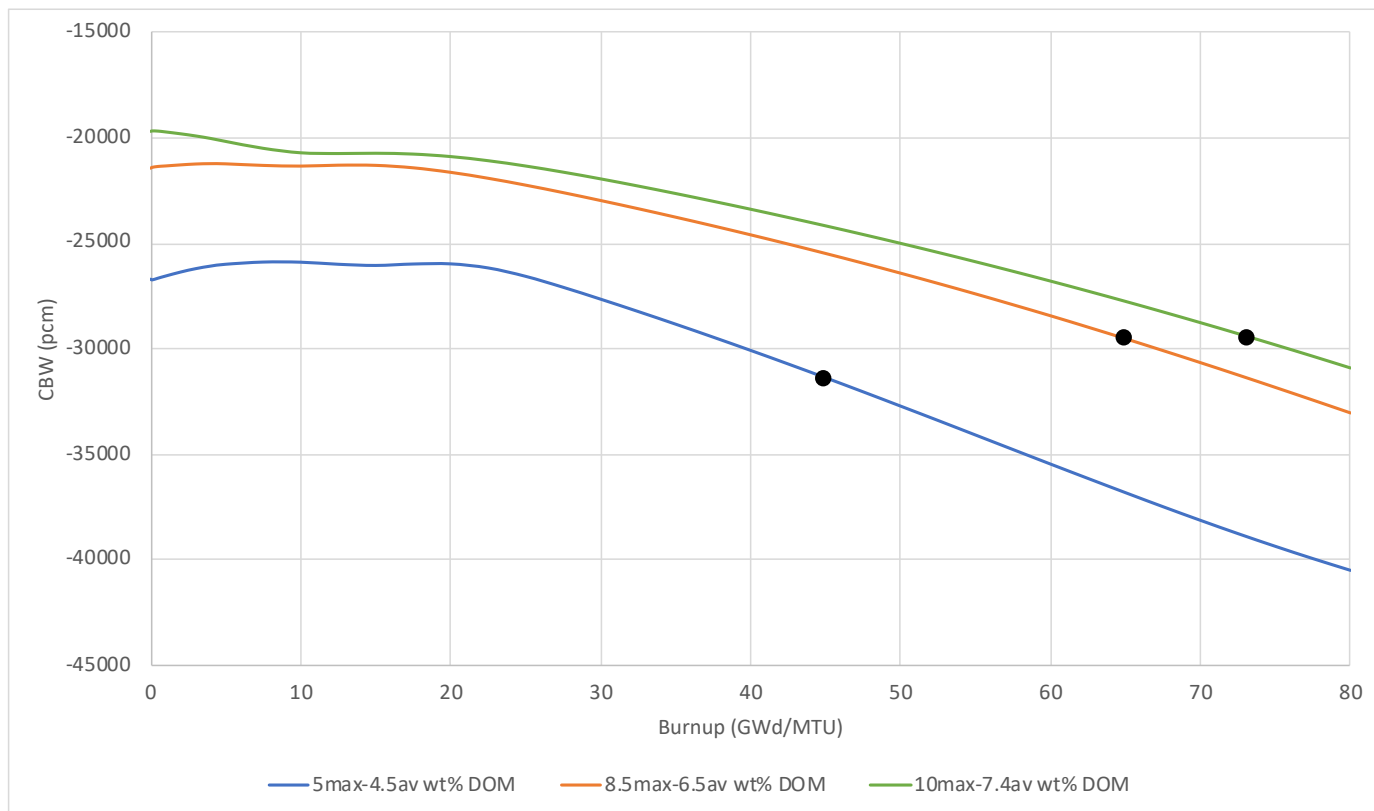

Figure 9. HFP CBW at $40 \%$ void fraction. 


\subsection{MACROSCOPIC CROSS SECTIONS}

\subsubsection{Lattice Cross Sections}

Polaris lattice-averaged macroscopic absorption cross sections for thermal and fast neutrons are shown in Figure 10 and Figure 11, respectively. These figures show similar relationships among the different enrichments throughout the fuel utilization period. Both fast and thermal neutron absorption generally increases with increasing fuel enrichment for both lattices. The vanished fuel lattices consistently display less absorption cross section than the dominant region lattices. This behavior is attributed smaller fuel to moderator ratio. Regardless, both lattices show the same trend with burnup and enrichment.

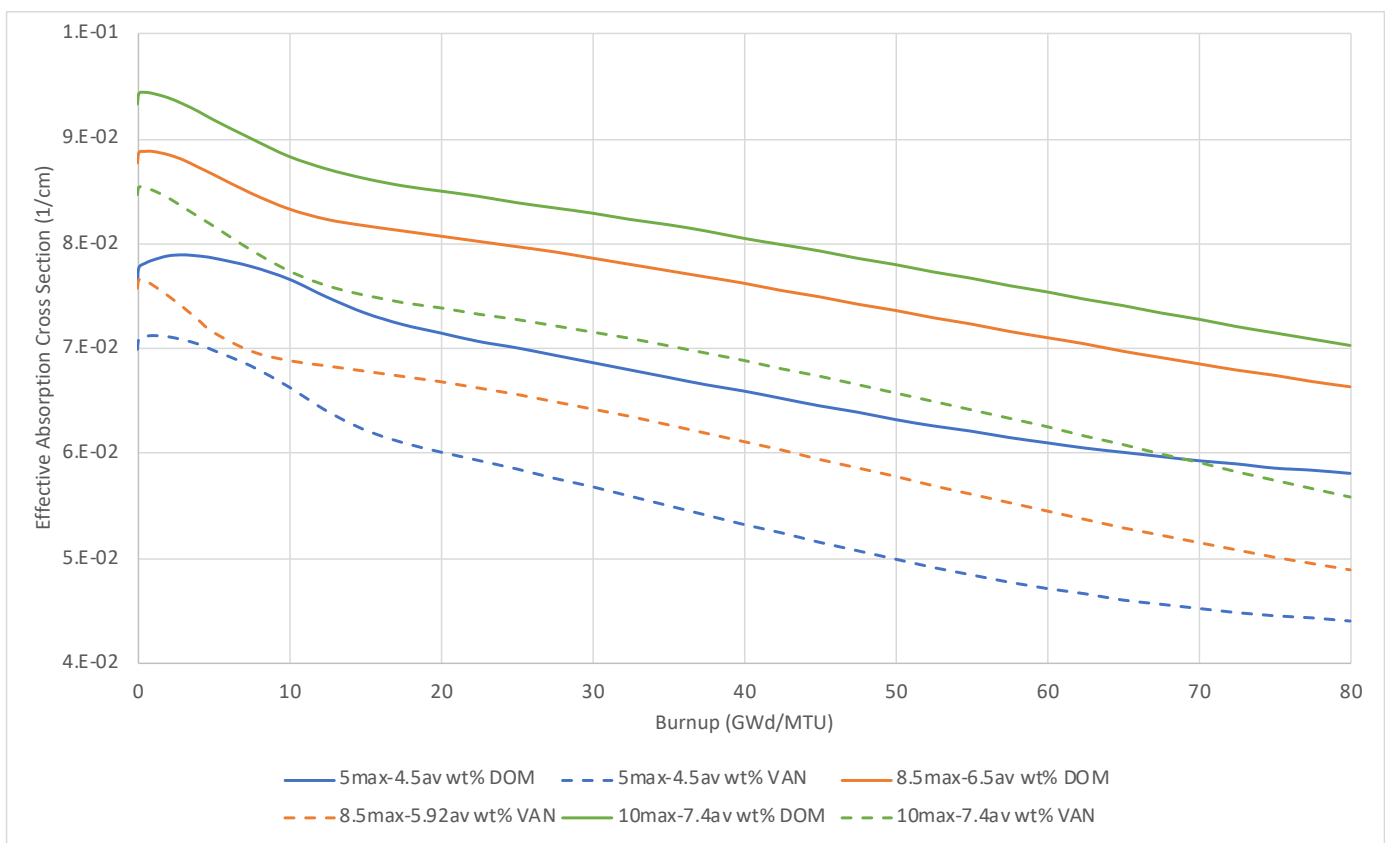

Figure 10. HFP macroscopic thermal absorption cross section 


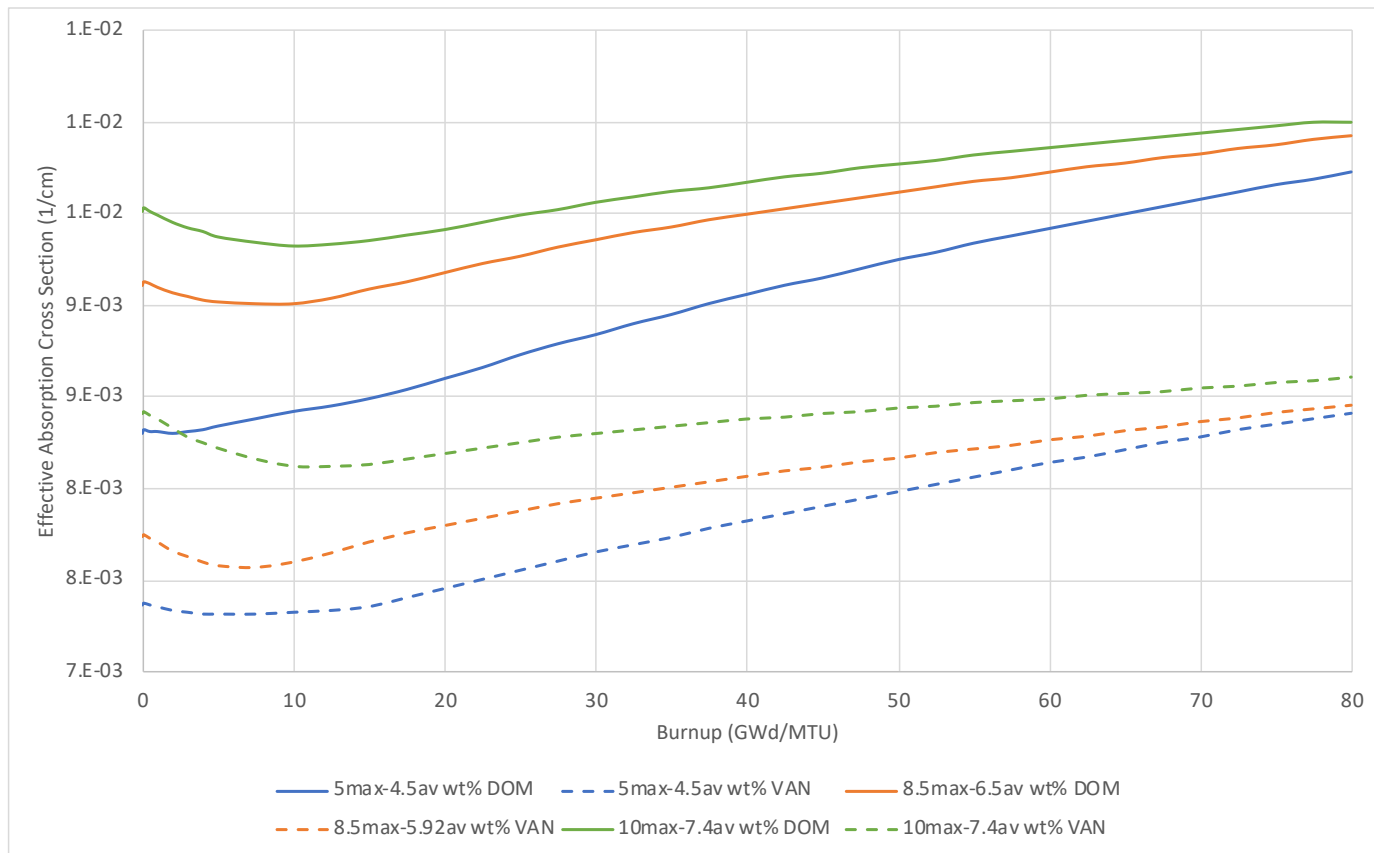

Figure 11. HFP macroscopic fast absorption cross section

Lattice-averaged macroscopic fission cross sections in Figure 12 and Figure 13 for thermal and fast neutrons, show a similar relationship among curves: increased thermal and fast fission cross sections with increased enrichment and decreased cross sections for vanished lattices. The thermal fission cross section initially increases as gadolinia is depleted because gadolinia shields out the uranium nuclei in the thermal region.

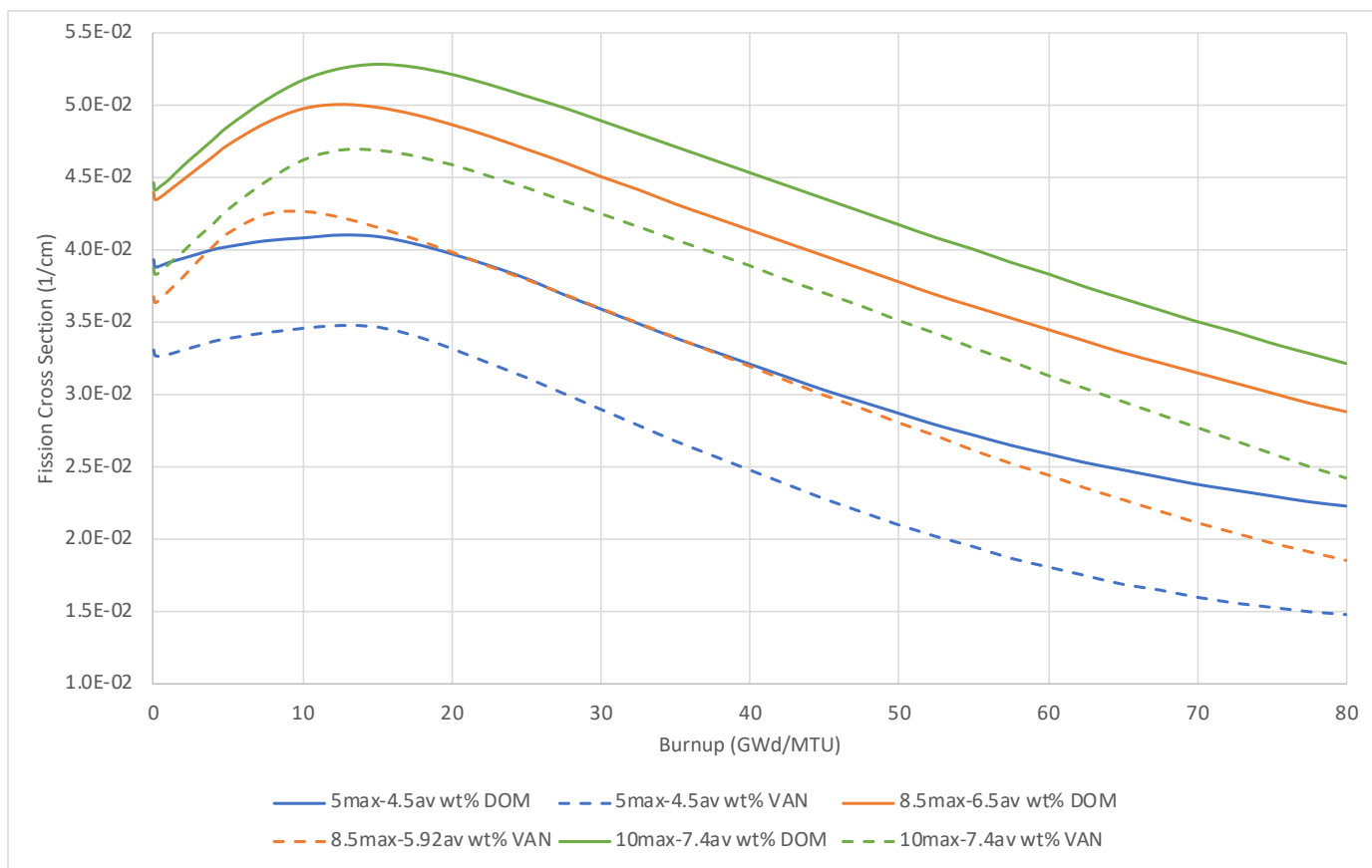

Figure 12. HFP macroscopic thermal fission cross section 


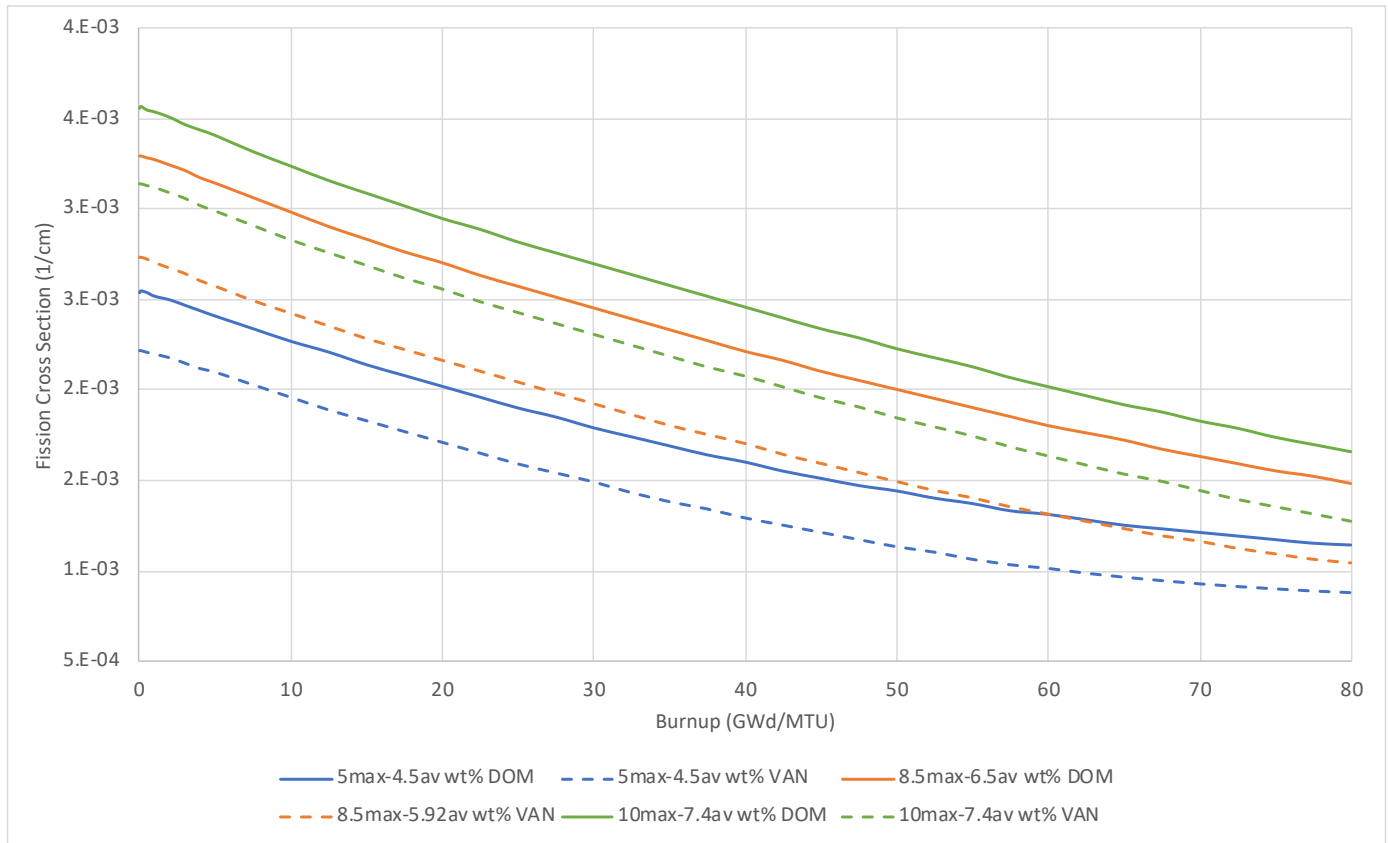

Figure 13. HFP macroscopic fast fission cross section

\subsubsection{Kinetics Parameters}

The total effective delayed neutron fraction ( $\beta$-eff.) shown in Figure 14 increases with increasing enrichment, and it consistently decreases with increasing burnup. Among similar fuel burnups, DOM and VAN lattices for each lattice enrichment show similar delayed neutron fractions. The delayed neutron fraction is much lower for $\mathrm{Pu}$ fission $\left(\beta \sim 0.0021\right.$ for $\left.{ }^{239} \mathrm{Pu}\right)$ than for $\mathrm{U}$ fission $(\beta$ $\sim 0.0064$ for $\left.{ }^{235} \mathrm{U}\right)$. Higher enrichment depletion results in a lower fraction of fissions in $\mathrm{Pu}$ than the reference depletion at the same burnup, which results in a higher $\beta$-eff. Increased burnup in a higher enrichment core tends to offset the enrichment-only effect. 


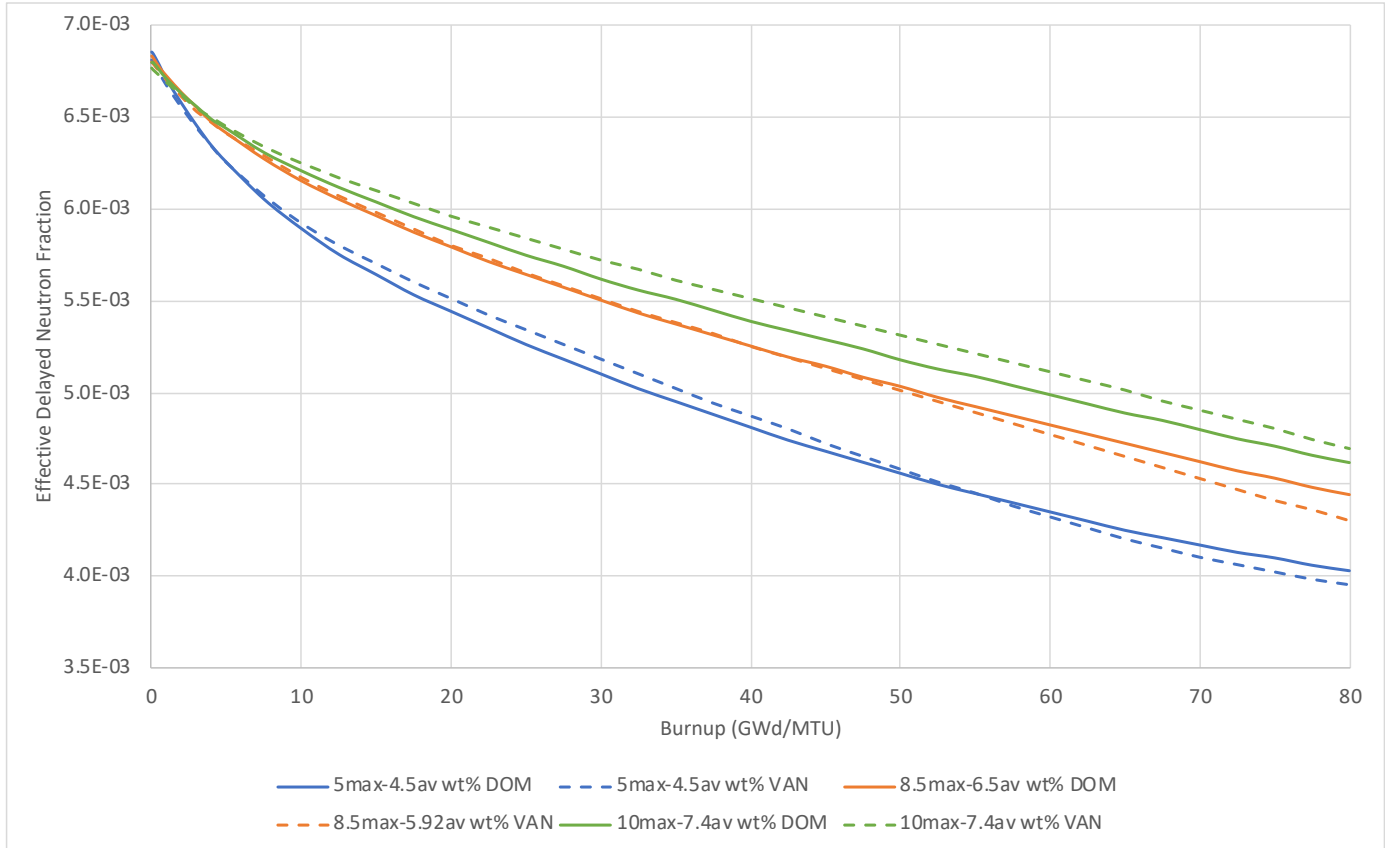

Figure 14. Effective delayed neutron fraction 


\section{SENSITIVITY AND UNCERTAINTY}

\subsection{NUCLIDE WORTH RANKING}

One way to assess the similarity between the reference case and the high burnup and extended enrichment cases is to compare nuclide worth. Individual isotope worths can be computed using the simplified expression for lattice $k_{\text {inf }}$ in Eq. 1.

$$
k_{\text {inf }}=\frac{\sum_{i} n_{i} v \sigma_{f, i}}{\sum_{i} n_{i} \sigma_{a, i}}
$$

where, $n_{i}$ and $\boldsymbol{\sigma}_{i}$ are number densities and microscopic cross sections of the $i^{\text {th }}$ isotope.

Using the lattice-average one-group microscopic cross sections and number densities from the Polaris depletion calculations and from ENDF/B VII.1 (only $\boldsymbol{v}$ for ${ }^{235} \mathrm{U},{ }^{236} \mathrm{U},{ }^{238} \mathrm{U},{ }^{239} \mathrm{Pu}$, and ${ }^{241} \mathrm{Pu}$ at $0.025 \mathrm{eV}$ ), the contribution of each isotope to $k_{\text {inf }}$ can be calculated from total number of fission neutrons (numerator) and total number of absorbed neutrons (denominator) in Eq. 1. Since one-group cross sections are generated consistently with transport calculations, this simple equation for $k_{\text {inf }}$ is accurate. Using Eq. 1, the worth of each nuclide can be ranked by ranking the change caused in $k_{i n f}$ for $1 \%$ change in concentration of each isotope.

Table 3 lists the top 25 nuclides by their respective worth. The change in reactivity worths for increased enrichment and increased burnups were calculated by comparing $10 \mathrm{max}-7.4 \mathrm{av} \mathrm{wt} \%$ lattice at $60 \mathrm{GWd} / \mathrm{MTU}$ and $80 \mathrm{GWd} / \mathrm{MTU}$ with the reference $5 \mathrm{max}-4.5 \mathrm{av}$ wt $\%$ lattice at 60 $\mathrm{GWd} / \mathrm{MTU}$ for nominal, $40 \%$ void fraction. The calculated nuclide rankings for high burnup and extended enrichment are consistent with the nuclide rankings in the PWR report [15]. The top 25 nuclides account more than $94 \%$ of the total reactivity at each depletion step.

The nuclide worth ranking table provides information about the source of reactivity changes for changes in enrichment and burnup. For most isotopes the effects of enrichment and burnup are counteracting in terms of reactivity worth, with no change in sign for the worth. The findings are consistent with those throughout this report that further increases in enrichment and burnup are typically counteracting, and the behaviors are smooth extensions of expected behavior at typical enrichments and burnups. 
Table 3. Nuclide worth $(\Delta \mathrm{k})$ at $\mathbf{4 0 \%}$ void fraction

\begin{tabular}{|c|c|c|c|c|c|c|}
\hline \multicolumn{4}{|c|}{$\begin{array}{c}\text { Worths }(\Delta \mathrm{k}) \text { for } 1 \% \text { increase in isotope's } \\
\text { composition }\end{array}$} & \multirow{2}{*}{$\begin{array}{c}\text { Percent change in } \\
\text { worth from } \\
\text { enrichment } \\
\text { increase }\end{array}$} & \multirow{2}{*}{$\begin{array}{l}\text { Percent change in } \\
\text { worth from } \\
\text { burnup increase }\end{array}$} & \multirow{2}{*}{$\begin{array}{c}\text { Percent change in } \\
\text { worth from } \\
\text { enrichment and } \\
\text { burnup increase }\end{array}$} \\
\hline Isotope & $\begin{array}{l}5 \mathrm{max}-4.5 \mathrm{av} \% \\
60 \mathrm{GWd} / \mathrm{MTU}\end{array}$ & $\begin{array}{l}10 \mathrm{max}-7.4 \mathrm{av} \% \\
60 \mathrm{GWd} / \mathrm{MTU}\end{array}$ & $\begin{array}{l}10 \mathrm{max}-7.4 \mathrm{av} \% \\
80 \mathrm{GWd} / \mathrm{MTU}\end{array}$ & & & \\
\hline${ }^{239} \mathrm{Pu}$ & $2.70 \mathrm{E}-03$ & $1.80 \mathrm{E}-03$ & $2.20 \mathrm{E}-03$ & $-33 \%$ & $22 \%$ & $-19 \%$ \\
\hline${ }^{238} \mathrm{U}$ & $-1.90 \mathrm{E}-03$ & $-2.10 \mathrm{E}-03$ & $-1.90 \mathrm{E}-03$ & $11 \%$ & $-10 \%$ & $0 \%$ \\
\hline${ }^{235} \mathrm{U}$ & $9.20 \mathrm{E}-04$ & $2.40 \mathrm{E}-03$ & $1.60 \mathrm{E}-03$ & $161 \%$ & $-33 \%$ & $74 \%$ \\
\hline${ }^{241} \mathrm{Pu}$ & $1.10 \mathrm{E}-03$ & $6.00 \mathrm{E}-04$ & $8.70 \mathrm{E}-04$ & $-45 \%$ & $45 \%$ & $-21 \%$ \\
\hline${ }^{240} \mathrm{Pu}$ & $-5.60 \mathrm{E}-04$ & $-5.10 \mathrm{E}-04$ & $-5.90 \mathrm{E}-04$ & $-9 \%$ & $16 \%$ & $5 \%$ \\
\hline${ }^{1} \mathrm{H}$ & $-5.30 \mathrm{E}-04$ & $-5.00 \mathrm{E}-04$ & $-4.20 \mathrm{E}-04$ & $-6 \%$ & $-16 \%$ & $-21 \%$ \\
\hline${ }^{143} \mathrm{Nd}$ & $-1.20 \mathrm{E}-04$ & $-1.40 \mathrm{E}-04$ & $-1.30 \mathrm{E}-04$ & $17 \%$ & $-7 \%$ & $8 \%$ \\
\hline${ }^{103} \mathrm{Rh}$ & $-1.10 \mathrm{E}-04$ & $-1.10 \mathrm{E}-04$ & $-1.20 \mathrm{E}-04$ & $0 \%$ & $9 \%$ & $9 \%$ \\
\hline${ }^{135} \mathrm{Xe}$ & $-1.40 \mathrm{E}-04$ & $-1.90 \mathrm{E}-04$ & $-1.20 \mathrm{E}-04$ & $36 \%$ & $-37 \%$ & $-14 \%$ \\
\hline${ }^{236} \mathrm{U}$ & $-6.70 \mathrm{E}-05$ & $-1.00 \mathrm{E}-04$ & $-1.10 \mathrm{E}-04$ & $49 \%$ & $10 \%$ & $64 \%$ \\
\hline${ }^{133} \mathrm{Cs}$ & $-6.60 \mathrm{E}-05$ & $-7.00 \mathrm{E}-05$ & $-8.10 \mathrm{E}-05$ & $6 \%$ & $16 \%$ & $23 \%$ \\
\hline${ }^{131} \mathrm{Xe}$ & $-6.30 \mathrm{E}-05$ & $-7.00 \mathrm{E}-05$ & $-7.40 \mathrm{E}-05$ & $11 \%$ & $6 \%$ & $17 \%$ \\
\hline${ }^{237} \mathrm{~Np}$ & $-5.50 \mathrm{E}-05$ & $-5.50 \mathrm{E}-05$ & $-6.60 \mathrm{E}-05$ & $0 \%$ & $20 \%$ & $20 \%$ \\
\hline${ }^{91} \mathrm{Zr}$ & $-7.00 \mathrm{E}-05$ & $-7.30 \mathrm{E}-05$ & $-6.60 \mathrm{E}-05$ & $4 \%$ & $-10 \%$ & $-6 \%$ \\
\hline${ }^{242} \mathrm{Pu}$ & $-5.20 \mathrm{E}-05$ & $-3.30 \mathrm{E}-05$ & $-6.40 \mathrm{E}-05$ & $-37 \%$ & $94 \%$ & $23 \%$ \\
\hline${ }^{99} \mathrm{Tc}$ & $-5.00 \mathrm{E}-05$ & $-5.30 \mathrm{E}-05$ & $-6.20 \mathrm{E}-05$ & $6 \%$ & $17 \%$ & $24 \%$ \\
\hline${ }^{152} \mathrm{Sm}$ & $-4.40 \mathrm{E}-05$ & $-4.60 \mathrm{E}-05$ & $-4.90 \mathrm{E}-05$ & $5 \%$ & $7 \%$ & $11 \%$ \\
\hline${ }^{153} \mathrm{Eu}$ & $-4.30 \mathrm{E}-05$ & $-3.80 \mathrm{E}-05$ & $-4.60 \mathrm{E}-05$ & $-12 \%$ & $21 \%$ & $7 \%$ \\
\hline${ }^{149} \mathrm{Sm}$ & $-4.90 \mathrm{E}-05$ & $-7.40 \mathrm{E}-05$ & $-4.40 \mathrm{E}-05$ & $51 \%$ & $-41 \%$ & $-10 \%$ \\
\hline${ }^{155} \mathrm{Eu}$ & $-4.10 \mathrm{E}-05$ & $-3.20 \mathrm{E}-05$ & $-4.30 \mathrm{E}-05$ & $-22 \%$ & $34 \%$ & $5 \%$ \\
\hline${ }^{145} \mathrm{Nd}$ & $-3.40 \mathrm{E}-05$ & $-3.60 \mathrm{E}-05$ & $-4.10 \mathrm{E}-05$ & $6 \%$ & $14 \%$ & $21 \%$ \\
\hline${ }^{154} \mathrm{Eu}$ & $-4.10 \mathrm{E}-05$ & $-3.40 \mathrm{E}-05$ & $-4.00 \mathrm{E}-05$ & $-17 \%$ & $18 \%$ & $-2 \%$ \\
\hline${ }^{151} \mathrm{Sm}$ & $-4.10 \mathrm{E}-05$ & $-4.90 \mathrm{E}-05$ & $-3.60 \mathrm{E}-05$ & $20 \%$ & $-27 \%$ & $-12 \%$ \\
\hline${ }^{147} \mathrm{Pm}$ & $-3.20 \mathrm{E}-05$ & $-4.00 \mathrm{E}-05$ & $-3.50 \mathrm{E}-05$ & $25 \%$ & $-13 \%$ & $9 \%$ \\
\hline${ }^{243} \mathrm{Am}$ & $-2.90 \mathrm{E}-05$ & $-1.50 \mathrm{E}-05$ & $-3.30 \mathrm{E}-05$ & $-48 \%$ & $120 \%$ & $14 \%$ \\
\hline
\end{tabular}




\subsection{SAMPLER/POLARIS DEPLETION UNCERTAINTY}

Sampler is a sequence in SCALE code suit for statistical uncertainty analysis with SCALE sequences. Sampler was used with Polaris to propagate nuclear data uncertainties (cross sections, fission yields, decay constants) through depletion calculations and calculate the uncertainties in isotope inventories.

The reference $5 \mathrm{max}-4.5 \mathrm{av}$ wt $\%$ lattice was depleted $60 \mathrm{GWd} / \mathrm{MTU}$ and the variation in inventories of major isotopes were calculated. Similarly, relative variations in isotope inventories (Eq. 2) from depletion of 10 max-7.4 av wt $\%$ lattice at $60 \mathrm{GWd} / \mathrm{MTU}$ and $80 \mathrm{GWd} / \mathrm{MTU}$ were also calculated. All lattices were assumed to be at $40 \%$ void fraction.

Similar comparisons as in nuclide worth calculations were done in Table 4 between the three cases to show any effect of enrichment increase and extended burnup on isotope uncertainties. The difference in relative uncertainties between the cases (Eq. 3) are also shown in Table 4. In general, similar relative uncertainties are observed between the reference case, increased enrichment and increased enrichment and burnup cases. Except ${ }^{155} \mathrm{Eu}$, all relative uncertainties in isotopic inventory either does not increase significantly or decrease with increased burnup and enrichment. The relative uncertainty for ${ }^{155} \mathrm{Eu}$ was doubled for the both $10 \mathrm{max}-7.4 \mathrm{av} \mathrm{wt} \%$ lattice cases compared to the reference case. However, further investigation shows that although absolute uncertainty is reduced, because of large drop $(1 / 5)$ in ${ }^{155} \mathrm{Eu}$ content with increased enrichment and burnup, the relative uncertainty is larger for the two cases.

$$
\sigma_{\text {rel }}=\sigma / w,
$$

where $\boldsymbol{\sigma}$ is standard deviation and $w$ is the isotope weight

$$
\Delta \sigma_{r e l}=\sigma_{r e l}-\sigma_{r e l}^{\text {reference }}
$$

Uncertainties in $k_{\text {inf }}$ due to nuclear data uncertainties are also plotted in Figure 15 for 5 max$4.5 \mathrm{av} \mathrm{wt} \%$ and 10 max- $7.4 \mathrm{av} \mathrm{wt} \%$ DOM lattices at $40 \%$ void fraction. The standard deviation in $k_{\text {inf }}$ was approximately $550 \mathrm{pcm}$ for depletion of both lattices. The uncertainty for the reference lattice starts increase after the expected life time of the lattice ( $\sim 55 \mathrm{GWd} / \mathrm{MTU})$. No appreciable increase in uncertainty was observed for higher enrichments or burnups. 
Table 4. Predictions and relative standard deviations in isotope inventories

\begin{tabular}{|c|c|c|c|c|c|c|c|c|}
\hline \multirow[t]{2}{*}{ Isotope } & \multicolumn{2}{|c|}{$\begin{array}{c}5 \mathrm{max}-4.5 \mathrm{av} \text { wt } \% \\
60 \mathrm{GWd} / \mathrm{MTU}\end{array}$} & \multicolumn{2}{|c|}{$\begin{array}{c}10 \max -7.4 \mathrm{wt} \% \max \\
60 \mathrm{GWd} / \mathrm{MTU}\end{array}$} & \multicolumn{2}{|c|}{$\begin{array}{c}\text { 10max-7.4 wt\% max, } \\
80 \mathrm{GWd} / \mathrm{MTU}\end{array}$} & \multirow{2}{*}{$\begin{array}{c}\text { Enrichment } \\
\text { increase } \\
\Delta \sigma_{\text {rel }}\end{array}$} & \multirow{2}{*}{$\begin{array}{c}\text { Enrichment } \\
\text { and Burnup } \\
\text { increase } \\
\Delta \sigma_{\text {rel }}\end{array}$} \\
\hline & Mass (g) & $\sigma_{\text {rel }}$ & Mass (g) & $\sigma_{\text {rel }}$ & Mass (g) & $\sigma_{\text {rel }}$ & & \\
\hline${ }^{239} \mathrm{Pu}$ & $1.98 \mathrm{E}-01$ & $2.1 \%$ & $1.33 \mathrm{E}-01$ & $1.7 \%$ & $1.37 \mathrm{E}-01$ & $2.1 \%$ & $-0.4 \%$ & $0.0 \%$ \\
\hline${ }^{238} \mathrm{U}$ & $4.22 \mathrm{E}+01$ & $0.0 \%$ & $1.35 \mathrm{E}+01$ & $0.0 \%$ & $1.33 \mathrm{E}+01$ & $0.0 \%$ & $0.0 \%$ & $0.0 \%$ \\
\hline${ }^{235} \mathrm{U}$ & $8.05 \mathrm{E}-02$ & $3.6 \%$ & 7.27E-01 & $0.6 \%$ & $5.05 \mathrm{E}-01$ & $1.2 \%$ & $-3.0 \%$ & $-2.4 \%$ \\
\hline${ }^{241} \mathrm{Pu}$ & $6.70 \mathrm{E}-02$ & $2.3 \%$ & $2.20 \mathrm{E}-02$ & $1.3 \%$ & $3.04 \mathrm{E}-02$ & $1.4 \%$ & $-1.0 \%$ & $-0.8 \%$ \\
\hline${ }^{240} \mathrm{Pu}$ & $1.38 \mathrm{E}-01$ & $2.3 \%$ & $3.15 \mathrm{E}-02$ & $1.8 \%$ & 4.48E-02 & $1.9 \%$ & $-0.6 \%$ & $-0.4 \%$ \\
\hline${ }^{143} \mathrm{Nd}$ & 7.04E-02 & $2.8 \%$ & $4.06 \mathrm{E}-02$ & $1.5 \%$ & $5.00 \mathrm{E}-02$ & $2.0 \%$ & $-1.3 \%$ & $-0.7 \%$ \\
\hline${ }^{103} \mathrm{Rh}$ & $7.21 \mathrm{E}-02$ & $2.1 \%$ & $2.29 \mathrm{E}-02$ & $1.4 \%$ & $2.87 \mathrm{E}-02$ & $1.8 \%$ & $-0.7 \%$ & $-0.4 \%$ \\
\hline${ }^{135} \mathrm{Xe}$ & 8.94E-06 & $4.0 \%$ & $9.02 \mathrm{E}-06$ & $1.6 \%$ & 8.37E-06 & $2.0 \%$ & $-2.4 \%$ & $-2.0 \%$ \\
\hline${ }^{236} \mathrm{U}$ & $2.48 \mathrm{E}-01$ & $1.3 \%$ & $1.81 \mathrm{E}-01$ & $1.6 \%$ & $2.18 \mathrm{E}-01$ & $1.6 \%$ & $0.3 \%$ & $0.3 \%$ \\
\hline${ }^{133} \mathrm{Cs}$ & $1.58 \mathrm{E}-01$ & $1.1 \%$ & $5.12 \mathrm{E}-02$ & $0.7 \%$ & $6.62 \mathrm{E}-02$ & $0.9 \%$ & $-0.4 \%$ & $-0.2 \%$ \\
\hline${ }^{131} \mathrm{Xe}$ & $5.27 \mathrm{E}-02$ & $6.5 \%$ & $1.92 \mathrm{E}-02$ & $4.3 \%$ & 2.34E-02 & $5.7 \%$ & $-2.2 \%$ & $-0.7 \%$ \\
\hline${ }^{237} \mathrm{~Np}$ & $3.19 \mathrm{E}-02$ & $4.2 \%$ & $1.42 \mathrm{E}-02$ & $3.8 \%$ & $2.02 \mathrm{E}-02$ & $3.6 \%$ & $-0.5 \%$ & $-0.6 \%$ \\
\hline${ }^{91} \mathrm{Zr}$ & $1.18 \mathrm{E}-01$ & $0.4 \%$ & $4.26 \mathrm{E}-02$ & $0.4 \%$ & $5.62 \mathrm{E}-02$ & $0.5 \%$ & $0.0 \%$ & $0.1 \%$ \\
\hline${ }^{242} \mathrm{Pu}$ & $7.31 \mathrm{E}-02$ & $3.9 \%$ & $4.13 \mathrm{E}-03$ & $4.0 \%$ & 8.81E-03 & $4.4 \%$ & $0.1 \%$ & $0.5 \%$ \\
\hline${ }^{99} \mathrm{Tc}$ & $1.54 \mathrm{E}-01$ & $0.9 \%$ & 4.89E-02 & $0.5 \%$ & 6.37E-02 & $0.6 \%$ & $-0.4 \%$ & $-0.3 \%$ \\
\hline${ }^{152} \mathrm{Sm}$ & $1.23 \mathrm{E}-02$ & $2.8 \%$ & $3.33 \mathrm{E}-03$ & $2.5 \%$ & $4.01 \mathrm{E}-03$ & $3.1 \%$ & $-0.3 \%$ & $0.3 \%$ \\
\hline${ }^{153} \mathrm{Eu}$ & $1.51 \mathrm{E}-02$ & $3.6 \%$ & $3.71 \mathrm{E}-03$ & $2.8 \%$ & $5.21 \mathrm{E}-03$ & $3.5 \%$ & $-0.8 \%$ & $-0.1 \%$ \\
\hline${ }^{149} \mathrm{Sm}$ & $1.04 \mathrm{E}-04$ & $3.2 \%$ & $1.64 \mathrm{E}-04$ & $2.6 \%$ & $1.38 \mathrm{E}-04$ & $3.3 \%$ & $-0.6 \%$ & $0.1 \%$ \\
\hline${ }^{155} \mathrm{Eu}$ & $1.29 \mathrm{E}-03$ & $18.3 \%$ & $2.67 \mathrm{E}-04$ & $31.2 \%$ & 4.49E-04 & $30.3 \%$ & $12.9 \%$ & $12.1 \%$ \\
\hline${ }^{145} \mathrm{Nd}$ & $8.43 \mathrm{E}-02$ & $2.0 \%$ & $2.92 \mathrm{E}-02$ & $1.3 \%$ & $3.75 \mathrm{E}-02$ & $1.8 \%$ & $-0.7 \%$ & $-0.2 \%$ \\
\hline${ }^{154} \mathrm{Eu}$ & $3.12 \mathrm{E}-03$ & $9.2 \%$ & $1.03 \mathrm{E}-03$ & $6.9 \%$ & $1.61 \mathrm{E}-03$ & $7.8 \%$ & $-2.2 \%$ & $-1.4 \%$ \\
\hline${ }^{151} \mathrm{Sm}$ & 8.35E-04 & $3.6 \%$ & $7.68 \mathrm{E}-04$ & $3.4 \%$ & $7.71 \mathrm{E}-04$ & $4.1 \%$ & $-0.2 \%$ & $0.4 \%$ \\
\hline${ }^{147} \mathrm{Pm}$ & $1.30 \mathrm{E}-02$ & $2.8 \%$ & $6.02 \mathrm{E}-03$ & $1.9 \%$ & $6.18 \mathrm{E}-03$ & $2.2 \%$ & $-0.9 \%$ & $-0.6 \%$ \\
\hline${ }^{243} \mathrm{Am}$ & $1.74 \mathrm{E}-02$ & $7.8 \%$ & $7.50 \mathrm{E}-04$ & $10.0 \%$ & $1.98 \mathrm{E}-03$ & $9.2 \%$ & $2.2 \%$ & $1.4 \%$ \\
\hline${ }^{95} \mathrm{Mo}$ & $1.42 \mathrm{E}-01$ & $0.6 \%$ & $4.70 \mathrm{E}-02$ & $0.6 \%$ & $6.24 \mathrm{E}-02$ & $0.7 \%$ & $0.0 \%$ & $0.1 \%$ \\
\hline${ }^{101} \mathrm{Ru}$ & $1.56 \mathrm{E}-01$ & $0.9 \%$ & 4.42E-02 & $0.7 \%$ & 5.91E-02 & $0.9 \%$ & $-0.2 \%$ & $-0.1 \%$ \\
\hline${ }^{238} \mathrm{Pu}$ & $2.38 \mathrm{E}-02$ & $5.6 \%$ & $5.48 \mathrm{E}-03$ & $4.7 \%$ & $1.13 \mathrm{E}-02$ & $4.2 \%$ & $-1.0 \%$ & $-1.4 \%$ \\
\hline${ }^{109} \mathrm{Ag}$ & $1.62 \mathrm{E}-02$ & $9.0 \%$ & $3.09 \mathrm{E}+01$ & $0.0 \%$ & $3.09 \mathrm{E}+01$ & $0.0 \%$ & $-9.0 \%$ & $-9.0 \%$ \\
\hline${ }^{241} \mathrm{Am}$ & $2.59 \mathrm{E}-03$ & $5.8 \%$ & $2.20 \mathrm{E}-03$ & $9.6 \%$ & $3.53 \mathrm{E}-03$ & $9.1 \%$ & $3.8 \%$ & $3.2 \%$ \\
\hline${ }^{156} \mathrm{Gd}$ & $2.36 \mathrm{E}-02$ & $2.6 \%$ & $1.57 \mathrm{E}-03$ & $2.6 \%$ & $2.45 \mathrm{E}-03$ & $3.5 \%$ & $0.0 \%$ & $0.9 \%$ \\
\hline${ }^{147} \mathrm{Sm}$ & $1.24 \mathrm{E}-02$ & $2.7 \%$ & $1.75 \mathrm{E}-03$ & $5.4 \%$ & $3.85 \mathrm{E}-03$ & $4.8 \%$ & $2.6 \%$ & $2.1 \%$ \\
\hline${ }^{150} \mathrm{Sm}$ & $3.69 \mathrm{E}-02$ & $1.7 \%$ & $5.56 \mathrm{E}-03$ & $1.8 \%$ & $7.13 \mathrm{E}-03$ & $2.3 \%$ & $0.1 \%$ & $0.6 \%$ \\
\hline${ }^{157} \mathrm{Gd}$ & $9.61 \mathrm{E}-06$ & $8.5 \%$ & $1.02 \mathrm{E}-02$ & $1.4 \%$ & $1.39 \mathrm{E}-02$ & $1.8 \%$ & $-7.1 \%$ & $-6.7 \%$ \\
\hline
\end{tabular}




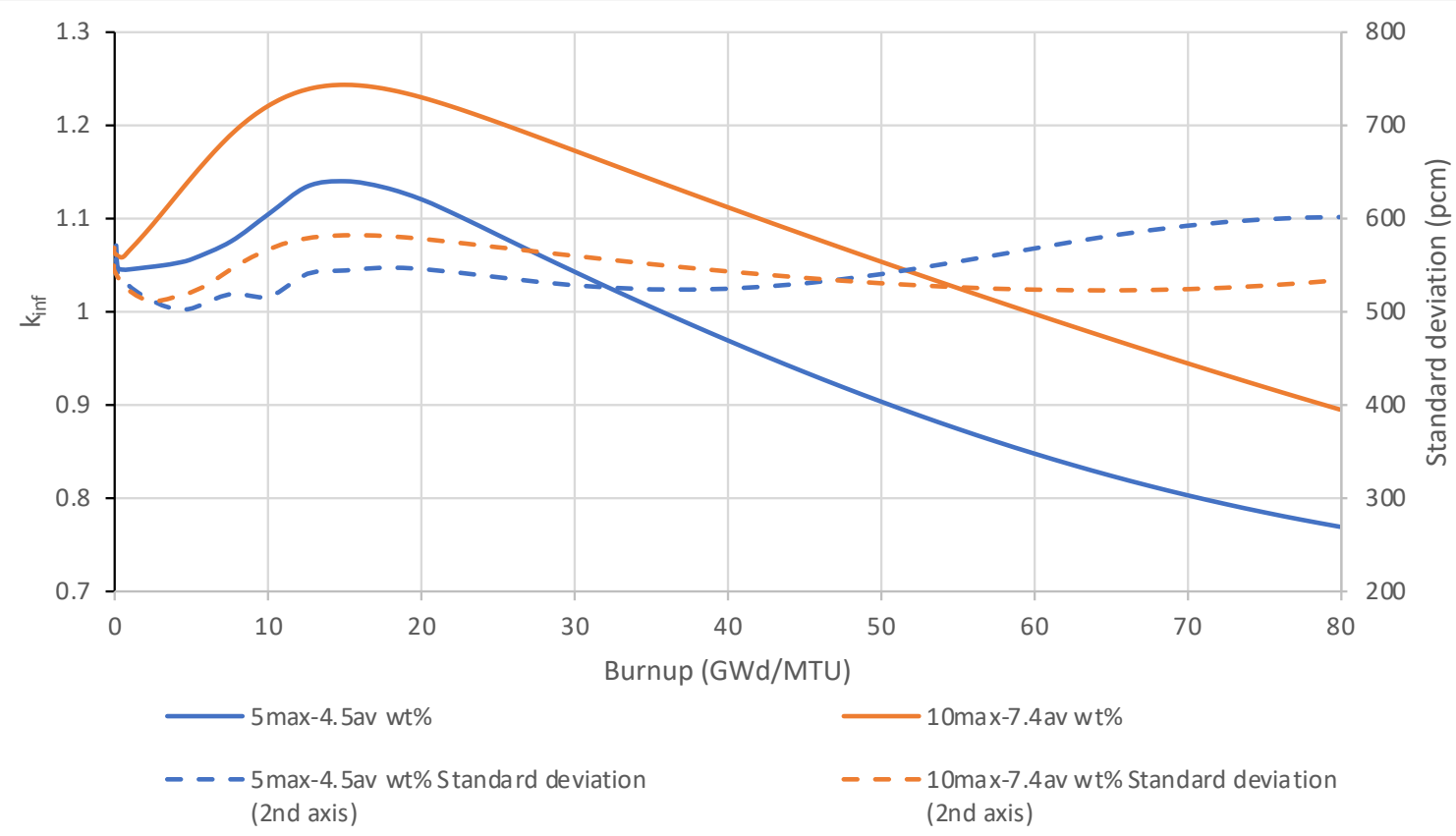

Figure 15. Uncertainty in $k_{\text {inf }}$ at $40 \%$ void fraction due to nuclear data uncertainties. 


\section{ISOTOPIC INVENTORY}

The interactions between several factors and isotopic compositions are evaluated here for a total of 16 cases evaluated. All combinations of the following factors (independent variables) and factor levels (discrete values of each variable) were evaluated.

- Enrichment: $5 \%$ maximum enrichment, $10 \%$ maximum pin enrichment

- Burnup: $60 \mathrm{GWd} / \mathrm{MTU}, 80 \mathrm{GWd} / \mathrm{MTU}$

- Lattice design: DOM, VAN lattice

- Void: $10 \%$ (DOM lattice only), 40\%, 70\% (VAN lattice only)

Five decay times were evaluated for each case in this section. The reasons for selections of the various time points are listed below:

- 0 seconds: provides a reference value for other time points

- 30 min: captures possible impacts of isotopics on core cooling events (e.g., LOCA)

- 5 days: captures possible impacts of isotopics during refueling outage/discharge

- 25 days: captures possible impacts of isotopics at the end of refueling outage/discharge

- 500 days: captures possible impacts of isotopics on early long-term storage. Isotopes are ranked by the root mean squared (RMS) value of the isotope's percent total contribution to some quantity such as activity or decay heat given by

$$
R M S_{i}=\sqrt{\sum_{n}\left(\frac{a_{i n}-b_{i n}}{b_{n}}\right)^{2}},
$$

where $a_{i n}$ and $b_{i n}$ are the values for isotope $i$ being compared at time point $n$, with $b_{n}$ being the total of all isotopes at time point $n$. The timepoint of 0 seconds of decay is not included in calculating any of the rankings. The RMS ranking presented in this section provides a measure of cumulative relative impact of an isotope to the quantity of interest over the analyzed decay period.

\subsection{DECAY HEAT TRENDS}

Figure 16 and Figure 17 show decay heat vs time for the burnup-enrichment combinations evaluated that bounded decay heat at 1000 days. The highest decay heat case was the VAN lattice with $5 \mathrm{max}-4.5 \mathrm{av}$ wt $\%$ enrichment operating at $70 \%$ void fraction and discharged at 80 GWD/MTU burnup. The lowest decay heat was the DOM lattice with 10max-7.4av wt $\%$ enrichment operating at $40 \%$ void fraction and discharged at $60 \mathrm{GWd} / \mathrm{MTU}$ burnup. All cases follow the similar decay heat curve with time after discharge. Based on discharge burnup, the decay heat curves split into two groups after 100 days of cooling. Decay heat as a fraction of full core power is also shown in Figure 18. Increased enrichment and burnup slightly increase fraction of decay heat, however, the difference is negligible and all cases start around $6 \%$ and follows the same curve (note that the decay heat assumes a sudden, complete shutdown). The relative difference in decay heat between the reference case and several representative cases (Eq. 5) with variations in void, burnup, enrichment and lattice types are shown in Figure 19. 
Although, up to $60 \%$ relative differences due to small decay heat values are observed for some cases, the absolute differences shown in Figure 20 are negligible.

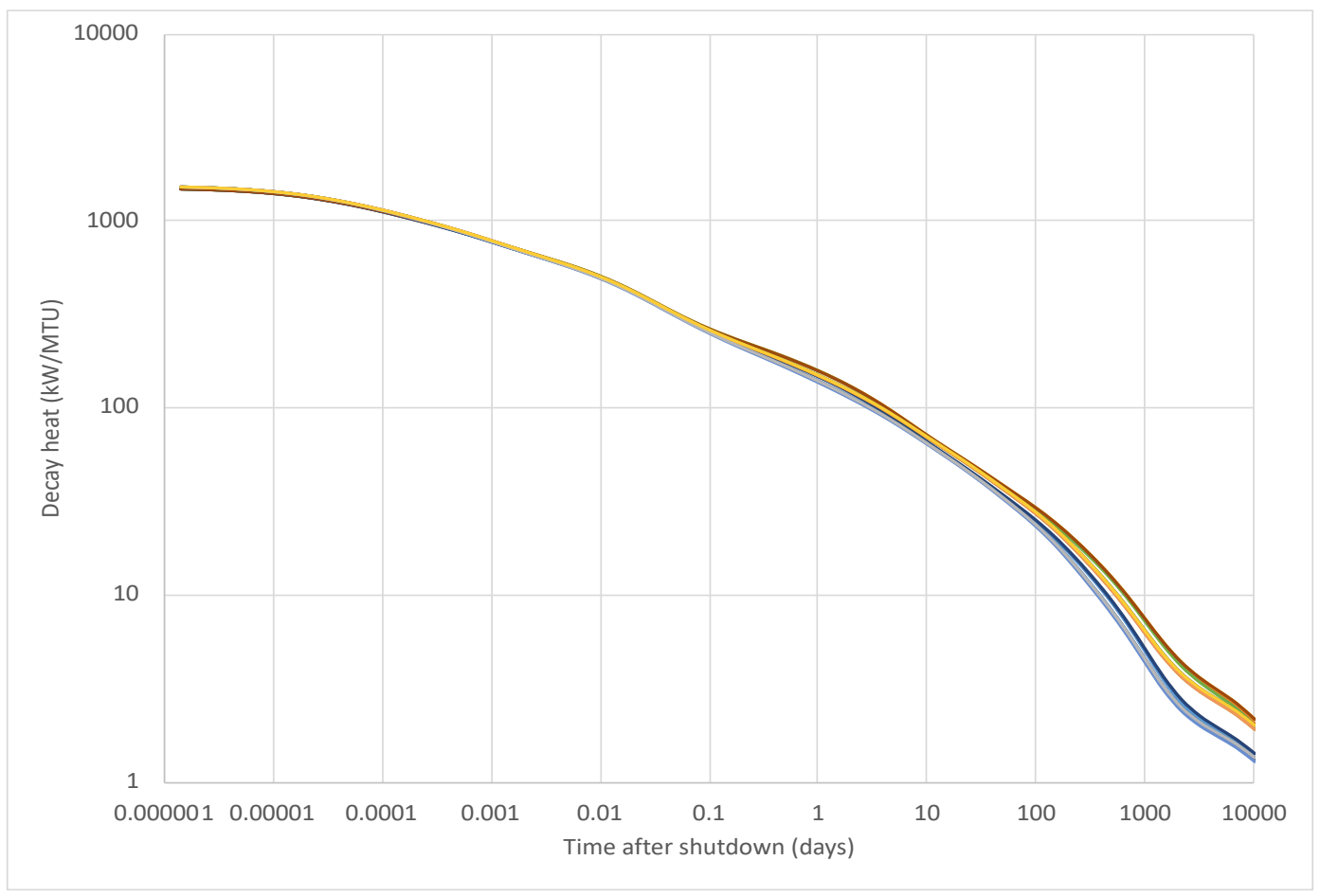

Figure 16. Decay heat as a function of cooling time for all cases 


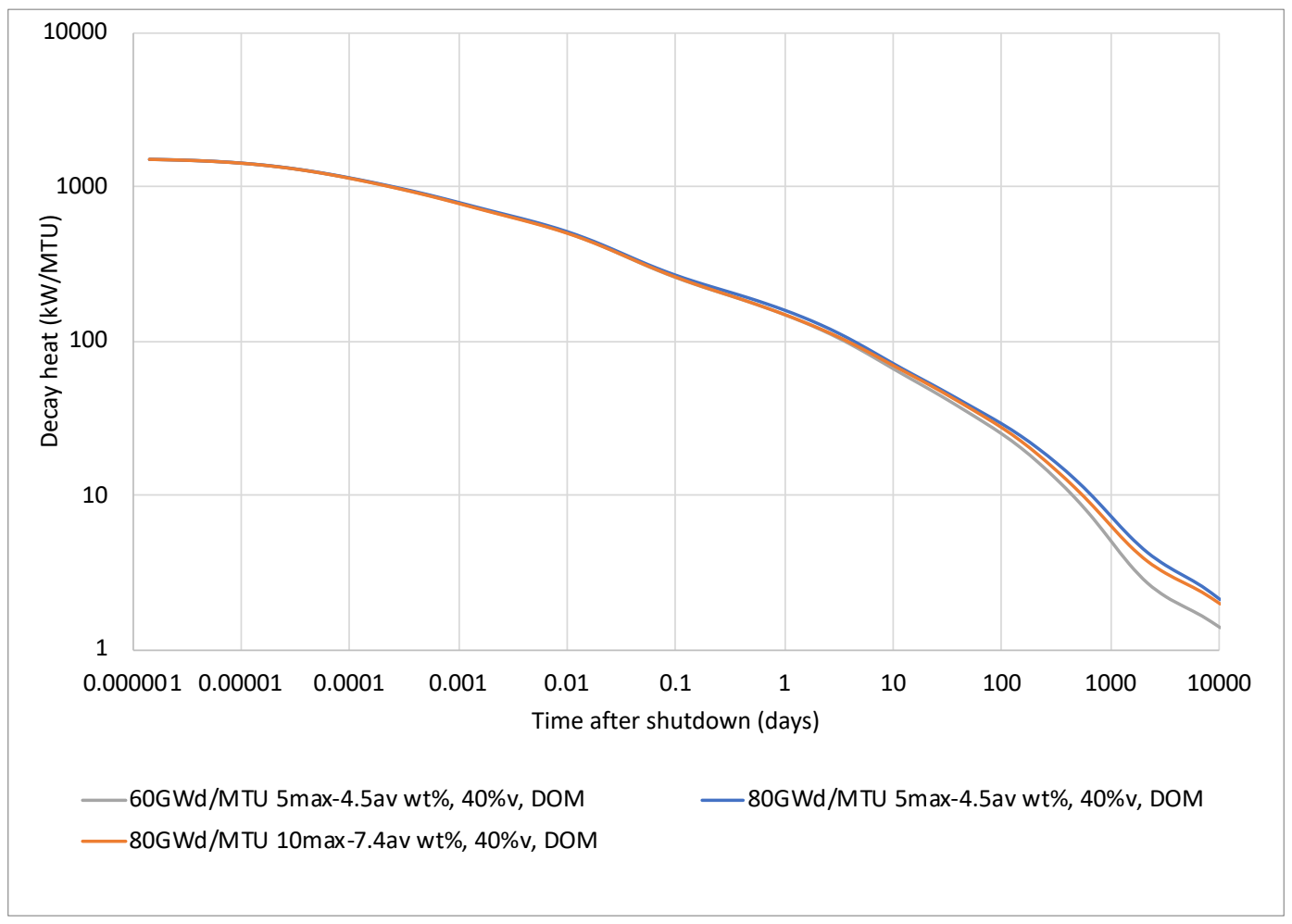

Figure 17. Decay heat as a function of cooling time (effect of enrichment and burnup)

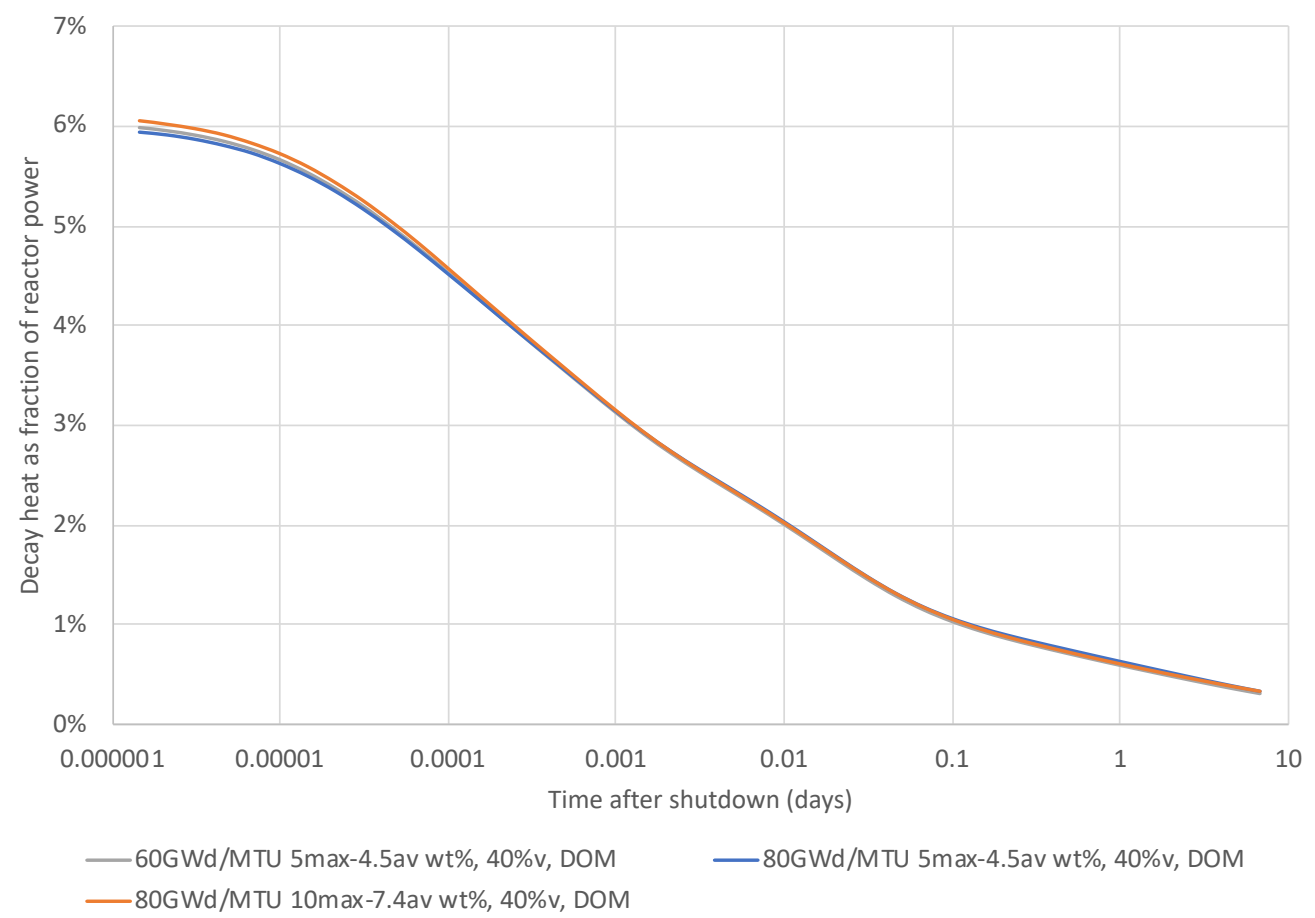

Figure 18. Decay heats as a fraction of full power vs cooling time. 


$$
Q_{r e l}(t)=\frac{Q(t)}{Q_{r e f}(t)}-1
$$

where $Q(t)$ is the decay heat as a function of time and $Q_{r e f}(t)$ is the decay heat for the reference 5 max-4.5av wt \% $60 \mathrm{GWd} / \mathrm{MTU} 40 \%$ void case.

In summary, shortly after reactor shutdown, operating power influences decay heat more than burnup and enrichment. As the short-lived fission products decay away, longer lived fission and activation products begin to contribute much more to decay heat, and decay heat begins to depend more on burnup and enrichment. Notably, no single isotope changed decay heat by more than $12 \%$ in any comparison evaluated below. Decay heat generally increased at later time points, when enrichment decreased, or burnup increased. This is consistent with the behavior of existing nuclear fuel.

Table 5 through Table 7 show the impact of HBU and EE on isotopics decay heats. Table 5 shows the impact on total decay heat for each isotope when enrichment increases from $5 \mathrm{max}-$ $4.5 \mathrm{av} w \mathrm{w} \%$ to $10 \mathrm{max}-7.4 \mathrm{av} \mathrm{wt} \%$. Table 6 shows the impact on total decay heat for each isotope when burnup increases from 60 to $80 \mathrm{GWd}$ /MTU. Finally, Table 7 shows the combined impact of increasing both burnup and enrichment.

The values in Table 5 through Table 7 are the difference in decay heat for the isotope expressed as a percentage of total decay heat of the reference case. The relative difference in contribution of each isotope to the total heat production $\left(Q_{r e l, i}\right)$ is calculated from Eq. 6 and presented color coded, with blue indicating a decreasing decay heat from baseline, and red indicating an increasing decay heat from baseline.

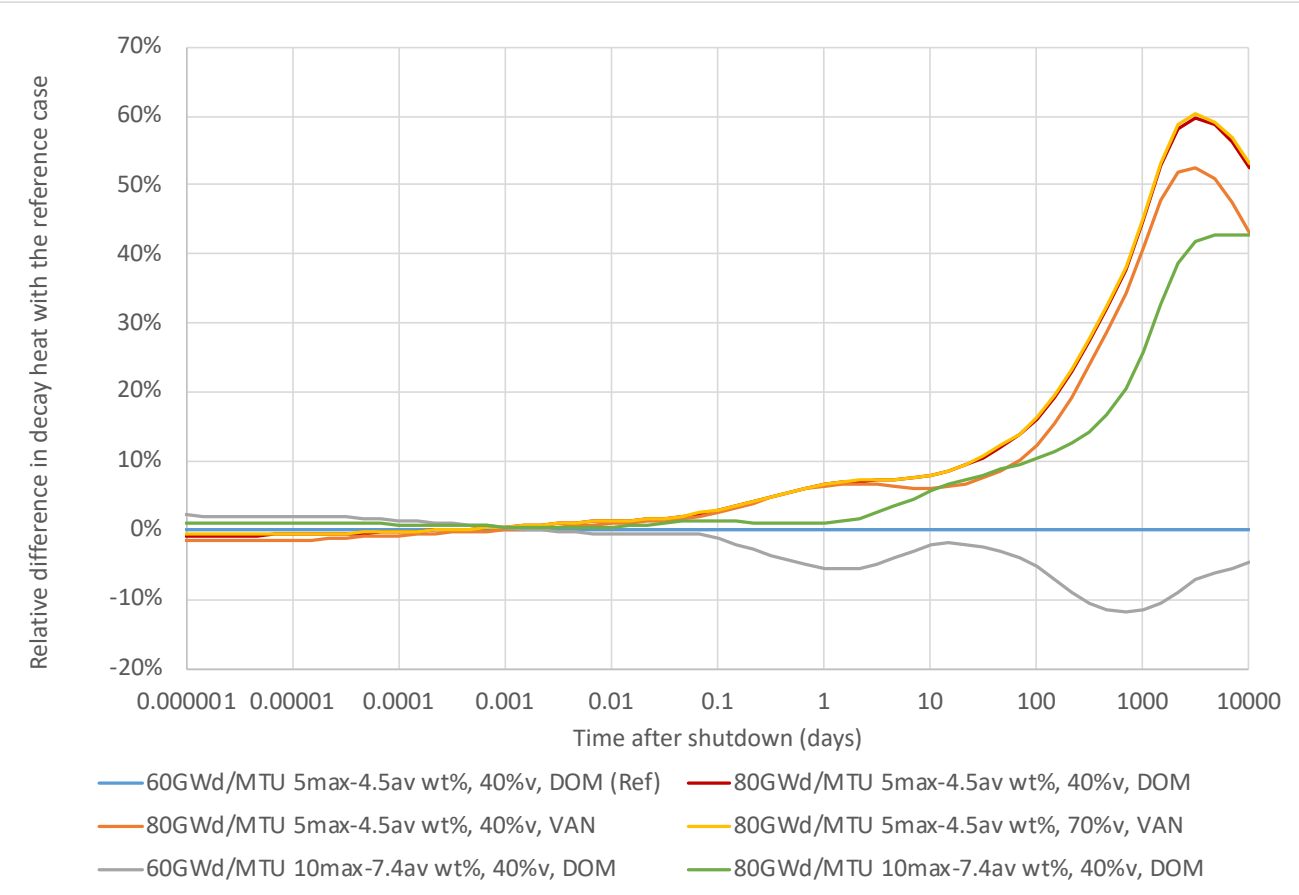

Figure 19. Decay heat relative to $60 \mathrm{GWd} / \mathrm{MTU}$ 5max-4.5av 40\% DOM case 


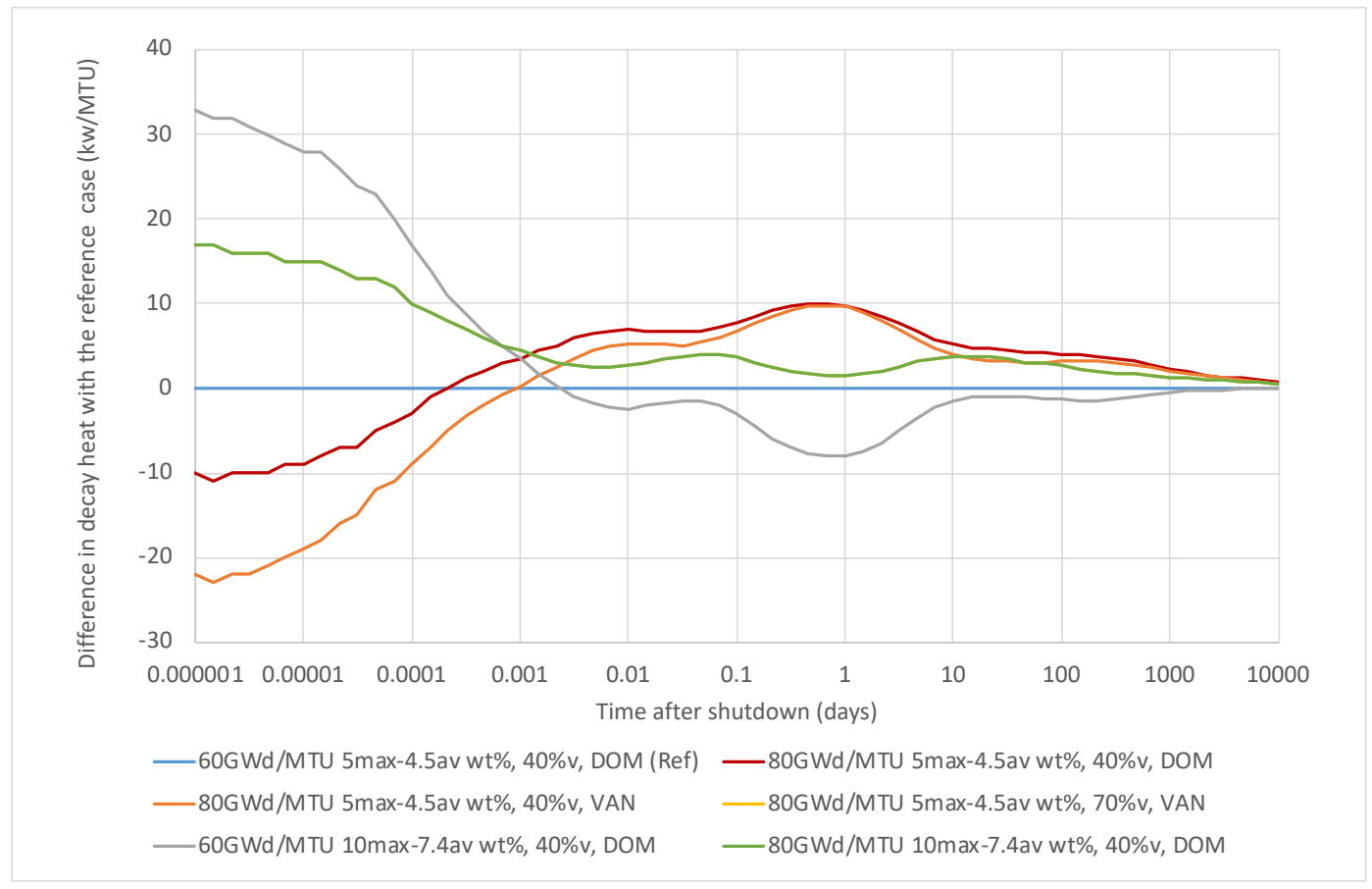

Figure 20. Decay heat difference with to $60 \mathrm{GWd} / \mathrm{MTU}$ 5max-4.5av 40\% DOM case

$$
Q_{r e l, i}=\frac{Q_{i}-Q_{r e f, i}}{Q_{r e f}}
$$

where $Q_{i}$ is the decay heat for isotope $i$ for $\mathrm{HBU}$ or EE, $Q_{r e f, i}$ is the decay heat for isotope $i$ for the reference case, $Q_{r e f}$ is the total decay heat for the reference case.

The top 10 isotopes are shown according to the RMS ranking introduced in Eq. (4). The RMS rankings in this report always exclude the time point $0 \mathrm{~s}$ after discharge. The row labeled Total is the total difference for the two cases reported by SCALE. Note that shortly after shutdown, many more isotopes than those listed contribute to decay heat, so the difference caused by the top 10 contributors by RMS ranking does not coincide with the total. At longer decay times, as shortlived fission products decay away, fewer isotopes are responsible for the decay heat, so the top 10 isotopes by RMS ranking correctly account for the majority of differences. For example, at 500 days with increased enrichment only (Table 5), the difference is driven by six isotopes${ }^{106} \mathrm{Rh},{ }^{134} \mathrm{Cs},{ }^{144} \mathrm{Pr},{ }^{244} \mathrm{Cm},{ }^{242} \mathrm{Cm}$, and ${ }^{90} \mathrm{Y}$ - and the top 15 isotopes across all times (subtotal) coincide with the total of $-10 \%$ change.

Increasing initial maximum pin enrichment from 5 to $10 \mathrm{wt} \%$ at $60 \mathrm{GWd} / \mathrm{MTU}$ (Table 5) leads to a reduction in the following isotopes: ${ }^{106} \mathrm{Rh},{ }^{134} \mathrm{Cs},{ }^{239} \mathrm{~Np},{ }^{244} \mathrm{Cm}$, and ${ }^{242} \mathrm{Cm}$. These isotopes are neutron absorption products, or they tend to result from ${ }^{239} \mathrm{Pu}$ fission, which is in turn an indirect product of neutron absorption. ${ }^{106} \mathrm{Rh}$ has a ${ }^{239} \mathrm{Pu}$ cumulative fission yield of $4.1 \mathrm{E}-2$. This 
is an order of magnitude larger than its ${ }^{235} \mathrm{U}$ yield of 4.1E-3, according to the Joint Evaluated Fission and Fusion File (JEFF) 3.3, as accessed through the International Atomic Energy Agency (IAEA) Live Chart of Nuclides. Note that ${ }^{134} \mathrm{Cs}$ results largely from neutron activation of ${ }^{133} \mathrm{Cs}$ which is mainly a stable fission product of ${ }^{239} \mathrm{Pu}$ fission (25x larger direct yield compared to ${ }^{235} \mathrm{U}$ fission); therefore, ${ }^{134} \mathrm{Cs}$ is an indicator for ${ }^{239} \mathrm{Pu}$ amount as well as magnitude of flux.

Table 5. Contributions of each isotope to total percent change in decay heat from enrichment increase

Decay heat

$10 \%$ max enriched vs $5 \%$ max enriched, $40 \%$ void, $60 \mathrm{GWd}$, full lattice

\begin{tabular}{|c|c|c|c|c|c|c|}
\hline${ }^{100} \mathrm{Rh}-$ & -0.13 & -0.4 & -1.8 & -3.4 & -7 & \multirow{3}{*}{-0.0} \\
\hline${ }^{134} \mathrm{Cs}$ - & -0.036 & -0.13 & -0.61 & -1.2 & -3.7 & \\
\hline${ }^{239} \mathrm{~Np}-$ & -0.61 & -2.2 & -2.4 & -0.013 & -0.00068 & \\
\hline${ }^{244} \mathrm{Cm}-$ & -0.018 & -0.065 & -0.3 & -0.58 & -2.8 & --2.5 \\
\hline ฏ ${ }^{144} \mathrm{Pr}-$ & 0.042 & 0.16 & 0.72 & 13 & 2.1 & \\
\hline${ }^{242} \mathrm{Cm}-$ & -0.058 & -0.21 & -0.98 & -1.7 & -1.1 & --5 \\
\hline${ }^{156} \mathrm{Eu}-$ & -0.089 & -0.32 & -1.2 & -0.93 & $-1.8 \mathrm{E}-09$ & \\
\hline${ }^{95} \mathrm{Nb}-$ & 0.037 & 0.13 & 0.63 & 11 & 0.059 & \\
\hline${ }^{91} Y$ - & 0.043 & 0.16 & 0.7 & 11 & 0.019 & \\
\hline total - & 2.18 & -0.4116 & -3.67 & -2.107 & -11.49 & \\
\hline & $0.000^{\prime} \mathrm{e}+00$ & $2.0801 \mathrm{e}-02$ & $5.000 \mathrm{e}+00$ & $2.500 \mathrm{e}+01$ & $5.000 \mathrm{e}+02$ & \\
\hline
\end{tabular}

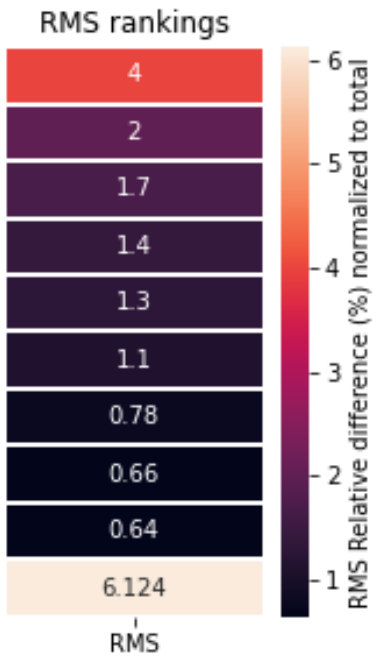

Effect of increasing burnup from the $60 \mathrm{GWd} / \mathrm{MTU}$ to $80 \mathrm{GWd} / \mathrm{MTU}$ for $10 \mathrm{max}-7.4 \mathrm{av} \mathrm{wt} \%$ enrichment case is shown in Table 6 . In this case, both fission products and products of neutron absorption increase. The largest relative increases include isotopes created through neutron absorption: ${ }^{244} \mathrm{Cm}$, and ${ }^{242} \mathrm{Cm}$, or isotopes with ${ }^{239} \mathrm{Pu}$ cumulative fission yields that vastly exceed their ${ }^{235} \mathrm{U}$ yields. Notably, however, ${ }^{239} \mathrm{~Np}$ is affected less by the burnup increase( due to 2.3 days half-life) than the enrichment increase discussed in the paragraph above. Increases in fission product decay heats are also notable with the burnup increase, specifically ${ }^{90} \mathrm{Y}$ and ${ }^{137 m} \mathrm{Ba}$. The activity of ${ }^{137 \mathrm{~m}} \mathrm{Ba}$ is proportional to burnup due to identical fission yields for ${ }^{235} \mathrm{U}$ and ${ }^{239} \mathrm{Pu}$. 
Table 6. Contributions of each isotope to total percent change in decay heat from burnup increase

Decay heat

$80 \mathrm{GWD} / \mathrm{MTU}$ vs $60 \mathrm{GWD} / \mathrm{MTU}, 10 \%$ max enriched, $40 \%$ void, full lattice

\begin{tabular}{|c|c|c|c|c|c|}
\hline${ }^{134} \mathrm{Cs}$ - & 0.088 & 0.33 & 16 & 2.9 & 11 \\
\hline${ }^{106} \mathrm{Rh}$ - & 0.085 & 0.29 & 14 & 2.5 & 5.8 \\
\hline${ }^{244} \mathrm{Cm}$ - & 0.029 & 0.11 & 0.53 & 1 & 5.3 \\
\hline${ }^{242} \mathrm{Cm}-$ & 0.12 & 0.44 & 2.1 & 3.6 & 2.6 \\
\hline${ }^{238} \mathrm{Pu}-$ & 0.015 & 0.057 & 0.27 & 0.52 & 29 \\
\hline${ }^{13} \mathrm{~m}^{\mathrm{m}} \mathrm{Ba}$ - & 0.015 & 0.056 & 0.27 & 0.51 & 2.7 \\
\hline${ }^{90} \mathrm{Y}-$ & 0.013 & 0.048 & 0.23 & 0.42 & 2.2 \\
\hline${ }^{144} \mathrm{Pr}-$ & -0.026 & -0.1 & -0.48 & -0.86 & -1.5 \\
\hline${ }^{156} \mathrm{Eu}$ - & 0.092 & 0.35 & 13 & 1 & 2.1E-09 \\
\hline total - & -1.034 & 124 & 7.631 & 9.942 & 32.57 \\
\hline & $0.000^{\prime} \mathrm{e}+00$ & 2.080 e- 02 & $5.000^{\prime} \mathrm{e}+00$ & $2.500^{\prime} \mathrm{e}+01$ & $5.000^{\prime} \mathrm{e}+02$ \\
\hline
\end{tabular}

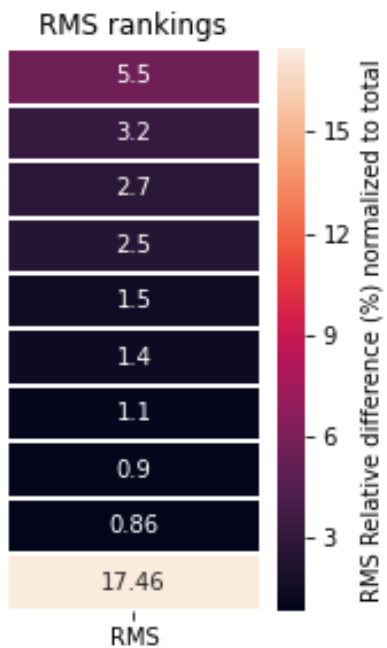

The effect of increasing both enrichment and burnup from the $60 \mathrm{GWd} / \mathrm{MTU} 5 \mathrm{max}-4.5 \mathrm{av}$ wt $\%$ case to the $80 \mathrm{GWd} / \mathrm{MTU} 10 \mathrm{max}-7.4 \mathrm{av} \mathrm{wt} \%$ enrichment case is shown in Table 7. Almost all isotopes increase in abundance when both enrichment and burnup are increased, with the exception of ${ }^{239} \mathrm{~Np}$ and ${ }^{106} \mathrm{Rh}$. The decay heat increases in fission products ${ }^{90} \mathrm{Y}$ and ${ }^{137 \mathrm{~m}} \mathrm{Ba}$.

Table 7. Contributions of each isotope to total percent change in decay heat from combined enrichment and burnup increase

Decay heat

$10 \% \max , 80 \mathrm{GWd} / \mathrm{MTU}$ vs $5 \% \max , 60 \mathrm{GWd} / \mathrm{MTU}$, full lattice $40 \%$ void

\begin{tabular}{|c|c|c|c|c|c|}
\hline${ }^{134} \mathrm{Cs}$ - & 0.054 & 0.2 & 0.92 & 17 & 5.6 \\
\hline${ }^{90} \mathrm{Y}-$ & 0.019 & 0.071 & 0.33 & 0.63 & 3 \\
\hline${ }^{13} \mathrm{~mm} \mathrm{Ba}-$ & 0.015 & 0.056 & 0.26 & 0.5 & 24 \\
\hline${ }^{242} \mathrm{Cm}-$ & 0.061 & 0.22 & 1 & 18 & 12 \\
\hline${ }^{106} \mathrm{Rh}$ - & -0.04 & -0.11 & -0.5 & -0.92 & -1.9 \\
\hline${ }^{238} \mathrm{Pu}-$ & 0.013 & 0.047 & 0.22 & 0.42 & 2.1 \\
\hline${ }^{244} \mathrm{Cm}-$ & 0.012 & 0.045 & 0.21 & 0.4 & 19 \\
\hline${ }^{239} \mathrm{~Np}-$ & -0.35 & -1.3 & -1.4 & -0.0073 & 0.00031 \\
\hline${ }^{144} \mathrm{Pr}-$ & 0.015 & 0.055 & 0.26 & 0.48 & 0.74 \\
\hline total - & 1.123 & 0.8232 & 3.681 & 7.625 & 17.35 \\
\hline & $0.000 e^{\prime}+00$ & 2080 e- 02 & $5.000 \mathrm{e}+00$ & $2.500 \mathrm{e}+01$ & $5.000 e^{\prime}+02$ \\
\hline
\end{tabular}

\begin{tabular}{|c|}
\hline RMS rankings \\
\hline 3 \\
\hline 1.6 \\
\hline 13 \\
\hline 1.2 \\
\hline 1.1 \\
\hline 1.1 \\
\hline 0.98 \\
\hline 0.93 \\
\hline 0.46 \\
\hline 9.661 \\
\hline RMS
\end{tabular}

${ }^{144} \mathrm{Pr}$ is generally a high-ranking decay heat contributor, behaving opposite of many of the other isotopes in the comparison charts. This is because it is preferentially produced by ${ }^{235} \mathrm{U}$ fission and not ${ }^{239} \mathrm{Pu}$ fission, so it increases with enrichment and can decrease with burnup, unlike many other isotopes. ${ }^{144} \mathrm{Pr}$ increases in abundance compared to $60 \mathrm{GWd} / \mathrm{MTU} 5 \mathrm{max}-4.5 \mathrm{av} \mathrm{wt} \%$ reference. It is the short- lived $\left(\mathrm{T}_{1 / 2}=17 \mathrm{~min}\right)$ progeny of ${ }^{144} \mathrm{Ce}\left(\mathrm{T}_{1 / 2}=284 \mathrm{~d}\right) .{ }^{144} \mathrm{Ce}$ and ${ }^{144} \mathrm{Pr}$ are both progeny of ${ }^{144} \mathrm{La} .{ }^{144} \mathrm{La}$ and its parents in the $144 \mathrm{amu}$ beta decay series all have half-lives 
on the order of tens of seconds or less. ${ }^{144} \mathrm{La}$ has a ${ }^{239} \mathrm{Pu}$ cumulative fission yield of $3.59 \%$ and a ${ }^{235} \mathrm{U}$ cumulative fission yield of $5.44 \% .{ }^{144} \mathrm{Pr}$ cumulative fission yields are close to the ${ }^{144} \mathrm{La}$ values, with a ${ }^{239} \mathrm{Pu}$ fission yield of $3.75 \%$ and a ${ }^{235} \mathrm{U}$ fission yield of $5.47 \%$. This indicates ${ }^{144} \mathrm{La}$ abundance in-core and generally reflects when the ${ }^{144} \mathrm{Pr}$ is produced. The plotting of the ${ }^{144} \mathrm{La}$ abundance shown in Figure 21 reflects the observations above. ${ }^{144} \mathrm{Pr}$ tracks with its parent ${ }^{144} \mathrm{Ce}$. ${ }^{144} \mathrm{La}$ decreases as the proportion of the power produced by ${ }^{235} \mathrm{U}$ decreases.

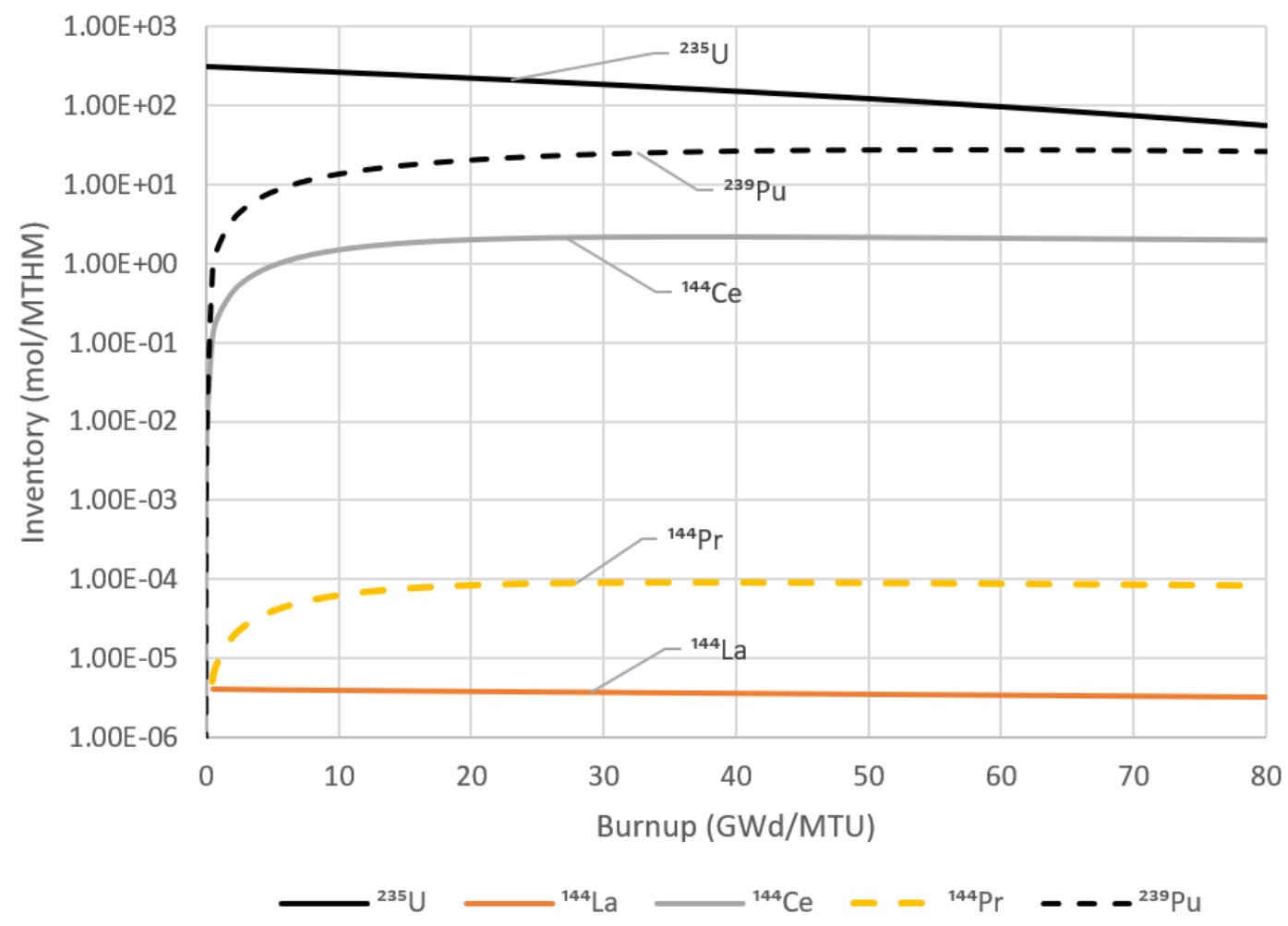

Figure 21. In-core abundances of ${ }^{144} \mathrm{Pr}$ beta chain isotopes for $10 \mathrm{max}-7.4 \mathrm{av}$ wt $\%$ initial enrichment.

Table 8 thorough Table 10 show the isotopes with the largest absolute changes for the same cases as Table 5 through Table 7. Decay heats for the isotopes are much higher shortly after discharge, and hundreds of isotopes contribute to total. Therefore, even the largest contributions look small compared to the total in the tables. Again, note that RMS values in this report always exclude the values at 0 seconds of cooling time. 
Table 8. Difference in isotopic decay heats resulting from enrichment increase at various cooling times

Decay heat

$10 \%$ max enriched vs $5 \%$ max enriched, $40 \%$ void, $60 \mathrm{GWd}$, full lattice

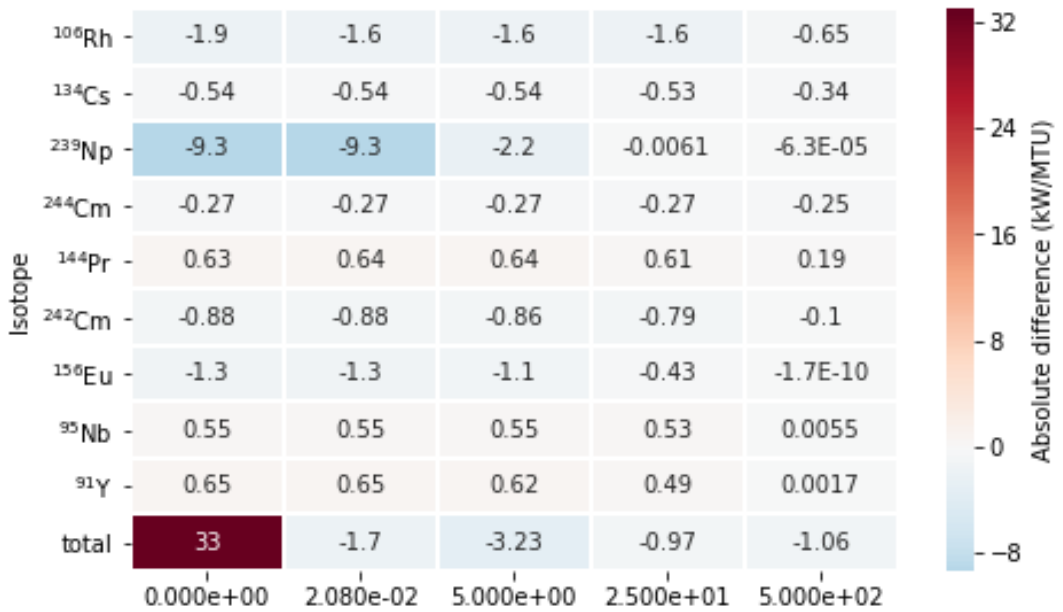

\begin{tabular}{|c|c|}
\hline RMS rankings & \multicolumn{2}{|c|}{-4.8} \\
\hline 1.4 & -4.0 \\
\hline 0.5 \\
\hline 4.8 \\
\hline 0.26 \\
\hline 0.55 \\
\hline 0.73 \\
\hline 0.88 \\
\hline 0.47 \\
\hline 0.51 \\
\hline 1.961 \\
\hline RMS \\
\hline 12 \\
\hline
\end{tabular}

Table 9. Difference in isotopic decay heats resulting from burnup increase at various cooling times

Decay heat

$80 \mathrm{GWD} / \mathrm{MTU}$ vs $60 \mathrm{GWD} / \mathrm{MTU}, 10 \%$ max enriched, $40 \%$ void, full lattice

\begin{tabular}{|c|c|c|c|c|c|c|}
\hline${ }^{134} \mathrm{Cs}$ - & 14 & 14 & 14 & 13 & 0.86 & \\
\hline${ }^{106} \mathrm{Rh}-$ & 1.3 & 12 & 12 & 11 & 0.47 & \\
\hline${ }^{244} \mathrm{Cm}-$ & 0.45 & 0.45 & 0.45 & 0.45 & 0.43 & $\Sigma$ \\
\hline${ }^{242} \mathrm{Cm}-$ & 18 & 18 & 18 & 16 & 0.22 & $\frac{3}{y}$ \\
\hline${ }^{238} \mathrm{Pu}-$ & 0.23 & 0.23 & 0.23 & 0.23 & 0.24 & $-4 \stackrel{\mathscr{U}}{\check{C}}$ \\
\hline 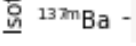 & 0.23 & 0.23 & 0.23 & 0.23 & 0.22 & $=$ \\
\hline${ }^{90} \mathrm{Y}-$ & 0.2 & 0.2 & 0.19 & 0.19 & 0.18 & --8 \\
\hline${ }^{144} \mathrm{Pr}-$ & -0.41 & -0.41 & -0.41 & -0.39 & -0.12 & \\
\hline${ }^{156} \mathrm{Eu}$ & 14 & 14 & 11 & 0.45 & $18 \mathrm{E}-10$ & -12 \\
\hline total & -16 & 5.1 & 6.47 & 4.48 & 2.661 & \\
\hline & $0.000 \mathrm{e}+00$ & $2.080 \mathrm{e}-02$ & $5.000 \mathrm{e}+00$ & $2.500 \mathrm{e}+01$ & $5.000 \mathrm{e}+02$ & \\
\hline
\end{tabular}

\begin{tabular}{|c|c|}
\hline RMS rankings & \multicolumn{2}{|c}{-4.8} \\
\hline 12 \\
\hline 1 \\
\hline 0.45 \\
\hline 1.5 \\
\hline 0.23 \\
\hline 0.23 \\
\hline 0.19 \\
\hline 0.35 \\
\hline 0.94 \\
\hline 4.874 \\
\hline RMS
\end{tabular}


Table 10. Difference in isotopic decay heats resulting from burnup and enrichment increase at various cooling times

Decay heat

$10 \% \max , 80 \mathrm{GWd} / \mathrm{MTU}$ vs $5 \% \max , 60 \mathrm{GWd} / \mathrm{MTU}$, full lattice $40 \%$ void

\begin{tabular}{|c|c|c|c|c|c|c|}
\hline${ }^{134} \mathrm{Cs}$ - & 0.81 & 0.81 & 0.81 & 0.8 & 0.51 & 16 \\
\hline${ }^{90} \mathrm{Y}-$ & 0.29 & 0.29 & 0.29 & 0.29 & 0.28 & \\
\hline${ }^{13} \mathrm{~mm} \mathrm{Ba}$ - & 0.23 & 0.23 & 0.23 & 0.23 & 0.22 & \\
\hline${ }^{242} \mathrm{Cm}-$ & 0.92 & 0.92 & 0.91 & 0.83 & 0.11 & \\
\hline${ }^{106} \mathrm{Rh}-$ & -0.6 & -0.44 & -0.44 & -0.42 & -0.18 & \\
\hline${ }^{238} \mathrm{Pu}-$ & 0.19 & 0.19 & 0.19 & 0.19 & 0.19 & \pm \\
\hline${ }^{244} \mathrm{Cm}$ & 0.18 & 0.18 & 0.18 & 0.18 & 0.18 & 5 \\
\hline${ }^{239} \mathrm{~N}$ & -5.2 & -5.2 & -1.2 & -0.0033 & $2.8 \mathrm{E}-05$ & -0 崩 \\
\hline${ }^{144} \mathrm{Pr}$ & 0.23 & 0.23 & 0.23 & 0.22 & 0.068 & \\
\hline total & 17 & 3.4 & 3.24 & 3.51 & 1601 & --4 \\
\hline & $000 \mathrm{e}+00$ & $2.080 \mathrm{e}-02$ & $5.000 \mathrm{e}+00$ & $2.500 \mathrm{e}+01$ & $5.000 \mathrm{e}+02$ & \\
\hline
\end{tabular}

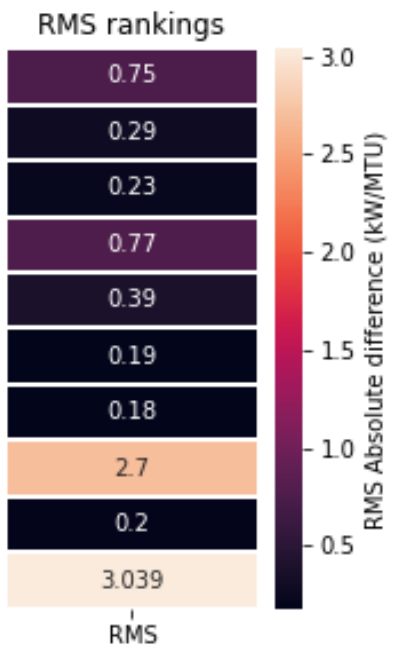

The BWR assembly experiences various combinations of void fractions and lattice designs along its axial length. To capture the impact of this variation, trends in enrichment, burnup, and combined enrichment and burnup are provided in Table 11 through Table 13 below. Specifically, the tables plot the signed RMS values of the change in decay heat from an isotope as a percentage of total decay heat, as in preceding tables. With signed RMS, a positive or negative sign is reintroduced to Eq. (2) result to reflect whether the isotope primarily increases or decreases with the burnup change.

Table 11 through Table 13 show that void fraction and lattice designs do not greatly affect the changes introduced by enrichment and burnup changes for the top-ranked isotopes. There is almost no change across lattice type and void fraction. 
Table 11. Signed RMS change in isotope decay heat relative to total for enrichment increase from $5 \mathrm{max}-4.5 \mathrm{av} \%$ to $10 \mathrm{max}-7.4 \mathrm{av} \%$ enrichment

\begin{tabular}{|c|c|}
\hline${ }^{144} \mathrm{Pr}$ & 1.4 \\
\hline${ }^{95} \mathrm{Nb}$ & 0.74 \\
\hline${ }^{91} Y \quad 0$ & 0.72 \\
\hline${ }^{95} \mathrm{Zr}$ & 0.66 \\
\hline${ }^{140} \mathrm{La}$ & 0.65 \\
\hline${ }^{156} \mathrm{Eu}$ & -0.92 \\
\hline${ }^{242} \mathrm{Cm}$ & 1 \\
\hline${ }^{244} \mathrm{Cm}$ & -1.3 \\
\hline${ }^{239} \mathrm{~Np}$ & -1.9 \\
\hline${ }^{134} \mathrm{Cs}$ & -2.1 \\
\hline${ }^{106} \mathrm{Rh}$ & -4.4 \\
\hline total - & -6.269 \\
\hline
\end{tabular}

Full lattice
\begin{tabular}{|cc|}
$40 \%$ & void \\
\hline${ }^{144} \mathrm{Pr}$ & 1.3 \\
${ }^{95} \mathrm{Nb}$ & 0.66 \\
${ }^{91} \mathrm{Y}$ & 0.64 \\
${ }^{95} \mathrm{Zr}$ & 0.58 \\
${ }^{140} \mathrm{La}$ & 0.57 \\
${ }^{156} \mathrm{Eu}$ & -0.78 \\
${ }^{242} \mathrm{Cm}$ & -1.1 \\
${ }^{244} \mathrm{Cm}$ & -1.4 \\
${ }^{239} \mathrm{~Np}$ & -1.7 \\
${ }^{134} \mathrm{Cs}$ & -2 \\
\hline${ }^{106} \mathrm{Rh}$ & -4 \\
\hline total & -6.124 \\
\hline
\end{tabular}

Vanished lattice
$40 \%$ void
\begin{tabular}{|cc|}
\hline${ }^{144} \mathrm{Pr}$ & 1.5 \\
${ }^{95} \mathrm{Nb}$ & 0.79 \\
${ }^{91} \mathrm{Y}$ & 0.77 \\
${ }^{95} \mathrm{Zr}$ & 0.71 \\
${ }^{140} \mathrm{La}$ & 0.7 \\
${ }^{156} \mathrm{Eu}$ & -1 \\
${ }^{242} \mathrm{Cm}$ & -1 \\
${ }^{244} \mathrm{Cm}$ & -1.4 \\
${ }^{239} \mathrm{~Np}$ & -2.1 \\
${ }^{134} \mathrm{Cs}$ & -2.3 \\
\hline${ }^{106} \mathrm{Rh}$ & -4.6 \\
total & -6.61 \\
\hline
\end{tabular}

Vanished lattice

\begin{tabular}{|c|c|}
\hline${ }^{144} \mathrm{Pr}$ & 1.3 \\
\hline${ }^{95} \mathrm{Nb}$ & 0.67 \\
\hline${ }^{91} Y$ & 0.65 \\
\hline${ }^{95} \mathrm{Zr}$ & 0.6 \\
\hline${ }^{140} \mathrm{La}$ & 0.59 \\
\hline${ }^{156} \mathrm{Eu}$ & -0.8 \\
\hline${ }^{24} \mathrm{Cm}$ & -1.2 \\
\hline${ }^{244} \mathrm{Cm}$ & -1.5 \\
\hline${ }^{239} \mathrm{~Np}$ & -1.7 \\
\hline${ }^{134} \mathrm{Cs}$ & -2 \\
\hline${ }^{106} \mathrm{Rh}$ & -4.1 \\
\hline total - & -6.391 \\
\hline
\end{tabular}

Table 12. Signed RMS change in isotope decay heat relative to total for burnup increase from 60 to $80 \mathrm{GWd} / \mathrm{MTU}$ at $10 \mathrm{max}-7.4 \mathrm{av} \%$ enrichment

\begin{tabular}{|c|c|}
\hline${ }^{134} \mathrm{Cs}$ & \\
\hline${ }^{106} \mathrm{Rh}$ & 3.4 \\
\hline${ }^{244} \mathrm{Cm}$ & 2.5 \\
\hline${ }^{242} \mathrm{Cm}$ & 2.2 \\
\hline${ }^{13} \mathrm{~m} \mathrm{Ba}$ & 1.4 \\
\hline${ }^{238} \mathrm{Pu}$ & 1.3 \\
\hline${ }^{90} \mathrm{Y}$ & 1.2 \\
\hline${ }^{156} \mathrm{Eu}$ & 0.96 \\
\hline${ }^{239} \mathrm{~Np}$ & 0.89 \\
\hline${ }^{95} \mathrm{Nb}$ & -0.48 \\
\hline${ }^{144} \mathrm{Pr}$ & -0.98 \\
\hline total & 17.23 \\
\hline
\end{tabular}

$$
\begin{array}{cc}
\text { Full lattice } \\
40 \% & \text { void } \\
{ }^{134} \mathrm{Cs} & 5.5 \\
{ }^{106} \mathrm{Rh} & 3.2 \\
{ }^{244} \mathrm{Cm} & 2.7 \\
{ }^{242} \mathrm{Cm} & 2.5 \\
{ }^{238} \mathrm{Pu} & 1.5 \\
{ }^{13 \mathrm{~m}^{3}} \mathrm{Ba} & 1.4 \\
{ }^{90} \mathrm{Y} & 1.1 \\
{ }^{156} \mathrm{Eu} & 0.86 \\
{ }^{239} \mathrm{~Np} & 0.74 \\
{ }^{95} \mathrm{Nb} & -0.43 \\
{ }^{144} \mathrm{Pr} & -0.9 \\
\hline \text { total } & 17.46
\end{array}
$$

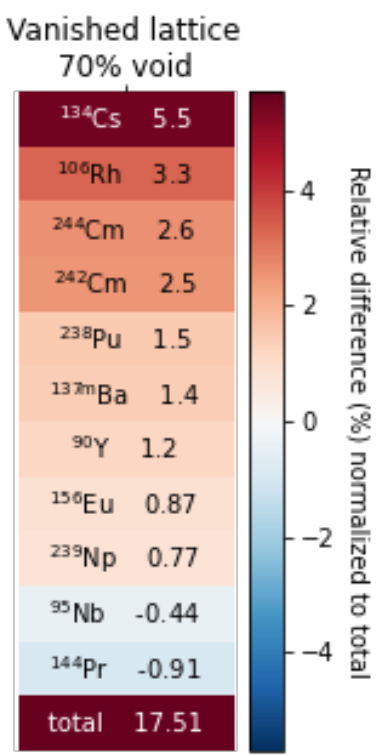


Table 13. Signed RMS change in isotope decay heat relative to total for enrichment and burnup increase from 5max-4.5av wt\% $60 \mathrm{GWd} / \mathrm{MTU}$ to $10 \mathrm{max}-7.4 \mathrm{av}$ wt\% enrichment at $80 \mathrm{GWd} / \mathrm{MTU}$

\begin{tabular}{|c|c|c|c|}
\hline $\begin{array}{l}\text { Full lattice } \\
10 \% \text { void }\end{array}$ & $\begin{array}{l}\text { Full lattice } \\
40 \% \text { void }\end{array}$ & $\begin{array}{c}\text { Vanished lattice } \\
40 \% \text { void }\end{array}$ & $\begin{array}{c}\text { Vanished lattice } \\
70 \% \text { void }\end{array}$ \\
\hline${ }^{134} \mathrm{Cs} \quad 2.9$ & ${ }^{134} \mathrm{Cs} \quad 3$ & ${ }^{134} \mathrm{Cs} \quad 2.8$ & ${ }^{134} \mathrm{Cs} \quad 2.9$ \\
\hline${ }^{90} Y \quad 1.6$ & $90 Y \quad 1.6$ & ${ }^{90} \mathrm{Y} \quad 1.7$ & ${ }^{90} \mathrm{Y} \quad 1.6$ \\
\hline${ }^{13 \mathrm{~m} m} \mathrm{Ba} \quad 1.3$ & ${ }^{13 \mathrm{~mm}} \mathrm{Ba} \quad 1.3$ & ${ }^{13} \mathrm{~mm} \mathrm{Ba} \quad 1.3$ & ${ }^{13} \mathrm{~mm} \mathrm{Ba} \quad 1.3$ \\
\hline${ }^{242} \mathrm{Cm} \quad 1.1$ & ${ }^{242} \mathrm{Cm} \quad 1.2$ & ${ }^{242} \mathrm{Cm} \quad 1.1$ & ${ }^{242} \mathrm{Cm} \quad 1.2$ \\
\hline${ }^{238} \mathrm{Pu} \quad 0.97$ & ${ }^{238} \mathrm{Pu} \quad 1.1$ & ${ }^{238} \mathrm{Pu} \quad 0.91$ & ${ }^{238} \mathrm{Pu} \quad 1.1$ \\
\hline${ }^{244} \mathrm{Cm} \quad 0.89$ & ${ }^{244} \mathrm{Cm} \quad 0.98$ & ${ }^{244} \mathrm{Cm} \quad 0.73$ & ${ }^{244} \mathrm{Cm} \quad 0.84$ \\
\hline${ }^{144} \mathrm{Pr} \quad 0.53$ & ${ }^{144} \mathrm{Pr} \quad 0.46$ & ${ }^{144} \mathrm{Pr} \quad 0.59$ & ${ }^{144} \mathrm{Pr} \quad 0.49$ \\
\hline${ }^{137} \mathrm{Cs} \quad 0.37$ & ${ }^{137} \mathrm{Cs} \quad 0.36$ & ${ }^{137} \mathrm{Cs} \quad 0.37$ & ${ }^{137} \mathrm{Cs} \quad 0.36$ \\
\hline${ }^{239} \mathrm{U} \quad-0.34$ & ${ }^{239} \mathrm{U} \quad-0.3$ & ${ }^{239} \mathrm{U} \quad-0.36$ & ${ }^{239} \mathrm{U} \quad-0.3$ \\
\hline${ }^{239} \mathrm{~Np} \quad-1.1$ & ${ }^{239} \mathrm{~Np} \quad-0.93$ & ${ }^{239} \mathrm{~Np} \quad-1.1$ & ${ }^{239} \mathrm{~Np} \quad-0.95$ \\
\hline${ }^{106} \mathrm{Rh} \quad-1.3$ & ${ }^{106} \mathrm{Rh} \quad-1.1$ & ${ }^{106} \mathrm{Rh} \quad-1.4$ & ${ }^{106} \mathrm{Rh} \quad-1.2$ \\
\hline total 9.302 & total 9.661 & total 8.89 & total 9.353 \\
\hline
\end{tabular}

As shown in Table 14, the effect of lattice type and void fraction on decay heat appears to be minimal. The table shows the signed RMS differences in decay heats from each isotope relative to the total decay heat of the assembly. Most of the change is driven by neutron absorption products such as ${ }^{242} \mathrm{Cm},{ }^{244} \mathrm{Cm},{ }^{238} \mathrm{Pu}$, and ${ }^{134} \mathrm{Cs}$. ${ }^{106} \mathrm{Rh}$ is preferentially produced in fission of ${ }^{239} \mathrm{Pu}$.

Table 14. Signed RMS change in isotopic decay heat due to changes in lattice design and void fraction for 10max-7.4av wt\% DOM lattice at $80 \mathrm{GWd} / \mathrm{MTU}$

\begin{tabular}{|c|c|c|c|c|c|c|c|c|}
\hline \multicolumn{2}{|c|}{$\begin{array}{l}\text { Full lattice } \\
10 \% \text { void }\end{array}$} & \multicolumn{2}{|c|}{$\begin{array}{l}\text { Full lattice } \\
40 \% \text { void }\end{array}$} & \multicolumn{2}{|c|}{$\begin{array}{c}\text { Vanished lattice } \\
40 \% \text { void }\end{array}$} & \multicolumn{2}{|c|}{$\begin{array}{c}\text { Vanished lattice } \\
70 \% \text { void }\end{array}$} & \\
\hline${ }^{106} \mathrm{Rh}$ & 0 & ${ }^{242} \mathrm{Cm}$ & 0.53 & ${ }^{144} \mathrm{Pr}$ & 0.06 & ${ }^{242} \mathrm{Cm}$ & 0.53 & \\
\hline${ }^{136} \mathrm{Cs}$ & 0 & ${ }^{134} \mathrm{Cs}$ & 0.45 & ${ }^{90} \mathrm{Y} \quad 0$. & 0.052 & ${ }^{134} \mathrm{Cs}$ & 0.36 & 0.4 \\
\hline${ }^{134} \mathrm{Cs}$ & 0 & ${ }^{244} \mathrm{Cm}$ & 0.36 & ${ }^{100} \mathrm{~Tb} \quad 0$ & 0.0015 & ${ }^{238} \mathrm{Pu}$ & 0.3 & \\
\hline${ }^{100} \mathrm{~Tb}$ & 0 & ${ }^{106} \mathrm{Rh}$ & 0.29 & ${ }^{136} \mathrm{Cs}$ & -0.0051 & ${ }^{244} \mathrm{Cm}$ & 0.28 & -0.2 \\
\hline${ }^{239} \mathrm{~Np}$ & 0 & ${ }^{238} \mathrm{Pu}$ & 0.29 & ${ }^{154} \mathrm{Eu}$ & -0.024 & ${ }^{106} \mathrm{Rh}$ & 0.18 & \\
\hline${ }^{238} \mathrm{Pu}$ & 0 & ${ }^{239} \mathrm{~Np}$ & 0.17 & ${ }^{239} \mathrm{~Np}$ & -0.085 & ${ }^{239} \mathrm{~Np}$ & 0.12 & 00 \\
\hline${ }^{154} \mathrm{Eu}$ & 0 & ${ }^{154} \mathrm{Eu}$ & 0.089 & ${ }^{238} \mathrm{Pu}$ & -0.086 & ${ }^{154} \mathrm{Eu}$ & 0.094 & \\
\hline${ }^{90} \mathrm{Y} \mathrm{C}$ & 0 & ${ }^{136} \mathrm{Cs}$ & 0.067 & ${ }^{242} \mathrm{Cm}$ & -0.18 & ${ }^{136} \mathrm{Cs}$ & 0.084 & \\
\hline${ }^{244} \mathrm{Cm}$ & 0 & ${ }^{160} \mathrm{~Tb}$ & 0.055 & ${ }^{244} \mathrm{Cm}$ & -0.2 & ${ }^{160} \mathrm{~Tb}$ & 0.079 & $-0.2 \stackrel{\overline{\mathrm{N}}}{\mathrm{g}}$ \\
\hline${ }^{242} \mathrm{Cm}$ & 0 & ${ }^{90} \mathrm{Y}$ & -0.091 & ${ }^{106} \mathrm{Rh}$ & -0.21 & ${ }^{144} \mathrm{Pr}$ & -0.067 & \\
\hline${ }^{144} \mathrm{Pr}$ & 0 & ${ }^{144} \mathrm{Pr}$ & -0.097 & ${ }^{134} \mathrm{Cs}$ & -0.23 & ${ }^{90} \mathrm{Y}$ & -0.069 & -0.4 过 \\
\hline total & 0 & total & 1.847 & total -0 & 0.7624 & total & 1.677 & \\
\hline
\end{tabular}




\subsection{ISOTOPES RELEVANT TO ACTIVITY}

For all different enrichment and burnup cases studied (16 lattices), total activity per MTU is plotted in Figure 22. As in decay heat, all cases follow similar activity curve with time after shutdown. The activity curves start to split after 100 days and group in two curves based on the burnup of each case. Higher burnup cases exhibit higher activities at long cooling times.

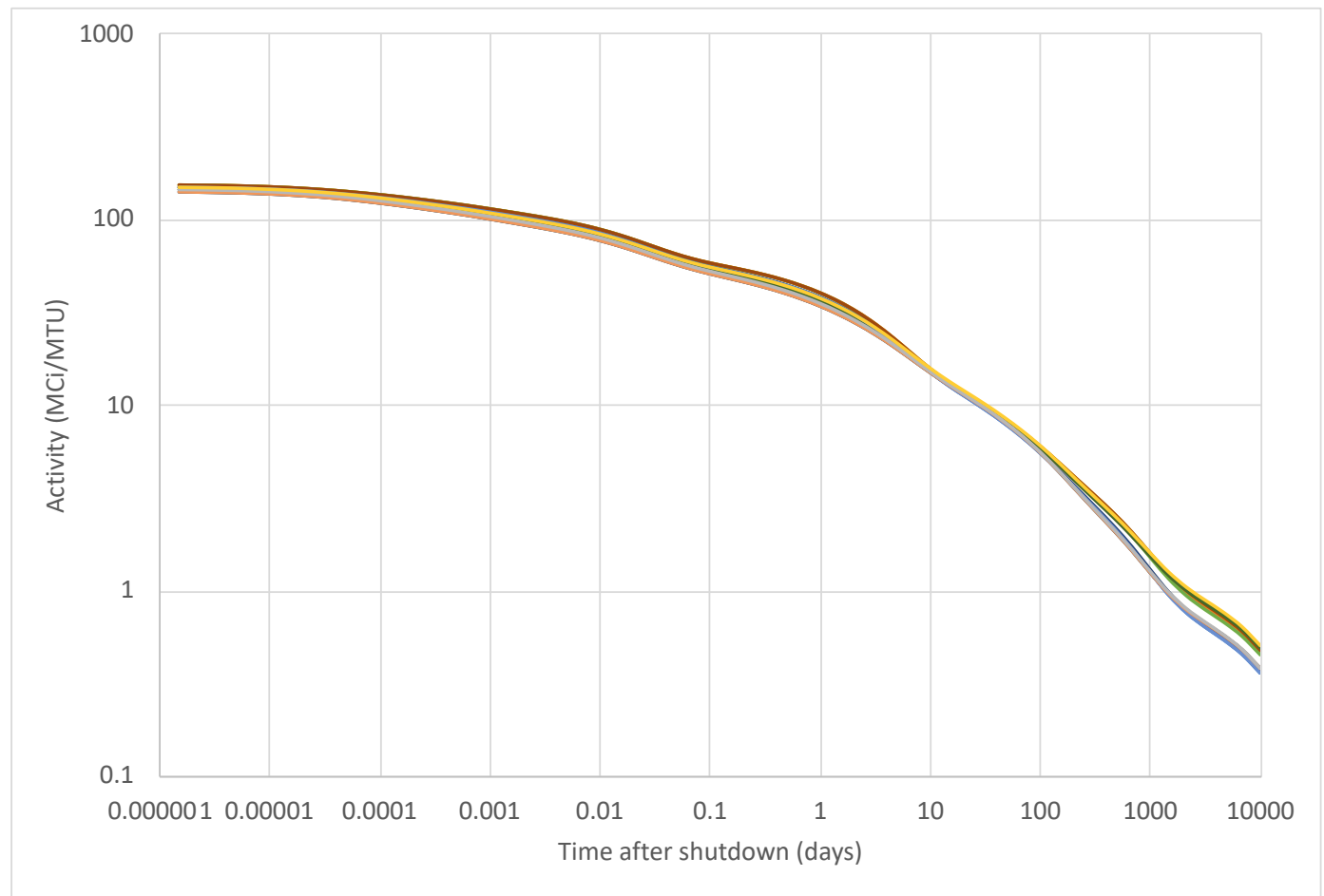

Figure 22. Activity as a function of cooling time for all 16 lattices.

In order to analyze the differences in activities in more detail, the relative (Eq. 7) and absolute differences in activities with respect to the reference, 5 max- $4.5 \mathrm{av} w \mathrm{wt} \%, 60 \mathrm{GWd} / \mathrm{MTU} 40 \%$ void case are plotted in Figure 23, and Figure 24, respectively. The observed trends in in both figures are similar to the trends in decay heat. While increased enrichment reduces activity, increased burnup increases activity. However, as in decay heat the enrichment have a more muted effect on activity than the burnup after 10 days, so total activity is more dominated more by burnup.

$$
A_{\text {rel }}(t)=\frac{A(t)}{A_{\text {ref }}(t)}-1
$$

where $A(t)$ is the activity as a function of time and $A_{r e f}(t)$ is the activity for the reference 5max-4.5av wt $\% 60 \mathrm{GWd} / \mathrm{MTU} 40 \%$ void case. 

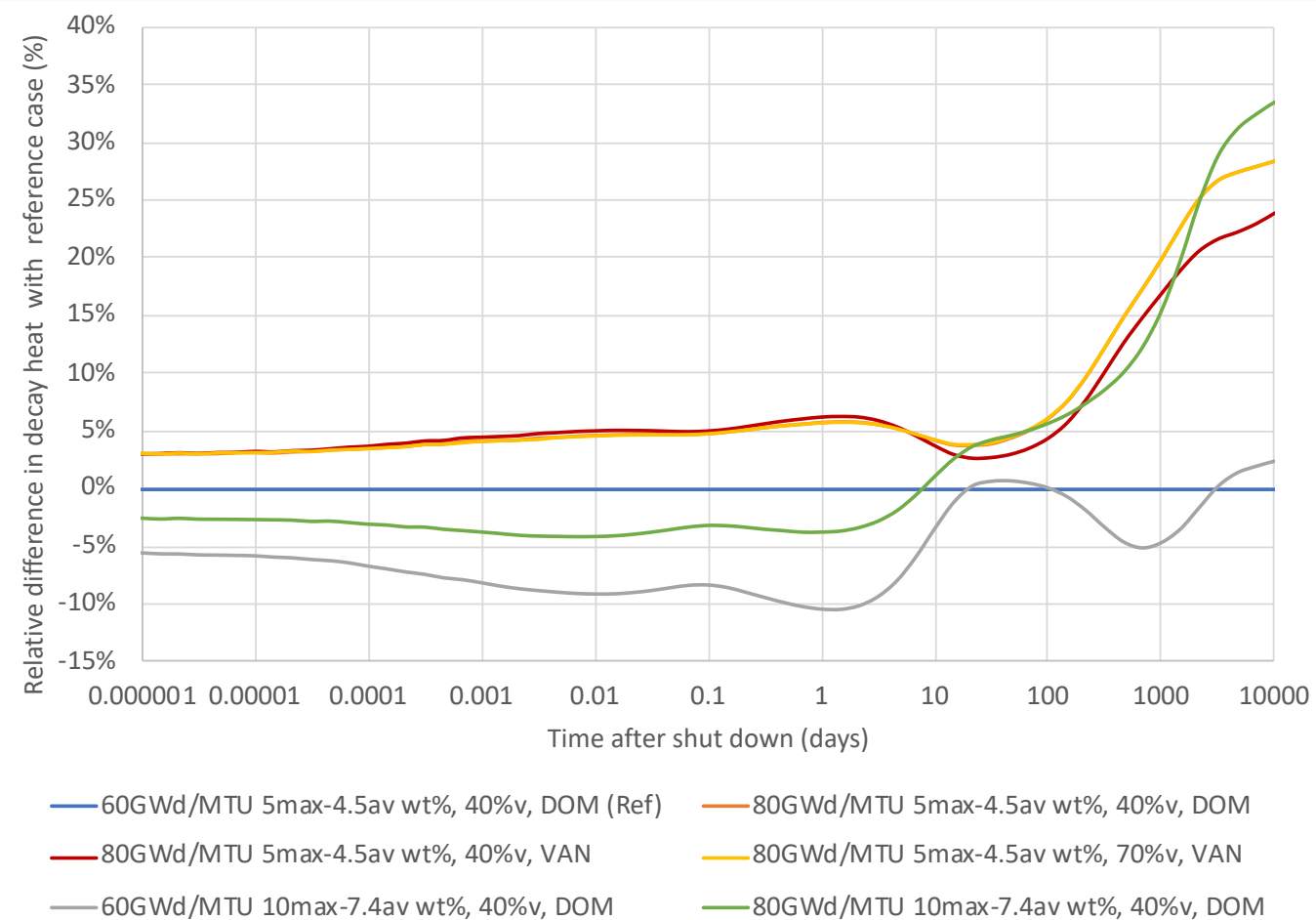

Figure 23. Relative difference in activity with the reference case a function of cooling time.

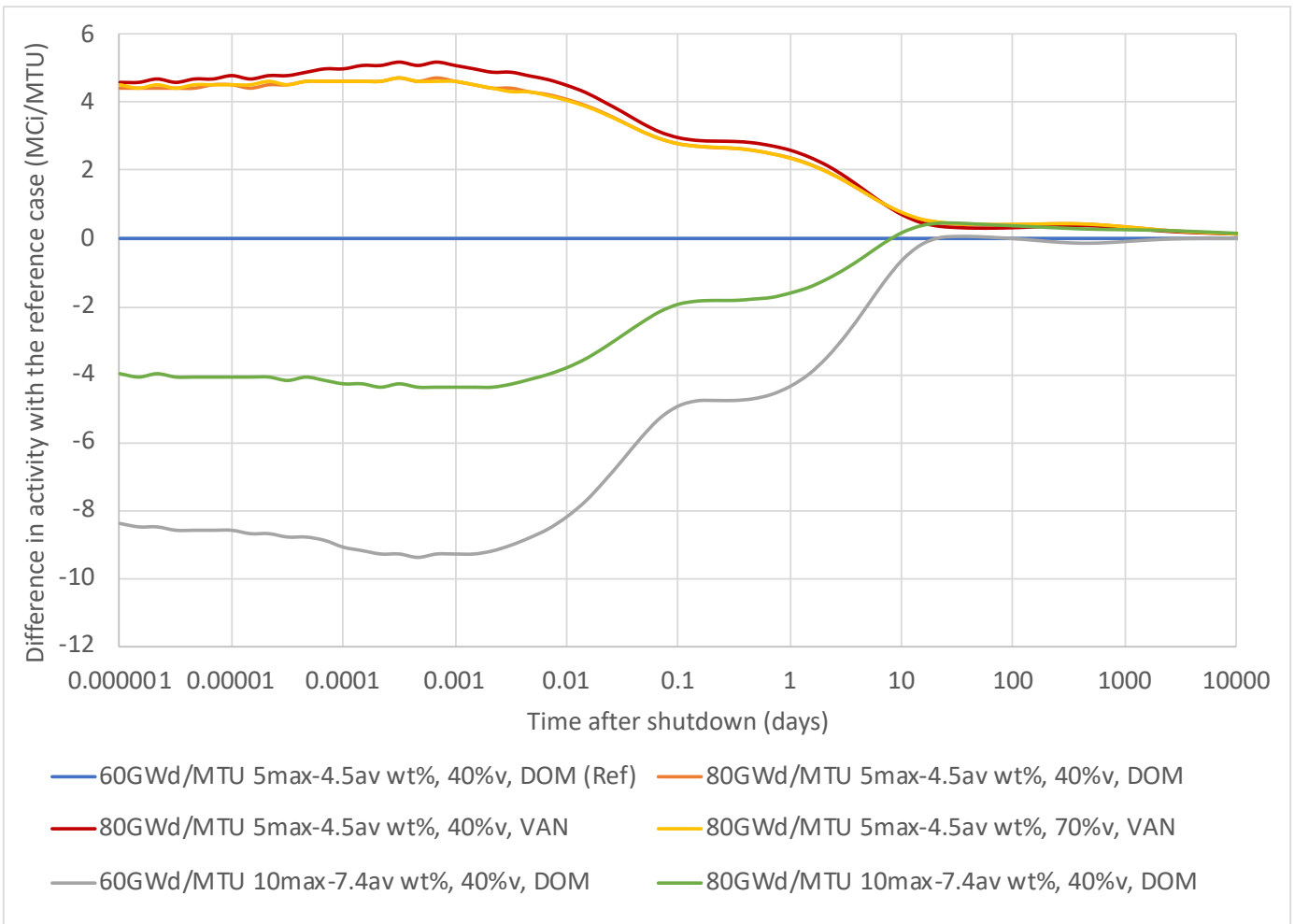

Figure 24. Difference in activity with the reference case a function of cooling time. 
A procedure similar to that used for decay heat was performed to find isotopes with large changes in activity for extended enrichment and burnup.

Table 15 through Table 17 show the impact of HBU and EE on isotopic activities. Table 15 shows the impact on total activity for each isotope when enrichment increases from 5max-4.5av $\mathrm{wt} \%$ to $10 \mathrm{max}-7.4 \mathrm{av} \mathrm{wt} \%$. Table 16 shows the impact on total activity for each isotope when burnup increases from 60 to $80 \mathrm{GWd}$ /MTU. Finally, Table 17 shows the combined impact of increasing both burnup and enrichment.

The values in Table 15 through Table 17 are the difference in activity for the isotope expressed as a percentage of total activity of the reference case. The relative difference in contribution of each isotope to the total activity $\left(A_{r e l, i}\right)$ is calculated from Eq. 8 and presented color coded, with blue indicating a decreasing activity from baseline, and red indicating an increasing activity from baseline.

$$
A_{\text {rel }, i}=\frac{A_{i}-A_{\text {ref }, i}}{A_{\text {ref }}}
$$

where $A_{i}$ is the activity for isotope $i$ for HBU or EE, $A_{r e f, i}$ is the activity for isotope $i$ for the reference case, $A_{\text {ref }}$ is the total activity for the reference case

Many of the same trends observed for decay heat in Table 5 through Table 7 are observed for activity in Table 15 through Table 17. Most isotopes appearing in the activity tables that were not in the decay heat tables likely result from lower energy decays, some of which are isotopes in equilibrium with others in the decay heat ranking list that produce higher energy decays include ${ }^{242} \mathrm{Cm},{ }^{244} \mathrm{Cm}$, and ${ }^{238} \mathrm{Pu}$, which appear in the decay heat charts but not the activity charts.

As with decay heat, the activity is distributed across a larger number of isotopes at short cooling times and fewer isotopes at long cooling times. Like decay heat, the number of short-lived isotopes is large; however, these isotopes make a small contribution to change in total activity, with the exception of ${ }^{239} \mathrm{~Np}$ and ${ }^{239} \mathrm{U}$. At longer cooling times, fewer isotopes are decaying, so the total change in activity from the isotopes that are shown more closely matches the total calculated change in activity. No single isotope changes total activity by more than $5 \%$ in any of the comparisons. 
Table 15. Contributions of each isotope to total percent change in activity from enrichment increase Activity $10 \%$ max enriched vs $5 \%$ max enriched, $40 \%$ void, $60 \mathrm{GWd}$, full lattice

\begin{tabular}{|c|c|c|c|c|c|c|}
\hline${ }^{239} \mathrm{~Np}-$ & -2.6 & -5.2 & -4.2 & -0.024 & -0.0012 & \multirow{3}{*}{-0.0} \\
\hline${ }^{106} \mathrm{Rh}$ - & -0.13 & -0.23 & -0.8 & -1.6 & -3.2 & \\
\hline${ }^{106} \mathrm{Ru}$ - & -0.11 & -0.23 & -0.8 & -1.6 & -3.2 & \\
\hline${ }^{239} \mathrm{U}-$ & -2.6 & -2.2 & 0 & 0 & 0 & -1.5 \\
\hline${ }^{134} \mathrm{Cs}$ - & -0.035 & -0.072 & -0.25 & -0.5 & -1.6 & \\
\hline${ }^{91} Y-$ & 0.12 & 0.24 & 0.81 & 13 & 0.023 & -3.0 \\
\hline${ }^{144} \mathrm{Pr}-$ & 0.057 & 0.12 & 0.41 & 0.79 & 12 & \\
\hline${ }^{144} \mathrm{Ce}-$ & 0.058 & 0.12 & 0.41 & 0.79 & 12 & -4.5 \\
\hline${ }^{147} \mathrm{Pm}$ - & 0.026 & 0.054 & 0.19 & 0.38 & 13 & \\
\hline total - & -3.907 & -6.358 & -3.726 & 1056 & -3.025 & --6.0 \\
\hline & $0.000 \mathrm{e}+00$ & 2.080 e- 02 & $5.000 \mathrm{e}+00$ & $2.500 \mathrm{e}+01$ & $5.0000^{\prime}+02$ & \\
\hline
\end{tabular}

\begin{tabular}{|c|}
\hline RMS rankings \\
\hline 3.4 \\
\hline 18 \\
\hline 1.8 \\
\hline 1.1 \\
\hline 0.84 \\
\hline 0.77 \\
\hline 0.76 \\
\hline 0.76 \\
\hline 0.69 \\
\hline 4.018 \\
\hline RMS \\
\hline 1.2 \\
\hline
\end{tabular}

Table 16. Contributions of each isotope to total percent change in activity from burnup increase Activity $80 \mathrm{GWD} / \mathrm{MTU}$ vs $60 \mathrm{GWD} / \mathrm{MTU}, 10 \%$ max enriched, $40 \%$ void, full lattice

\begin{tabular}{|c|c|c|c|c|c|}
\hline${ }^{134} \mathrm{Cs}$ - & 0.092 & 0.19 & 0.65 & 12 & 4.1 \\
\hline${ }^{239} \mathrm{~Np}-$ & 12 & 2.4 & 19 & 0.011 & 0.0018 \\
\hline${ }^{137} \mathrm{Cs}-$ & 0.042 & 0.088 & 0.3 & 0.58 & 2.9 \\
\hline${ }^{106} \mathrm{Rh}-$ & 0.095 & 0.18 & 0.61 & 11 & 2.4 \\
\hline$\stackrel{ }{106} \mathrm{Ru}-$ & 0.086 & 0.18 & 0.61 & 11 & 2.4 \\
\hline${ }^{13} \mathrm{~mm} \mathrm{Ba}-$ & 0.04 & 0.084 & 0.29 & 0.55 & 2.8 \\
\hline${ }^{90} \mathrm{Y}-$ & 0.025 & 0.051 & 0.17 & 0.32 & 16 \\
\hline${ }^{90} \mathrm{Sr}-$ & 0.023 & 0.049 & 0.17 & 0.32 & 16 \\
\hline${ }^{241} \mathrm{Pu}-$ & 0.024 & 0.05 & 0.17 & 0.33 & 16 \\
\hline total - & 2.55 & 4.508 & 4.9 & 4.084 & 19.25 \\
\hline & $0.000^{\prime} \mathrm{e}+00$ & $2080^{\prime} \mathrm{e}-02$ & $5.000^{\prime} e+00$ & $2.500 \mathrm{e}+01$ & $5.0000^{\prime}+02$ \\
\hline
\end{tabular}

\begin{tabular}{|c|}
\hline RMS rankings \\
\hline 2.2 \\
\hline 1.6 \\
\hline 1.5 \\
\hline 14 \\
\hline 14 \\
\hline 14 \\
\hline 0.82 \\
\hline 0.82 \\
\hline 0.82 \\
\hline 10.39 \\
\hline RMS \\
\hline
\end{tabular}


Table 17. Contributions of each isotope to total percent change in activity from combined enrichment and burnup increase

\begin{tabular}{|c|c|c|c|c|c|c|}
\hline \multicolumn{7}{|c|}{$\begin{array}{c}\text { Activity } \\
\text { Acticis }\end{array}$} \\
\hline${ }^{239} \mathrm{~Np}-$ & -1.4 & -2.9 & -2.4 & -0.013 & 0.00055 & \\
\hline${ }^{137} \mathrm{Cs}-$ & 0.041 & 0.084 & 0.29 & 0.6 & 2.9 & \\
\hline${ }^{13} \mathrm{~mm} \mathrm{Ba}$ - & 0.039 & 0.08 & 0.28 & 0.57 & 2.7 & \\
\hline${ }^{134} \mathrm{Cs}$ - & 0.053 & 0.11 & 0.38 & 0.75 & 24 & \\
\hline ఏ $\quad{ }^{90} \mathrm{Y}-$ & 0.035 & 0.071 & 0.25 & 0.5 & 2.4 & \\
\hline${ }^{90} \mathrm{Sr}-$ & 0.035 & 0.071 & 0.25 & 0.5 & 24 & \\
\hline${ }^{241} \mathrm{Pu}-$ & 0.021 & 0.042 & 0.15 & 0.3 & 14 & \\
\hline${ }^{239} \mathrm{U}-$ & -1.5 & -1.2 & 0 & 0 & 0 & \\
\hline${ }^{147} \mathrm{Pm}-$ & 0.02 & 0.04 & 0.14 & 0.28 & 0.98 & -0 \\
\hline total - & -1.457 & -2.137 & 0.9906 & 5.182 & 15.64 & \\
\hline & $0.000{ }^{\prime} \mathrm{e}+00$ & $2.0801 \mathrm{e}-02$ & $5.000^{\prime} \mathrm{e}+00$ & $2.500 \mathrm{e}+01$ & $5.000 \mathrm{e}+02$ & \\
\hline
\end{tabular}

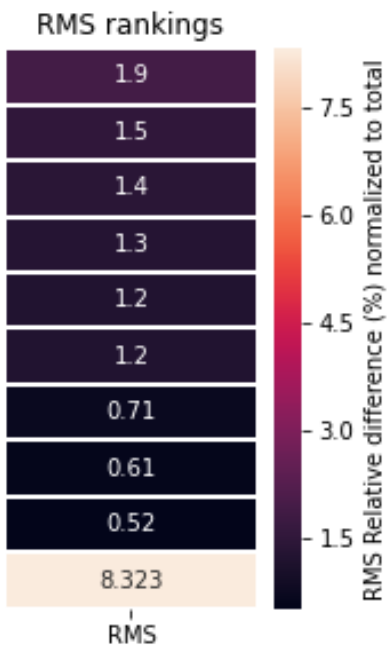

Since absolute differences in activity also follow the trends of the relative differences shown in Table 15 through Table 17, are not presented here. Again, ${ }^{239} \mathrm{~Np}$ dominated, and changes are larger at shorter cooling times than at longer cooling times due to its short half-life of 2.3 days. However, as seen in the case of decay heat, each isotope's change at a shorter cooling time is a smaller proportion of the total. Changes at shorter cooling times also depend more on specific power than burnup or initial enrichment.

Table 18 shows the effect of void fraction and lattice type on activity. Most of the small effect is concentrated in ${ }^{241} \mathrm{Pu},{ }^{239} \mathrm{~Np}$, and ${ }^{134} \mathrm{Cs} .{ }^{241} \mathrm{Pu}$ contributes approximately half of the activity change shown versus the DOM lattice at 10\% void. Regardless, overall effect of lattice and void change on activity is rather small, being only about $1 \%$ of total activity. 
Table 18. Signed RMS change in isotopic activity due to changes in lattice design and void fraction for 10max-7.4av wt\% DOM lattice at $80 \mathrm{GWd} / \mathrm{MTU}$

\begin{tabular}{|c|c|}
\hline \multicolumn{2}{|c|}{$\begin{array}{l}\text { Full lattice } \\
10 \% \text { void }\end{array}$} \\
\hline${ }^{106} \mathrm{Ru}$ & 0 \\
\hline${ }^{106} \mathrm{Rh}$ & 0 \\
\hline${ }^{90} \mathrm{Sr}$ & 0 \\
\hline${ }^{134} \mathrm{Cs}$ & 0 \\
\hline${ }^{239} \mathrm{U}$ & 0 \\
\hline${ }^{237} \mathrm{U}$ & 0 \\
\hline${ }^{239} \mathrm{~Np}$ & 0 \\
\hline${ }^{241} \mathrm{Pu}$ & 0 \\
\hline${ }^{90} \mathrm{Y}$ & 0 \\
\hline${ }^{24} \mathrm{Cm}$ & 0 \\
\hline${ }^{144} \mathrm{Pr}$ & 0 \\
\hline total & 0 \\
\hline
\end{tabular}
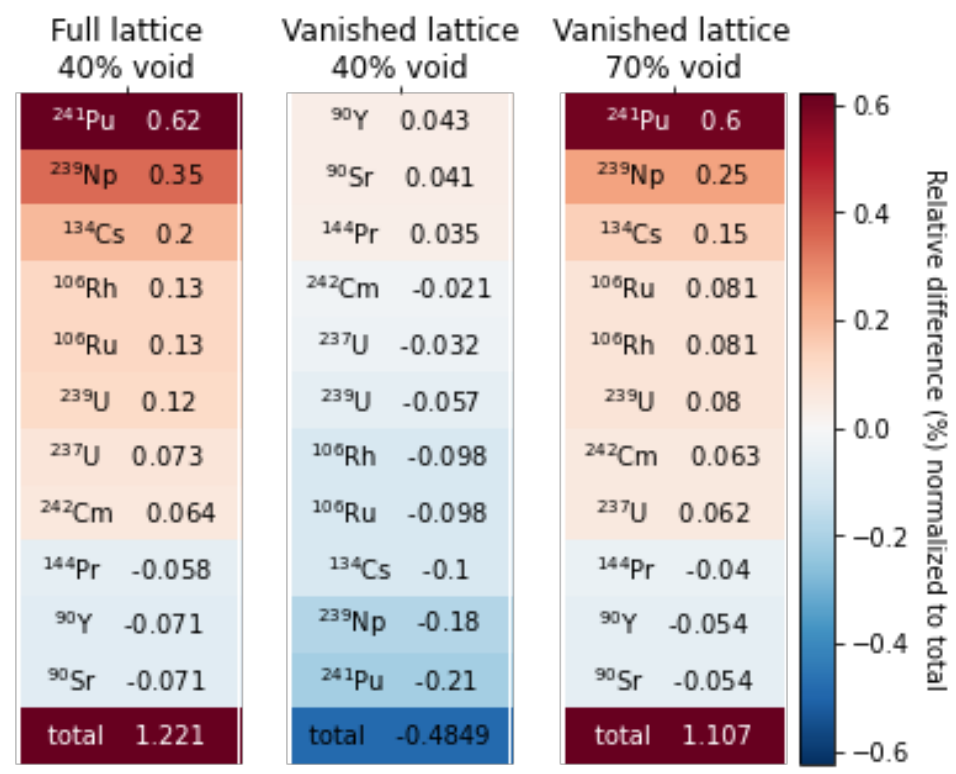

\subsection{ISOTOPES RELEVANT TO ACCIDENT RELEASE SOURCE TERM}

In addition to isotopes that contribute to large changes in activity, some may also be important to the release source term. To screen for these, the list of elements in Regulatory Guide 1.183, Alternative Radiological Source Terms for Evaluating Design Basis Accidents at Nuclear Power Reactors, lists these elements that must be considered when considering the alternative release source terms provided in Table 5 of that document [8].

- Noble gases: Xe, $\mathrm{Kr}$

- Halogens: I, Br

- Alkali metals: Cs, Rb

- Tellurium group: Te, Sb, Se, $\mathrm{Ba}, \mathrm{Sr}$

- Noble metals: Ru, Rh, Pd, Mo, Tc, Co

- Lanthanides: La, Zr, Nd, Eu, Nb, Pm, Pr, Sm, Y, Cm, Am

- Cerium: $\mathrm{Ce}, \mathrm{Pu}, \mathrm{Np}$

Every isotope of these elements included in SCALE was modeled, but only those creating more than a $0.1 \%$ of total activity at any evaluated timepoint are listed in Table 19 through Table 21 . Similar to previous sections, effect of EE and HBU are analyzed on release isotopes activities.

Comparisons showing the effects of increases in burnup and enrichment for a selection of isotopes are shown in Table 19 through Table 21 . The relative difference in each isotope activity $\left(A_{r e l, i}\right)$ is calculated from Eq. 9. The observed trends are very similar to the trends observed for PWR assemblies [15]. The relative differences for negligible concentrations of ${ }^{133} \mathrm{I}$ and ${ }^{135} \mathrm{I}$ at 500 days were left blank in the tables. 


$$
A_{r e l, i}=\frac{A_{i}-A_{r e f, i}}{A_{r e f, i}}
$$

where $A_{i}$ is the activity for isotope $i$ for HBU or EE, $A_{r e f, i}$ is the activity for isotope $i$ for the reference case.

Table 19. Relative differences of selected release isotopes activities due to enrichment increase Release isotope activity

$10 \%$ max enriched vs $5 \%$ max enriched, $40 \%$ void, $60 \mathrm{GWd}$, DOM lattice

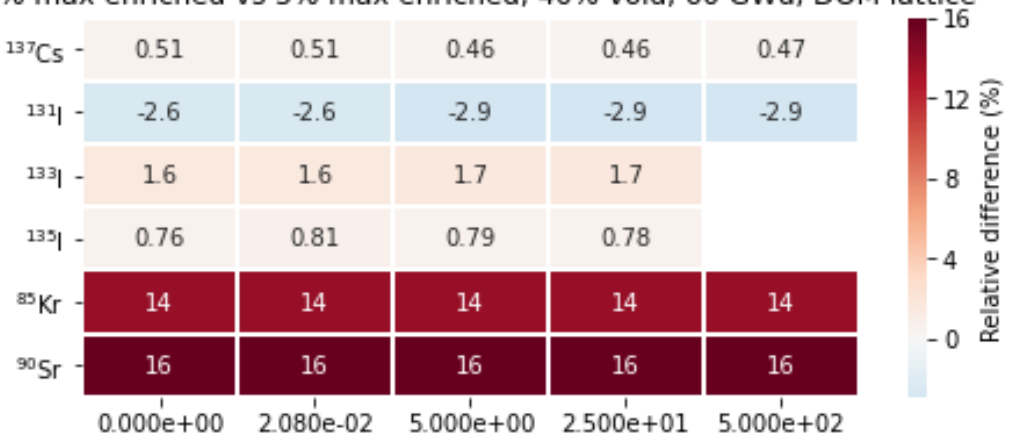

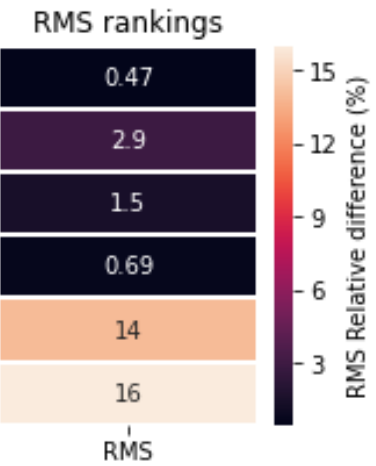

Table 20. Relative differences of selected release isotopes activities due to burnup increase Release isotope activity

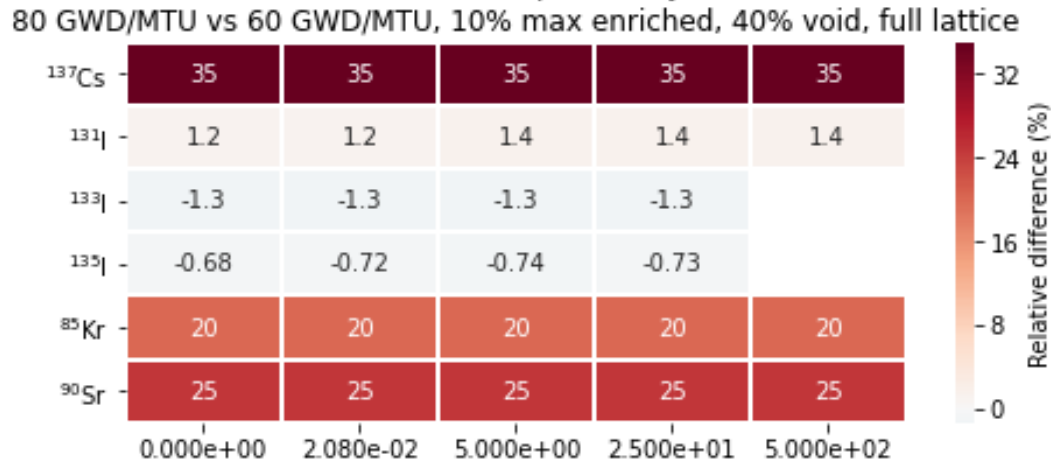

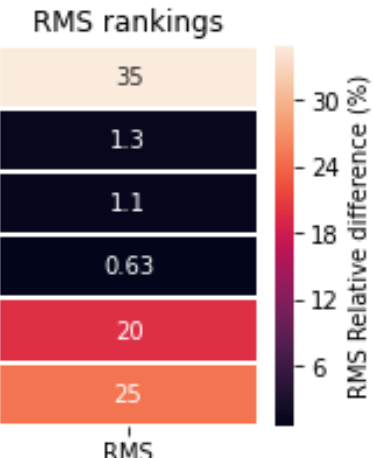


Table 21. Relative differences of selected release isotopes activities due to both enrichment and burnup increase

Release isotope activity

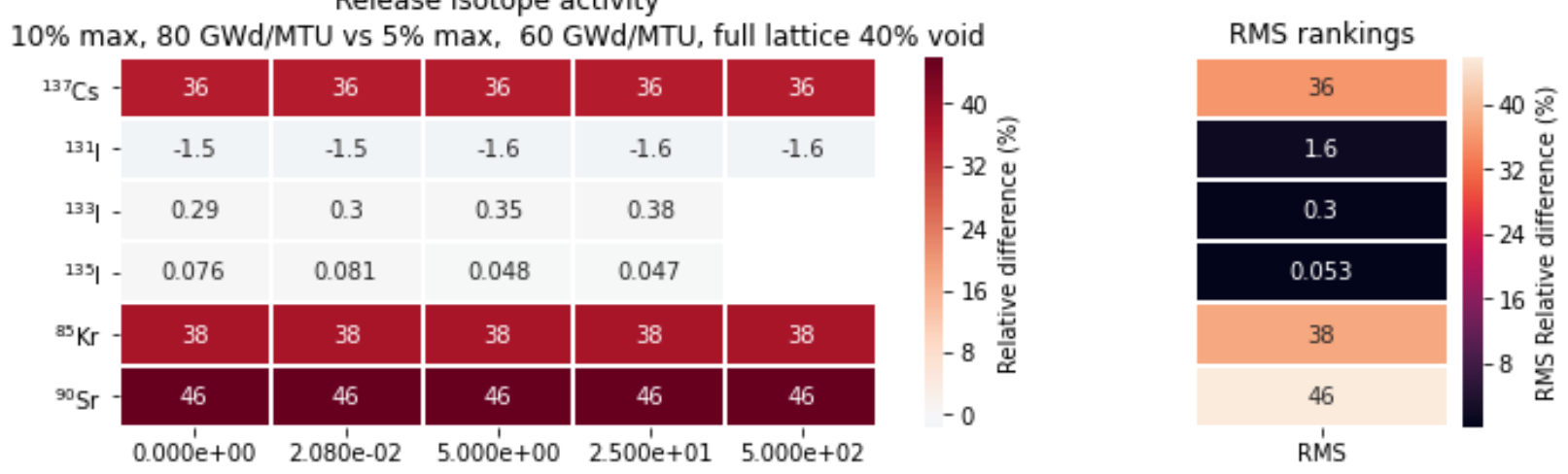

The effect of lattice type and void fraction on release isotopes is relatively small when both enrichment and burnup are increased. ${ }^{90} \mathrm{Sr}$, and ${ }^{85} \mathrm{Kr}$ are the most affected isotopes, while decrease in void fraction increases inventories, DOM lattices show lower inventories compared to VAN lattices.

Table 22. Signed RMS relative differences in abundance of selected release isotopes due to changes in lattice design and void fraction for 10max-7.4av wt \% DOM lattice at $80 \mathrm{GWd} / \mathrm{MTU}$

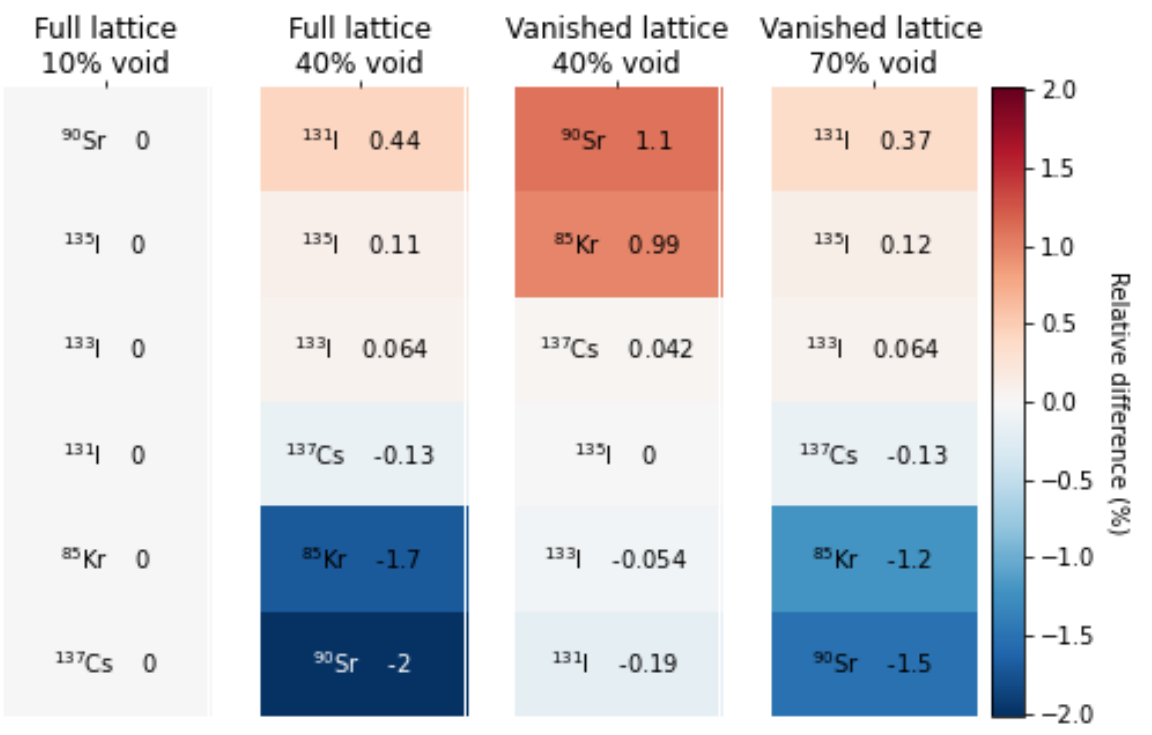

\subsection{ISOTOPES RELEVANT TO RADIATION SHIELDING SOURCE TERM}

Changes in the isotopes important to cask shielding in NUREG 6700 [9] are evaluated in this section. This list of isotopes is developed for longer time frames such as 5 years. Given that relative contributions of short-lived isotopes are mostly dependent on operating power, this should be reasonable. Table 23 through Table 25 address the percent each isotope increases or 
decreases in activity on an isotope basis. The relative difference for each isotope's activity is computed from Eq. 9.

Aside from the ${ }^{238} \mathrm{Pu}$ and $\mathrm{Cm}$ isotopes (addressed in section 5.5), given that there are no changes exceeding $100 \%$, the existing methods for shielding should remain suitable. Values are similar to the PWR cases [15], with the exception of the higher actinides, which are more sensitive to operating conditions than fission products. 
Table 23. Relative differences of selected shielding isotopes activities due to enrichment increase

Shielding isotope activity

$10 \%$ max enriched vs $5 \%$ max enriched, $40 \%$ void, $60 \mathrm{GWd}$, full lattice

\begin{tabular}{|c|c|c|c|c|c|c|}
\hline${ }^{241} \mathrm{Am}-$ & 24 & 24 & 23 & 22 & 8.7 & -20 \\
\hline${ }^{13} \mathrm{~mm} \mathrm{Ba}-$ & 0.42 & 0.48 & 0.48 & 0.48 & 0.44 & \\
\hline${ }^{244} \mathrm{Cm}$ & -61 & -61 & -61 & -61 & -61 & \\
\hline${ }^{246} \mathrm{Cm}$ & -75 & -75 & -75 & -75 & -75 & -0 \\
\hline${ }^{134} \mathrm{Cs}-$ & -20 & -20 & -20 & -20 & -20 & \\
\hline${ }^{154} \mathrm{Eu}-$ & -1.2 & -1.2 & -1.2 & -1.2 & -1.2 & \\
\hline${ }^{144} \mathrm{Pr}-$ & 9.7 & 9.8 & 9.9 & 9.9 & 9.9 & \\
\hline${ }^{238} \mathrm{Pu}-$ & -16 & -16 & -16 & -16 & -16 & \\
\hline${ }^{239} \mathrm{Pu}-$ & 25 & 25 & 24 & 24 & 24 & \\
\hline${ }^{240} \mathrm{Pu}-$ & -15 & -15 & -15 & -15 & -15 & \\
\hline${ }^{241} \mathrm{Pu}-$ & -2.2 & -2.2 & -2.2 & -2.2 & -2.1 & \\
\hline${ }^{242} \mathrm{Pu}-$ & 42 & 42 & 42 & 42 & 42 & -60 \\
\hline${ }^{106} \mathrm{Rh}-$ & -30 & -28 & -28 & -28 & -28 & \\
\hline${ }^{90} \mathrm{Y}-$ & 14 & 14 & 16 & 16 & 16 & \\
\hline & $0.000 e^{\prime}+00$ & $2.080^{\prime} \mathrm{e}-02$ & $5.000 e^{\prime}+00$ & $2.5000^{\prime} \mathrm{e}+01$ & $5.000 \mathrm{e}+02$ & \\
\hline
\end{tabular}

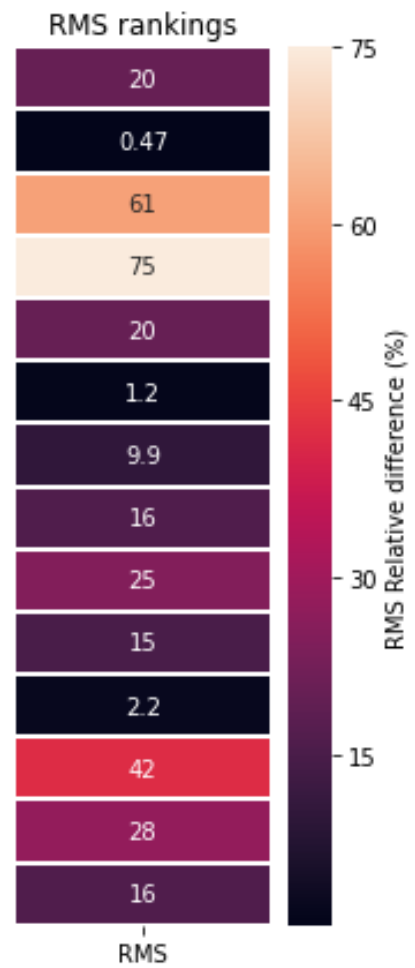

Table 24. Relative differences of selected shielding isotopes activities due to burnup increase Shielding isotope activity $80 \mathrm{GWD} / \mathrm{MTU}$ vs $60 \mathrm{GWD} / \mathrm{MTU}, 10 \%$ max enriched, $40 \%$ void, full lattice

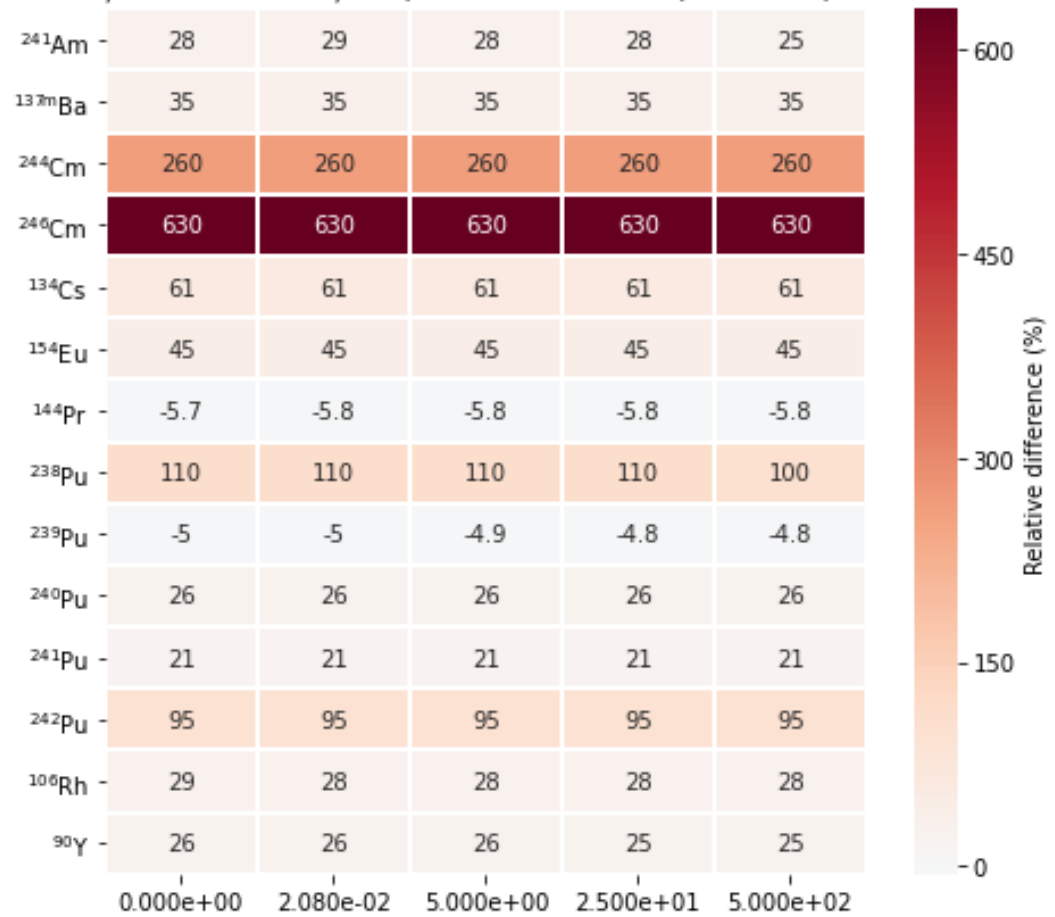

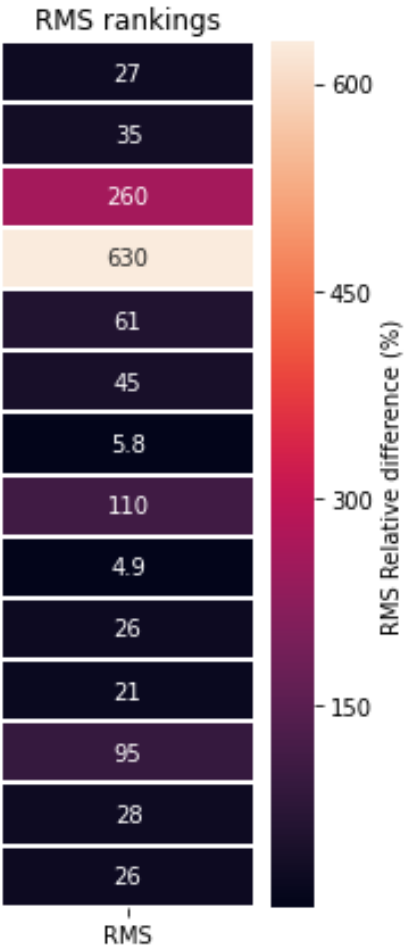


Table 25. Relative differences of selected shielding isotopes activities due to both enrichment and burnup increase

Shielding isotope activity

\begin{tabular}{|c|c|c|c|c|c|}
\hline${ }^{241} \mathrm{Am}$. & 59 & 59 & 58 & 56 & 36 \\
\hline${ }^{13} \mathrm{~mm} \mathrm{Ba}-$ & 36 & 36 & 36 & 36 & 36 \\
\hline${ }^{244} \mathrm{Cm}$ & 42 & 42 & 42 & 42 & 42 \\
\hline${ }^{246} \mathrm{Cm}$ & 82 & 82 & 82 & 82 & 82 \\
\hline${ }^{134} \mathrm{Cs}$ & 29 & 29 & 29 & 29 & 29 \\
\hline${ }^{154} \mathrm{Eu}$ & 43 & 43 & 43 & 43 & 43 \\
\hline${ }^{144} \mathrm{Pr}-$ & 3.4 & 3.5 & 3.6 & 3.6 & 3.5 \\
\hline${ }^{238} \mathrm{Pu}$ & 74 & 74 & 74 & 74 & 71 \\
\hline${ }^{239} \mathrm{Pu}$ & 19 & 19 & 18 & 18 & 18 \\
\hline${ }^{240} \mathrm{Pu}-$ & 7.4 & 7.4 & 7.4 & 7.4 & 7.5 \\
\hline${ }^{241} \mathrm{Pu}$ & 18 & 18 & 18 & 18 & 18 \\
\hline${ }^{242} \mathrm{Pu}$ & 12 & 12 & 12 & 12 & 12 \\
\hline${ }^{106} \mathrm{Rh}$ & -9.5 & -7.6 & -7.5 & -7.6 & -7.5 \\
\hline${ }^{90} \mathrm{Y}$ & 44 & 44 & 45 & 46 & 46 \\
\hline & $0.000 \mathrm{e}+00$ & $2.080^{\prime} \mathrm{e}-02$ & $5.000 \mathrm{e}+00$ & $2.500 \mathrm{e}+01$ & $5.000 \mathrm{e}+02$ \\
\hline
\end{tabular}

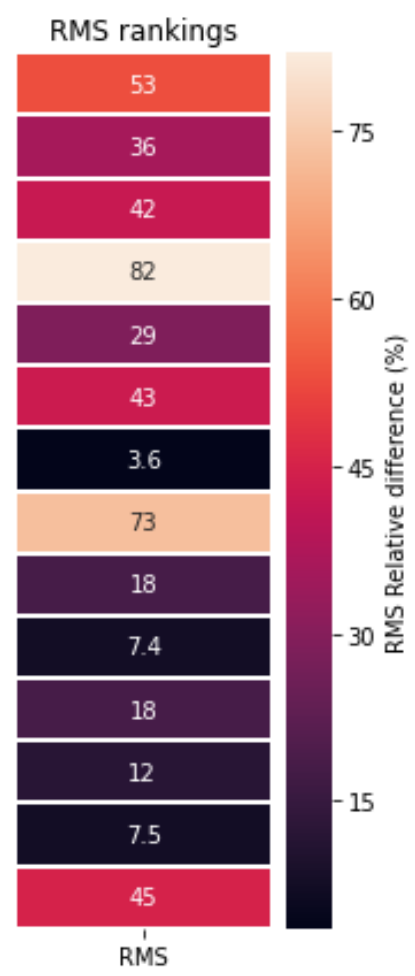

Table 26 shows effect lattice type and void fraction on RMS relative differences for the selected shielding isotopes for $10 \mathrm{max}-7.4 \mathrm{av} \mathrm{wt} \%$ lattice. Actinides like ${ }^{244} \mathrm{Cm}$ concentrations can change significantly with void fraction (14\% to $18 \%)$. Corollary, sensitivity to the lattice type due to change in moderation power is also expected $(21 \%)$. These differences are small compared to the effect of enrichment and burnup for the same isotopes; however, they imply that the trends seen in EE and HBU cases of DOM lattice at $40 \%$ void fraction may not apply to a VAN lattice at the same void fraction. Therefore, the analysis in this section should be repeated in the next phase of this study for VAN lattice as the reference lattice.

The curium isotopes in Table 24 are produced in small amounts and very sensitive to increasing burnup. Several isotopes on the activation chain leading to ${ }^{244} \mathrm{Cm}$ and ${ }^{246} \mathrm{Cm}$ are shown in Figure 25 , along with ${ }^{235} \mathrm{U}$ where the increasing sensitivity to burnup with increasing mass number is apparent.

Neutron emitters are important in some cask shielding applications, and the appearance of additional spontaneous fission neutron emitters could carry implications for shielding analyses. In the case evaluated, spontaneous fission neutron emitters such as ${ }^{244} \mathrm{Cm}$ and ${ }^{242} \mathrm{Cm}$ produce $\sim 95 \%$ of neutrons post-discharge. To verify that no additional significant spontaneous fission source appeared, the difference in spontaneous fission source intensity between the 80 GWd/MTU 10max-7.4av wt\% enrichment case and the $60 \mathrm{GWd} / \mathrm{MTU} 5 \mathrm{max}-4.5 \mathrm{av}$ wt $\%$ case are shown in Figure 26. It is clearly seen that ${ }^{244} \mathrm{Cm}$ is the main isotope that changes the spontaneous neutron emission source substantially for the timescales in question. Isotopes with relative differences under $0.1 \%$ are not listed. Despite the $82 \%$ increase in ${ }^{246} \mathrm{Cm}$ composition in the 80 
$\mathrm{GWd} / \mathrm{MTU} 10 \mathrm{wt} \%$ maximum enrichment case over the reference $60 \mathrm{GWd} / \mathrm{MTU} 5 \mathrm{wt} \%$ case seen in Table 25, this isotope due to long half-life (4700 years) should not substantially affect the neutron dose. Furthermore, no other new spontaneous fission isotopes become prominent. ${ }^{242} \mathrm{Cm}$ and ${ }^{244} \mathrm{Cm}$ increase in activity, and few actinides heavier than ${ }^{244} \mathrm{Cm}$ are produced because ${ }^{245} \mathrm{Cm}$ has a high neutron-induced fission probability.

Table 26. Signed RMS relative differences in abundance of selected shielding isotopes vs the dominant lattice with $10 \%$ void for $10 \%$ maximum enriched lattices burned to 80 GWd/MTU

\begin{tabular}{|c|c|c|c|c|c|c|c|c|}
\hline \multicolumn{2}{|c|}{$\begin{array}{l}\text { Full lattice } \\
10 \% \text {, void }\end{array}$} & \multicolumn{2}{|c|}{$\begin{array}{l}\text { Full lattice } \\
40 \% \text { void }\end{array}$} & \multicolumn{2}{|c|}{$\begin{array}{c}\text { Vanished lattice } \\
40 \% \text {, void }\end{array}$} & \multicolumn{2}{|c|}{$\begin{array}{c}\text { Vanished lattice } \\
70 \% \text { void }\end{array}$} & \\
\hline${ }^{106} \mathrm{Rh}$ & 0 & ${ }^{246} \mathrm{Cm}$ & 26 & ${ }^{90} \mathrm{Y} \quad \mathrm{T}$ & 1.2 & ${ }^{239} \mathrm{Pu}$ & 25 & \\
\hline${ }^{13} \mathrm{~mm} \mathrm{Ba}$ & 0 & ${ }^{241} \mathrm{Am}$ & 25 & ${ }^{144} \mathrm{Pr}$ & 0.48 & ${ }^{241} \mathrm{Am}$ & 24 & 20 \\
\hline${ }^{134} \mathrm{Cs}$ & 0 & ${ }^{239} \mathrm{Pu}$ & 25 & ${ }^{13} \mathrm{Tm}_{\mathrm{m}} \mathrm{Ba}$ & 0 & ${ }^{246} \mathrm{Cm}$ & 20 & \\
\hline${ }^{242} \mathrm{Pu}$ & 0 & ${ }^{241} \mathrm{Pu}$ & 18 & ${ }^{240} \mathrm{Pu} \quad-$ & -0.95 & ${ }^{241} \mathrm{Pu}$ & 18 & \\
\hline${ }^{241} \mathrm{Pu}$ & 0 & ${ }^{154} \mathrm{Eu}$ & 15 & ${ }^{106} \mathrm{Rh}$ & -1.8 & ${ }^{154} \mathrm{Eu}$ & 16 & -10 \\
\hline${ }^{240} \mathrm{Pu}$ & 0 & ${ }^{238} \mathrm{Pu}$ & 14 & ${ }^{134} \mathrm{Cs}$ & -2.1 & ${ }^{238} \mathrm{Pu}$ & 15 & \\
\hline${ }^{144} \mathrm{Pr}$ & 0 & ${ }^{244} \mathrm{Cm}$ & 14 & ${ }^{242} \mathrm{Pu}$ & -2.9 & ${ }^{244} \mathrm{Cm}$ & 11 & \\
\hline${ }^{154} \mathrm{Eu}$ & 0 & ${ }^{240} \mathrm{Pu}$ & 7.9 & ${ }^{154} \mathrm{Eu}$ & -4.1 & ${ }^{240} \mathrm{Pu}$ & 9.6 & \\
\hline${ }^{246} \mathrm{Cm}$ & 0 & ${ }^{134} \mathrm{Cs}$ & 4.1 & ${ }^{238} \mathrm{Pu}$ & -4.3 & ${ }^{134} \mathrm{Cs}$ & 3.3 & \\
\hline${ }^{24} \mathrm{Am}$ & 0 & ${ }^{106} \mathrm{Rh}$ & 2.6 & ${ }^{241} \mathrm{Pu}$ & -6.1 & ${ }^{106} \mathrm{Rh}$ & 1.5 & -10 \\
\hline${ }^{239} \mathrm{Pu}$ & 0 & ${ }^{13}{ }^{\mathrm{mm}} \mathrm{Ba}$ & -0.12 & ${ }^{239} \mathrm{Pu}$ & -7 & ${ }^{13}{ }^{7 m} \mathrm{Ba}$ & -0.13 & \\
\hline${ }^{238} \mathrm{Pu}$ & 0 & ${ }^{144} \mathrm{Pr}$ & -0.8 & ${ }^{244} \mathrm{Cm}$ & -7.7 & ${ }^{144} \mathrm{Pr}$ & -0.55 & \\
\hline${ }^{244} \mathrm{Cm}$ & 0 & ${ }^{24} \mathrm{Pu}$ & -1.8 & ${ }^{241} \mathrm{Am}$ & -8.2 & ${ }^{90} \mathrm{Y}$ & -1.7 & -20 \\
\hline${ }^{90} \mathrm{Y} \quad 0$ & 0 & ${ }^{90} \mathrm{Y}-$ & 2.1 & ${ }^{246} \mathrm{Cm}$ & -13 & ${ }^{242} \mathrm{Pu}$ & -5.3 & \\
\hline
\end{tabular}




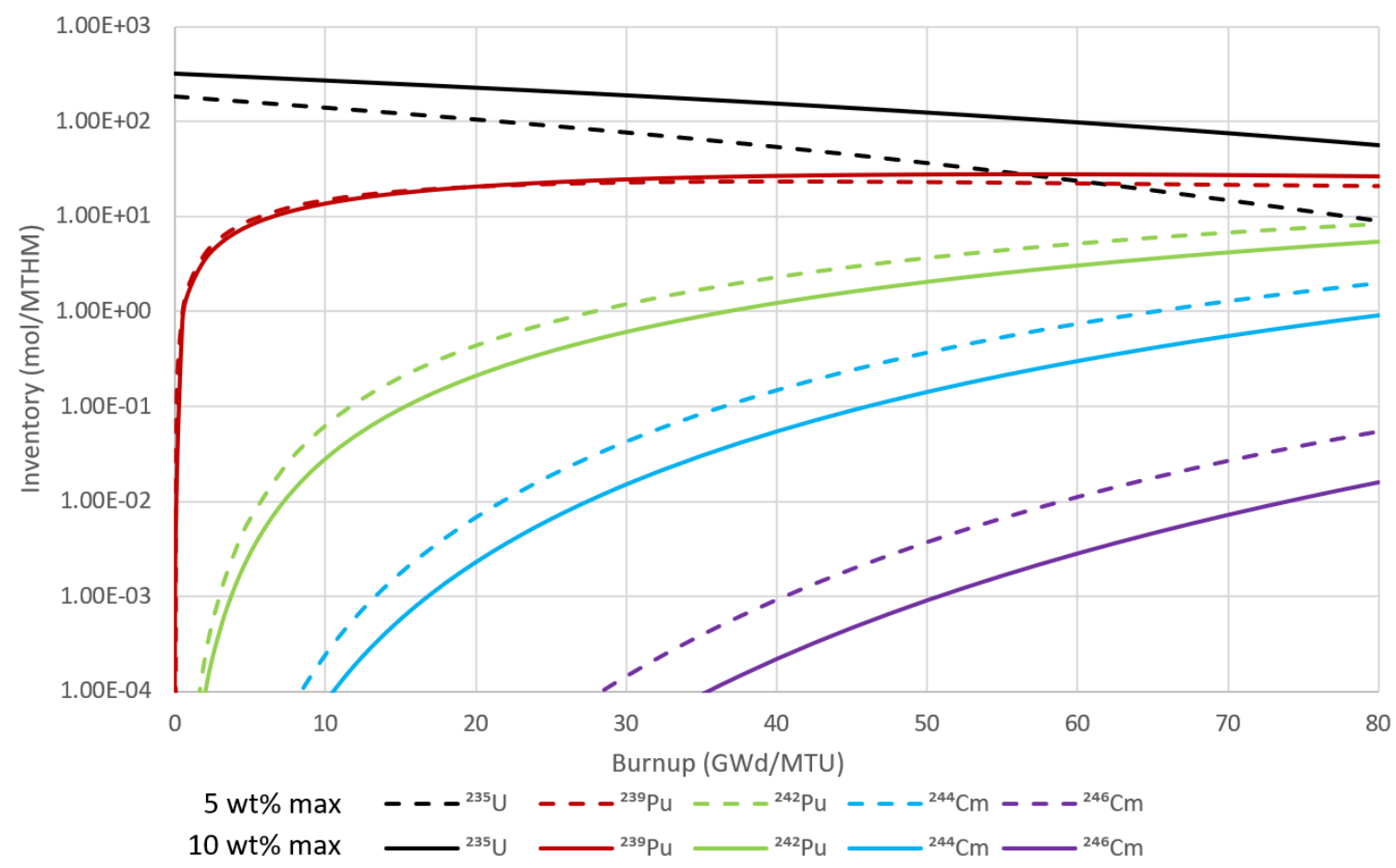

Figure 25. In-core abundances for isotopes in the activation chain for ${ }^{244} \mathrm{Cm}$ and ${ }^{246} \mathrm{Cm}$.

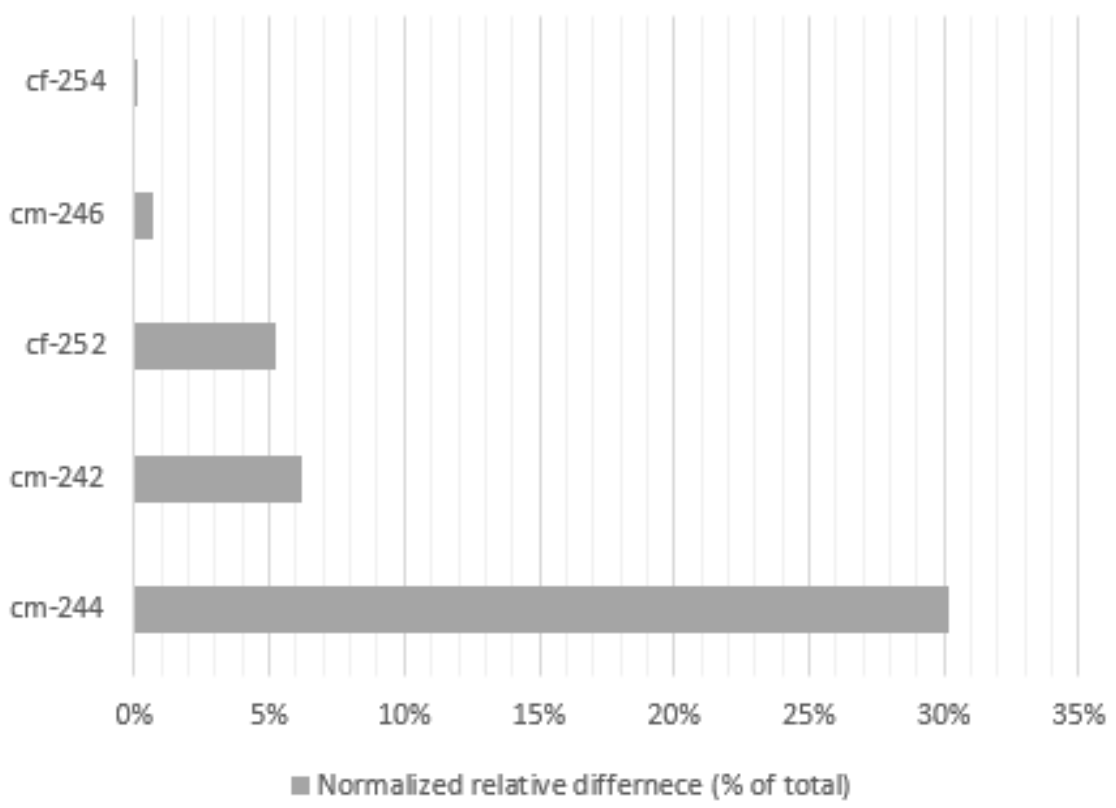

Figure 26. Relative difference in SF neutron emission on total SF neutron emission basis for time point $80 \mathrm{GWd} / \mathrm{MTU} 10 \mathrm{max}-7.4 \mathrm{av}$ wt $\%$ vs the reference case for $40 \%$ void fraction. 


\subsection{ISOTOPES FOR CRITICALITY}

The impacts of high burnups and enrichments of isotopes found to substantially contribute to the multiplication factor in Section 4.1 are examined here. Table 27 through Table 29 show relative differences between isotope masses with respect to the reference case. The relative differences are computed as

$$
M_{r e l, i}=\frac{M_{i}-M_{r e f, i}}{M_{r e f, i}}
$$

where $M_{i}$ is the mass for isotope $i$ for $\mathrm{HBU}$ or EE, $M_{\text {ref, } i}$ is the mass for isotope $i$ reference 5max-4.5av wt $\% 60 \mathrm{GWd} / \mathrm{MTU} 40 \%$ void case.

In general, increasing enrichment decreases the abundance of actinides after ${ }^{239} \mathrm{Pu}$ in the neutron activation sequence. Other notable increases are in fission products ${ }^{135} \mathrm{Xe}$ and ${ }^{149} \mathrm{Sm}$ due to reduced flux levels. Varying burnup or initial enrichment alone creates large relative changes in isotopic content for heavier actinides such as ${ }^{243} \mathrm{Am}$ and ${ }^{242} \mathrm{Pu}$. When increasing enrichment with burnup, the competing effects mostly cancel out for the heavier transuranics. This is because they are the products of multiple neutron absorptions, so their abundance increases with burnup. For a given burnup, increased enrichment results in lower overall neutron fluence, so neutron absorption products decrease with increasing enrichment.

Table 30 shows the percent change in mass for criticality isotopes due to changes in lattice types and void fractions. ${ }^{235} \mathrm{U},{ }^{239} \mathrm{Pu},{ }^{241} \mathrm{Pu},{ }^{149} \mathrm{Sm},{ }^{151} \mathrm{Sm},{ }^{154} \mathrm{Eu}$ have the largest relative changes in mass. 
Table 27. Relative differences of criticality isotope masses due to enrichment increase

Criticality isotope mass

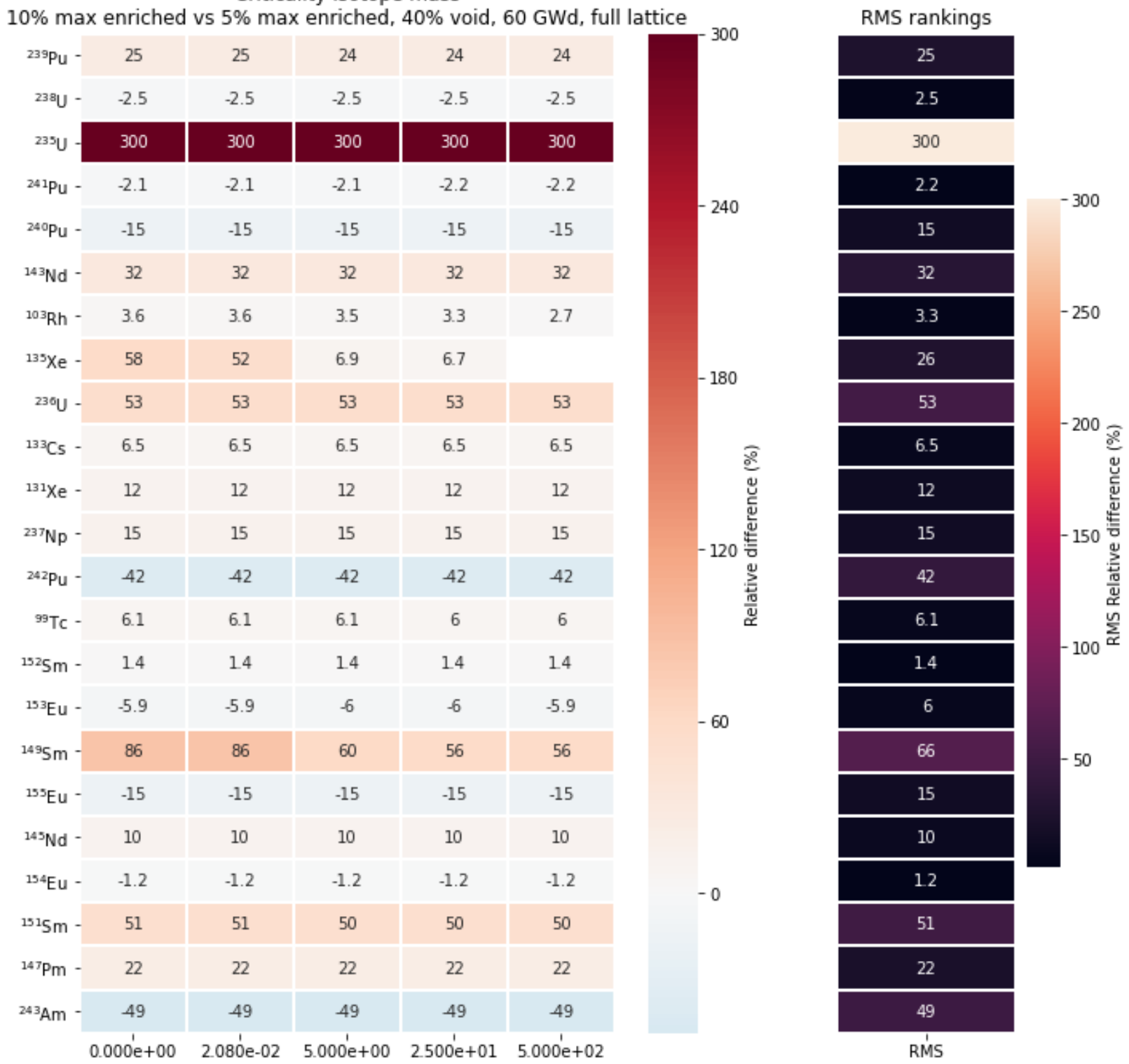


Table 28. Relative differences of criticality isotope masses due to burnup increase

Criticality isotope mass

$80 \mathrm{GWD} / \mathrm{MTU}$ vs $60 \mathrm{GWD} / \mathrm{MTU}, 10 \%$ max enriched, $40 \%$ void, full lattice

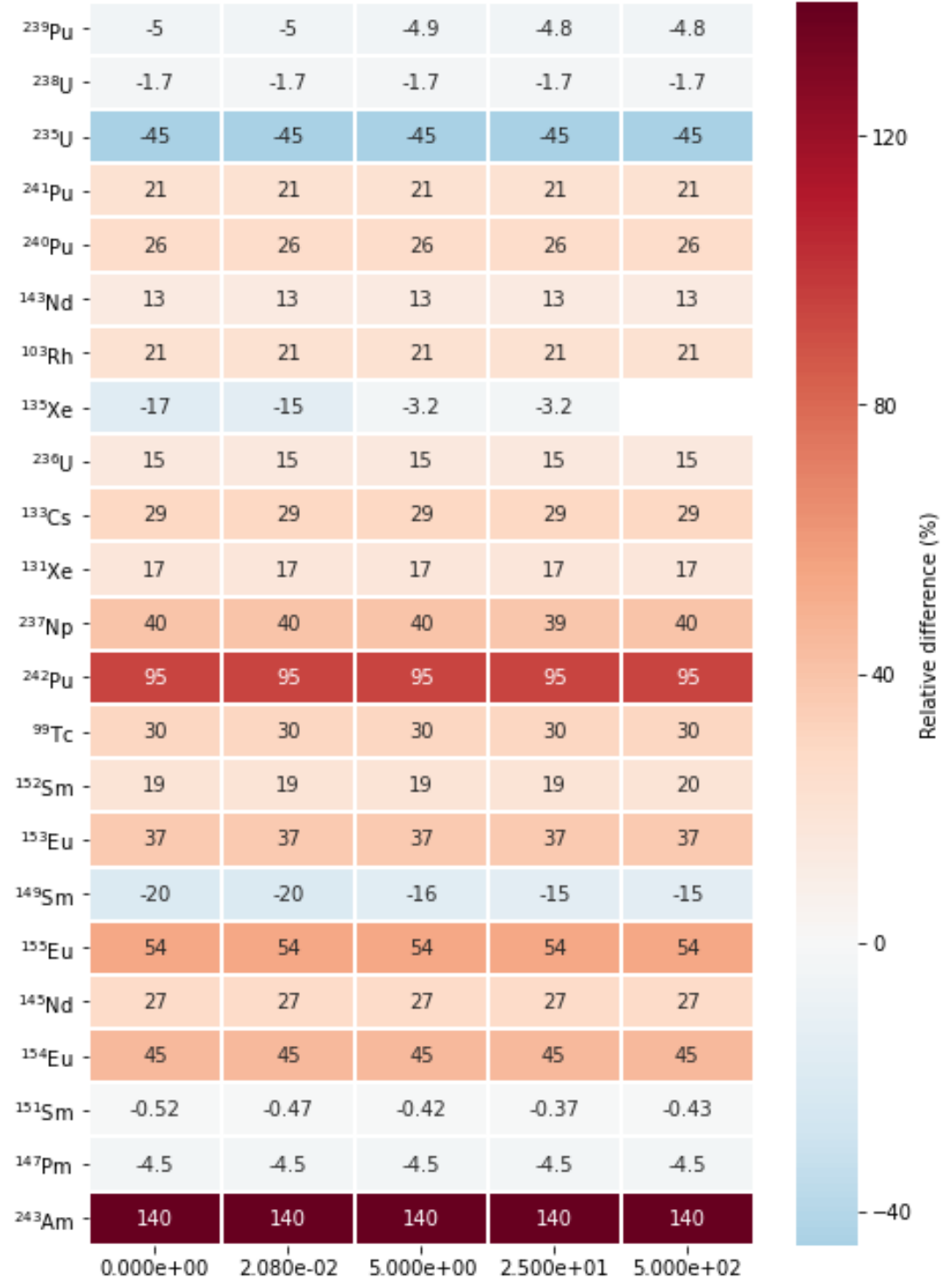

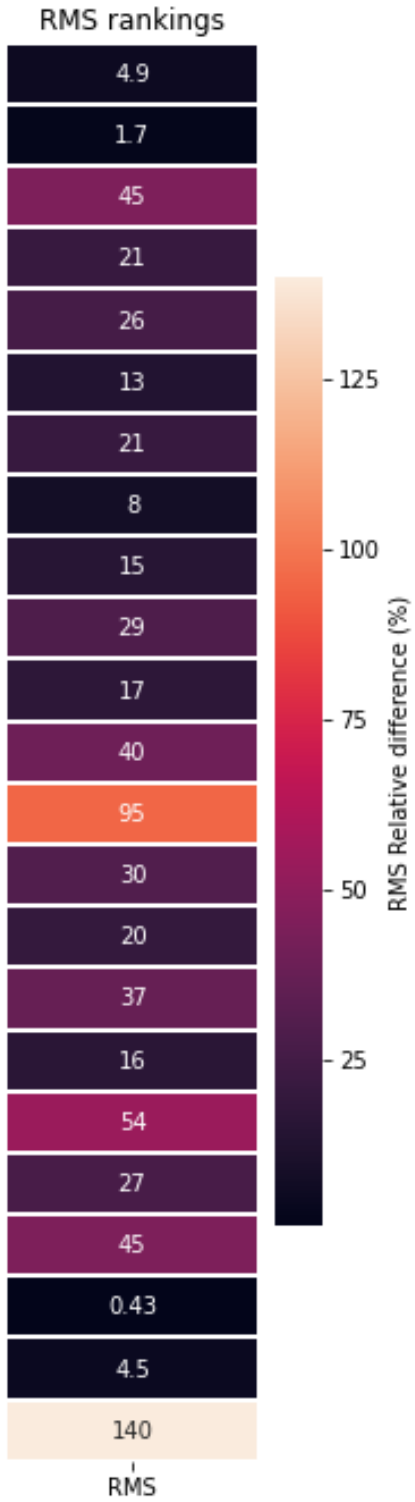


Table 29. Relative differences of criticality isotope masses due to both enrichment and burnup increase Criticality isotope mass $10 \% \max , 80 \mathrm{GWd} / \mathrm{MTU}$ vs $5 \% \max , 60 \mathrm{GWd} / \mathrm{MTU}$, full lattice $40 \%$ void

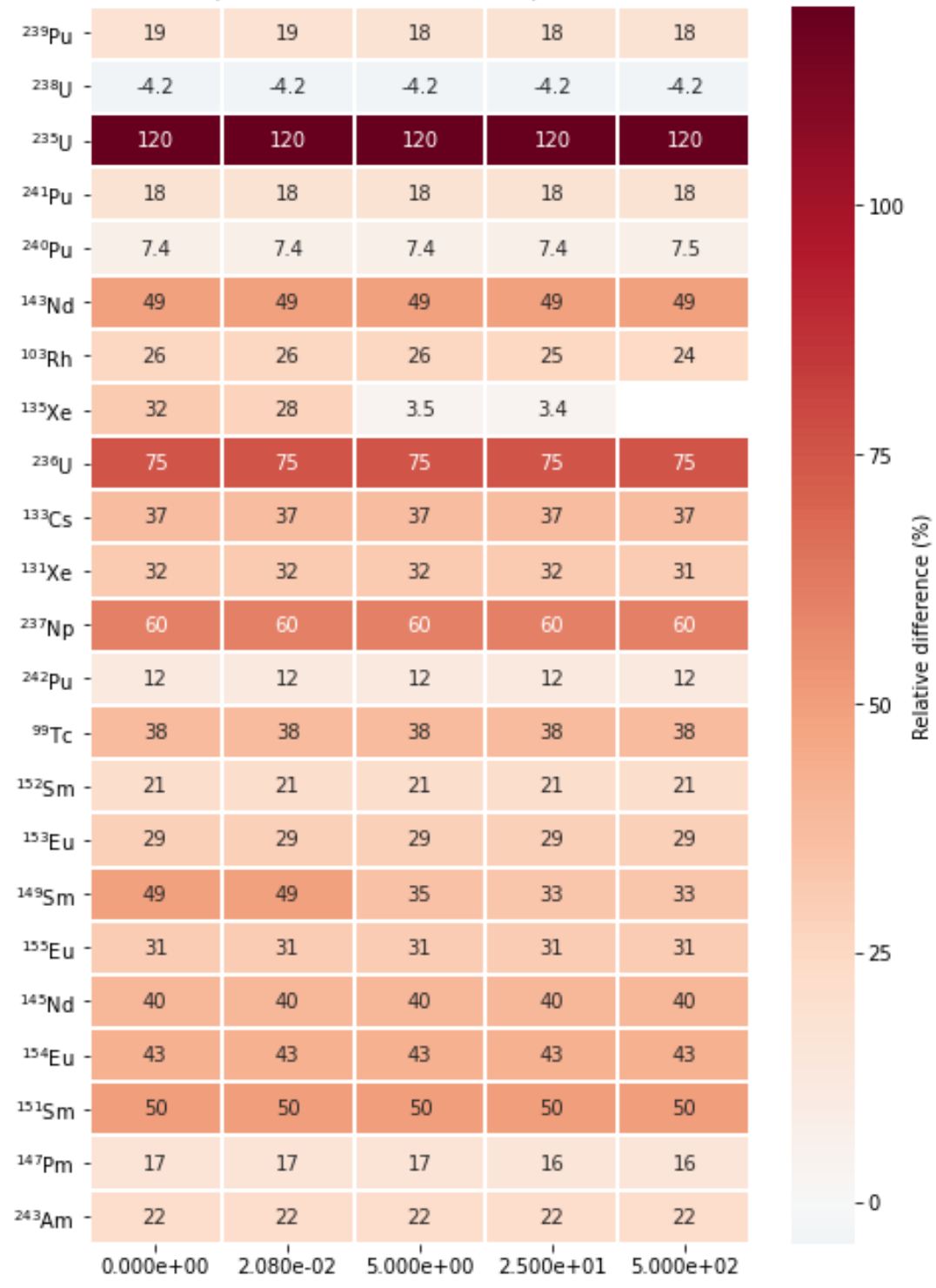

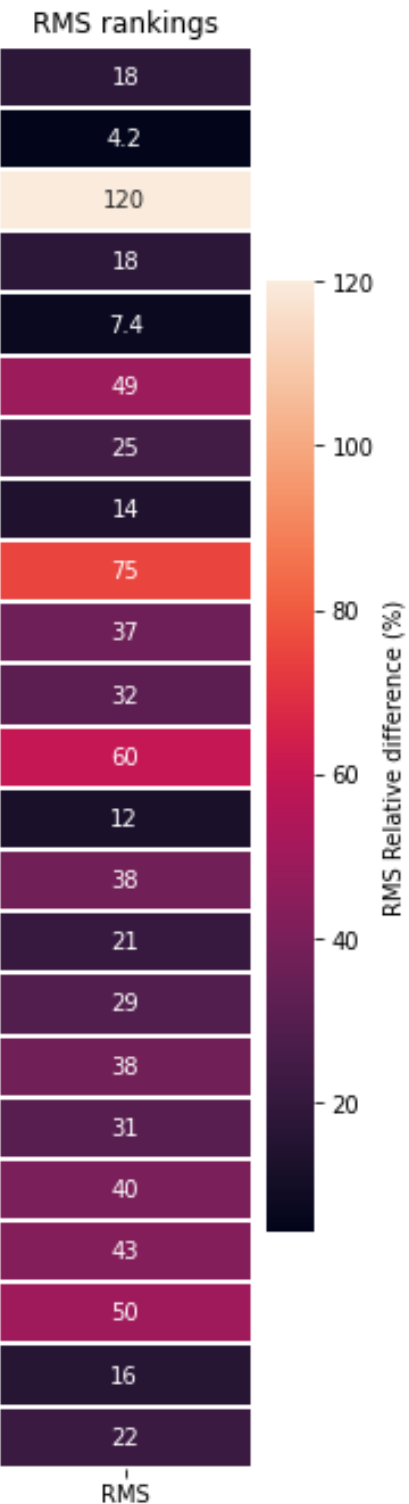


Table 30. Relative differences of criticality isotope masses due to changes in lattice design and void fraction for 10max-7.4av wt\% DOM lattice at $80 \mathrm{GWd} / \mathrm{MTU}$

\begin{tabular}{|c|c|c|c|c|c|c|c|}
\hline $\begin{array}{l}\text { Full lat } \\
10 \% \mathrm{v}\end{array}$ & & $\begin{array}{l}\text { Full lattice } \\
40 \% \text { void }\end{array}$ & $\begin{array}{r}\text { Vanished } \\
40 \%\end{array}$ & $\begin{array}{l}\text { d lattice } \\
\text { void }\end{array}$ & $\begin{array}{c}\text { Vanished } \\
70 \%\end{array}$ & $\begin{array}{l}\text { dattice } \\
\text { void }\end{array}$ & \\
\hline${ }^{103} \mathrm{Rh}$ & 0 & ${ }^{239} \mathrm{Pu} \quad 25$ & ${ }^{152} \mathrm{Sm}$ & 1.8 & ${ }^{239} \mathrm{Pu}$ & 25 & \\
\hline${ }^{145} \mathrm{Nd}$ & 0 & ${ }^{149} 5 \mathrm{~m} \quad 24$ & ${ }^{147} \mathrm{Pm}$ & 1.3 & ${ }^{1515} \mathrm{Sm}$ & 23 & \\
\hline${ }^{143} \mathrm{Nd}$ & 0 & ${ }^{151} \mathrm{Sm} \quad 22$ & ${ }^{236} \mathrm{U}$ & 1.1 & ${ }^{149} \mathrm{Sm}$ & 23 & \\
\hline${ }^{99} \mathrm{Tc}$ & 0 & ${ }^{241} \mathrm{Pu} \quad 18$ & ${ }^{131} \mathrm{Xe}$ & 0.96 & ${ }^{241} \mathrm{Pu}$ & 18 & \\
\hline${ }^{135} \mathrm{Xe}$ & 0 & ${ }^{235} \mathrm{U} \quad 16$ & ${ }^{133} \mathrm{Cs}$ & 0.75 & ${ }^{154} \mathrm{Eu}$ & 16 & \\
\hline${ }^{131} \mathrm{Xe}$ & 0 & ${ }^{154} \mathrm{Eu} \quad 15$ & ${ }^{99} \mathrm{Tc}$ & 0.63 & ${ }^{235} \mathrm{U}$ & 13 & -20 \\
\hline${ }^{133} \mathrm{Cs}$ & 0 & ${ }^{135} \mathrm{Xe} \quad 8.6$ & ${ }^{145} \mathrm{Nd}$ & 0.6 & ${ }^{240} \mathrm{Pu}$ & 9.6 & \\
\hline${ }^{152} \mathrm{Sm}$ & 0 & ${ }^{237} \mathrm{~Np} \quad 8$ & ${ }^{238} \mathrm{U}$ & 0.15 & ${ }^{135} \mathrm{Xe}$ & 8.6 & \\
\hline${ }^{147} \mathrm{Pm}$ & 0 & ${ }^{240} \mathrm{Pu} \quad 7.9$ & ${ }^{103} \mathrm{Rh}$ & -0.69 & ${ }^{143} \mathrm{Nd}$ & 6.5 & -10 \\
\hline${ }^{149} \mathrm{Sm}$ & 0 & ${ }^{143} \mathrm{Nd} \quad 5.4$ & ${ }^{153} \mathrm{Eu}$ & -0.81 & ${ }^{237} \mathrm{~Np}$ & 6.4 & \\
\hline${ }^{155} \mathrm{Eu}$ & 0 & ${ }^{155} \mathrm{Eu} \quad 4.4$ & ${ }^{240} \mathrm{Pu}$ & -0.95 & ${ }^{155} \mathrm{Eu}$ & 4.8 & \\
\hline${ }^{154} \mathrm{Eu}$ & 0 & ${ }^{243} \mathrm{Am} \quad 3.9$ & ${ }^{14}{ }^{3} \mathrm{Nd}$ & -0.97 & ${ }^{236} \mathrm{U}$ & 2 & -0 \\
\hline${ }^{153} \mathrm{Eu}$ & 0 & ${ }^{103} \mathrm{Rh} \quad 1.1$ & ${ }^{155} \mathrm{Eu}$ & -1.1 & ${ }^{103} \mathrm{Rh}$ & 0.62 & \\
\hline${ }^{151} \mathrm{Sm}$ & 0 & ${ }^{236} \mathrm{U} \quad 0.64$ & ${ }^{135} \mathrm{Xe}$ & -2.8 & ${ }^{243} \mathrm{Am}$ & 0.35 & \\
\hline${ }^{238} \mathrm{U}$ & 0 & ${ }^{153} \mathrm{Eu} \quad 0.47$ & ${ }^{242} \mathrm{Pu}$ & -2.9 & ${ }^{153} \mathrm{Eu}$ & -0.33 & -10 \\
\hline${ }^{239} \mathrm{Pu}$ & 0 & ${ }^{238} \mathrm{U} \quad-0.43$ & ${ }^{237} \mathrm{~Np}$ & -4 & ${ }^{238} \mathrm{U}$ & -0.42 & \\
\hline${ }^{240} \mathrm{Pu}$ & 0 & ${ }^{99} \mathrm{Tc} \quad-1.1$ & ${ }^{154} \mathrm{Eu}$ & -4.1 & ${ }^{147} \mathrm{Pm}$ & -0.63 & \\
\hline${ }^{241} \mathrm{Pu}$ & 0 & ${ }^{133} \mathrm{Cs} \quad-1.1$ & ${ }^{243} \mathrm{Am}$ & -4.9 & ${ }^{133} \mathrm{Cs}$ & -0.79 & --20 \\
\hline${ }^{236} \mathrm{U}$ & 0 & ${ }^{145} \mathrm{Nd} \quad-1.4$ & ${ }^{151} \mathrm{Sm}$ & -5.3 & ${ }^{99} \mathrm{Tc}$ & -0.85 & \\
\hline${ }^{235} \mathrm{U}$ & 0 & ${ }^{147} \mathrm{Pm} \quad-1.5$ & ${ }^{241} \mathrm{Pu}$ & -6.1 & ${ }^{145} \mathrm{Nd}$ & -1.4 & \\
\hline${ }^{237} \mathrm{~Np}$ & 0 & ${ }^{242} \mathrm{Pu} \quad-1.9$ & ${ }^{149} \mathrm{Sm}$ & -6.9 & ${ }^{131} \mathrm{Xe}$ & -1.5 & \\
\hline${ }^{242} \mathrm{Pu}$ & 0 & ${ }^{131} \mathrm{Xe} \quad-1.9$ & ${ }^{239} \mathrm{Pu}$ & -7 & ${ }^{242} \mathrm{Pu}$ & -5.3 & \\
\hline${ }^{243} \mathrm{Am}$ & 0 & ${ }^{152} \mathrm{Sm} \quad-6.1$ & ${ }^{235} \mathrm{U}$ & -7.9 & ${ }^{152} \mathrm{Sm}$ & -6.6 & \\
\hline
\end{tabular}

\subsection{COMPARISON OF 252g AND 56g MULTIGROUP LIBRARIES}

Currently, 56-group libraries are recommended for the majority of Polaris calculations because their runtimes are faster than those in the 252-group library, and they have minimal impact on lattice eigenvalues for a wide range of internally investigated LWR configurations. The 10max$7.4 \mathrm{av} \mathrm{wt} \%$ enrichment VAN lattice with $70 \%$ void fraction was depleted to $80 \mathrm{GWd} / \mathrm{MTU}$ using 252 group cross section library to gauge the influence of group structure on isotopic results. The $70 \%$ void fraction VAN case was selected for this study to since it is the most different design compared to the PWR design used in the PWR report in Volume 1 [15]. The relative differences in isotope predictions (Eq.10) are calculated for isotopes with weights higher than $500 \mu \mathrm{g}$ per metric ton of uranium. The relative differences larger than $1 \%$ are shown in Table 31 . Two columns listing the percent change introduced from increasing enrichment from $5 \mathrm{max}-4.5 \mathrm{av} w \mathrm{w} \%$ 
to $10 \mathrm{max}-7.4 \mathrm{av} \mathrm{wt} \%$ and burnup from $60 \mathrm{GWd} / \mathrm{MTU}$ to $80 \mathrm{GWd} / \mathrm{MTU}$ in addition to amount of each isotope per MTU of the fuel are included for comparison to demonstrate where the 56group approximation may affect the takeaways in the isotope section. The change in most isotopes is only a fraction of the change introduced with EE and HBU. Except ${ }^{234} U$ and ${ }^{235} U$, all of these isotopes appear on the release term list, but they are each a small component of the total term. ${ }^{242} \mathrm{Pu}$ and ${ }^{240} \mathrm{Pu}$ appear in the list of isotopes that influence both shielding and criticality. In the case of shielding, they contribute little to the overall activity of the spent nuclear fuel in the timescales studied in this work, so the impact on shielding is likely small. This is also seen in the analysis presented in NUREG CR-5700 [9], in which the isotopes contribute negligible amounts at 5 years of cooling but can be substantial source components at 100 years of cooling. Thus, the 56-group approximation used in work described in this section likely only impacts the ${ }^{242} \mathrm{Pu}$ values for criticality, as well as the quantities of some release nuclides. The 5-10\% differences observed in the isotopics predicted by the 56-group library compared with the 252-group are larger than expected for the high enrichment and burnup case. Although, EE and HBU cases are beyond validation basis for these libraries, the biases observed in this study do not provide any information regarding relative differences in isotope concentrations when consistent libraries are used to analyze effect of EE and HBU. In the next phase of this study, more cases will be analyzed using 252-group library to verify findings of this report involving the nuclides identified in this section. 
Table 31. Relative difference between 252- and 56-group cross section structures on isotope results (other comparisons shown for reference).

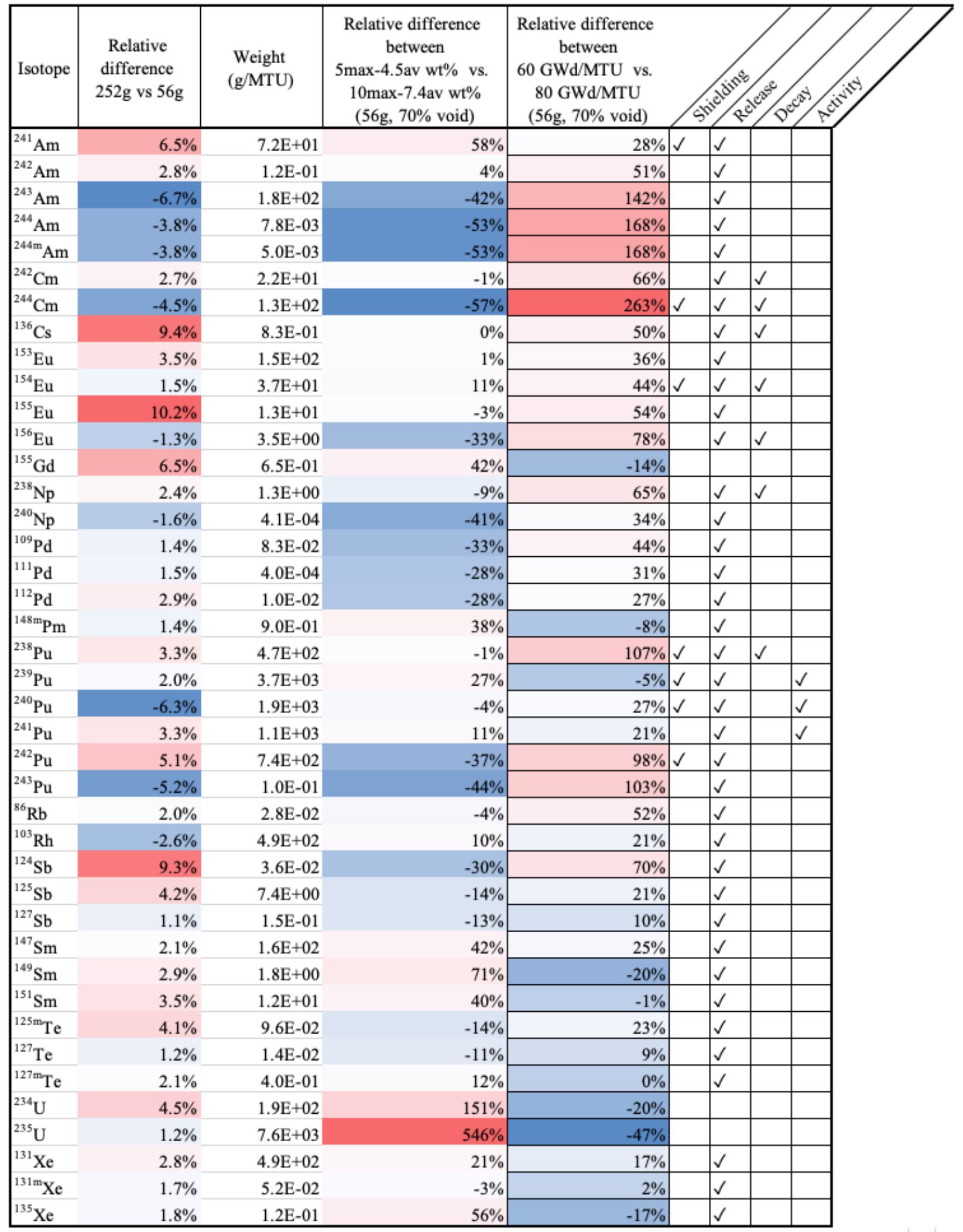




\section{CONCLUSIONS}

Calculations were performed using the pre-release version of SCALE 6.3 Polaris and ORIGEN codes with 56 -group ENDF/B-VII.1 cross section library. The effects of EE and HBU on lattice depletion characteristics of a representative commercial BWR assembly $(10 \times 10$ GNF-2) were evaluated. Similar to the first volume on PWR lattice behavior, the investigation focused on differences between depletion to conventional conditions with existing fuel (5max-4.5av wt $\%$

${ }^{235} \mathrm{U}$ enrichment depleted to $60 \mathrm{GWd} / \mathrm{MTU}$ ) and depletion with enrichments up to $10 \mathrm{max}-7.4 \mathrm{av}$ $\mathrm{wt} \%$ and burnup up to $80 \mathrm{GWd} / \mathrm{MTU}$. Unlike the PWR volume, here a new lattice enrichment map was developed for each different EE case with limited optimization on gadolinia loading, pin peaking and depletion curves.

Key quantities of interest include lattice physics quantities, isotopic inventory at various decay times and their effect on decay heat, activity and shielding applications. Limited comparisons between predictions using SCALE 56-group ENDF/B-VII.1 cross sections and SCALE 252group ENDF/B-VII.1 cross section are also presented. Conclusions from this evaluation are in general, very similar to the ones found the PWR Volume 1 report and are as follows.

1. No unexpected or anomalous trends were found that would call into question the accuracy of the Polaris code using SCALE 56-group ENDF/B-VII.1 data for depletion, lattice physics, and isotopic content calculations of the analyzed BWR fuel with enrichments up to 10max$7.4 \mathrm{av} \mathrm{wt} \%$ and burnup up to $80 \mathrm{GWd} / \mathrm{MTU}$.

2. Increased enrichment and higher burnup are positively correlated due to the requirements of commercial BWR fuel management (fuel economics and reactor physics). This correlation tends to result in offsetting lattice physics effects when combined with single-assembly results to estimate core average characteristics.

3. Lattice physics results from the Polaris model depletion of GNF-2 $10 \times 10$ DOM and VAN lattices with void fractions varying from $10 \%$ to $70 \%$ overall showed no unusual, unexpected, or adverse code performance trends.

a. Calculated fuel $k_{\text {inf, }}$, peaking factors, and reactivity coefficients are smooth and continuous as a function of enrichment and burnup.

b. Lattice physics trends were predictable from first principles (e.g., spectral hardening resulting from increased ${ }^{235} \mathrm{U}$ enrichment).

c. A first-order approximation shows that lattice average burnup is expected to 10 $\mathrm{GWd} / \mathrm{MTU}$ for each $1 \mathrm{wt} \%$ increase in lattice average fuel enrichment above $5 \mathrm{wt} \%$. This approximation can be used to extend the results of single-assembly lattice physics calculations to expected core average behavior.

d. Core average fuel temperature coefficient (DTC) and $\beta$-eff kinetics parameter are not expected to change substantially due to the offsetting effects of increased enrichment and increased burnup. However, moderator void coefficient depends on initial gadolinium loading, and the moderator void coefficient for a lattice at beginning of life was only 
slightly negative for some lattices in this study. Thus special attention should be paid when optimizing enrichment maps.

4. Uncertainty in depletion $k_{\text {inf }}$ due to cross section uncertainties changes negligibly for EE and HBU compared to the reference case. Increasing enrichment, increases $k_{\text {inf }}$ uncertainty initially $(\sim 50 \mathrm{pcm})$; however, the uncertainty decreases with burnup and becomes lower than the reference case after $50 \mathrm{GWd} / \mathrm{MTU}$.

5. Increasing enrichment from $5 \max -4.5 \mathrm{av} w \mathrm{t} \%$ to $10 \mathrm{max}-7.4 \mathrm{av} \mathrm{wt} \%$ at $60 \mathrm{GWd} / \mathrm{MTU}$ leads to minor changes in decay heat. At time $=0$, decay heat increased by $3 \%$ and then decreased to $-10 \%$ at 500 days and reaches to $-5 \%$ at 1000 days relatively compared with the reference 5 max -4.5 av wt $\%$ case.

6. Increasing burnup from 60 to $80 \mathrm{GWd} / \mathrm{MTU}$ for $5 \mathrm{max}-4.5 \mathrm{av} \mathrm{wt} \%$ leads to a negligible change at time $=0$ and a growing change from 10 days (7\%) to 1000 days (43\%) relatively compared with the reference $60 \mathrm{GWd} / \mathrm{MTU}$. However absolute difference is negligible at 1000 days, the $80 \mathrm{GWd} / \mathrm{MTU}$ fuel has less than $1.5 \mathrm{~kW} / \mathrm{MTU}$ decay heat difference compared with the reference $60 \mathrm{GWd} / \mathrm{MTU}$ case.

7. Effects of increases in burnup and enrichment on decay heat are in opposite directions, so the combined effect is a 18\% increase at 500 days for increased enrichment and burnup compared with a $35 \%$ increase for only burnup. However, the absolute difference only makes $1 \mathrm{~kW} / \mathrm{MTU}$ difference.

8. Decay heat calculations for VAN lattice show similar trends with DOM lattice. Increasing void fraction has negligible effect on decay heat compared to burnup and enrichment increase.

9. Activity shows similar trends to decay heat, but with less magnitude.

10. Isotopic results from the Polaris model depletion of GNF-2 $10 \times 10$ DOM and VAN fuel lattices overall showed no unusual, unexpected, or adverse code performance trends.

a. No single isotope influenced decay heat by more than $11 \%$ in any case analyzed.

b. No single isotope changed activity by more than $5.2 \%$ in any case analyzed.

c. ${ }^{244} \mathrm{Cm}$ is the main isotope that changes the spontaneous neutron emission source substantially for the timescales in question.

d. Of the criticality-related isotopes evaluated, when increasing burnup to $80 \mathrm{GWd} / \mathrm{MTU}$ and enrichment to $10 \mathrm{max}-7.4 \mathrm{av} \mathrm{wt} \%$, only ${ }^{243} \mathrm{Am}$ changed in composition by over a factor of 2 for the cases analyzed.

e. When changing from the 252- to the 56-group library, no isotope changed in mass by more than $10 \%$ for the $80 \mathrm{GWd} / \mathrm{MTU}, 10 \mathrm{max}-7.4 \mathrm{av} \mathrm{wt} \%$ VAN $70 \%$ void fraction case. 
11. Each EE lattice requires a new enrichment loading pattern to be designed to match the reference case lattice design constraints. The loading patterns designed in for this study are adequate for the first phase. However, a more rigorous gadolinia loading and enrichment pattern optimization is needed for more realistic MVC and pin power distribution comparisons. Based on loading pattern trends in the industry, higher gadolinia loadings are expected. Increased gadolinia loading is also expected to further reduce the differences observed in the gadolinia depletion region for EE cases.

12. The results do not show significant changes when lattice type was changed, and void fraction was increased from the reference case. These inconsistent comparisons (DOM to VAN, 40\% to $70 \%$ void fractions) show the bounding, conservative changes that could be expected for consistent comparisons (e.g., using 5max-4.5av wt\% VAN lattice at $70 \%$ as the reference case and performing the same EE and HBU analyses). For the cases with the largest changes due to lattice type or void fraction change, this assumption should be verified in the next phase.

13. Higher than expected differences were observed in isotope contents calculated at 80 $\mathrm{GWd} / \mathrm{MTU}$ with $56 \mathrm{~g}$ vs $252 \mathrm{~g}$ cross section libraries for some isotopes. However, these differences are negligible when compared to the magnitude of the change in isotopic contents when the reference case was compared to EE and HBU cases. Furthermore, comparison of $252 \mathrm{~g}$ library results to the reference case results calculated from $56 \mathrm{~g}$ library is an inconsistent bounding comparison to show that conclusions in this report would be valid when cross section library is changed. Reactivity coefficients calculated using $252 \mathrm{~g}$ library in Appendix A confirms this conclusion. However, this assumption will be further verified in the next phase by repeating selected isotopic analyses with $252 \mathrm{~g}$ library and confirming the findings.

14. Although no unexpected behavior was observed, verification basis for $56 \mathrm{~g}$ and $252 \mathrm{~g}$ cross section libraries will be extended to $80 \mathrm{GWd} / \mathrm{MTU}$ using continuous energy Monte Carlo depletion calculations in the next phase of this study.

15. Changes in pin power distributions were not analyzed in this phase because of their dependency to enrichment loading patterns which will be optimized in the next phase.

\section{ACKNOWLEDGMENTS}

Support for this work was provided by the US Nuclear Regulatory Commission Offices of Nuclear Regulatory Research, Nuclear Reactor Regulation, and Nuclear Material Safety and Safeguards. The authors would also like to thank many ORNL staff members for feedback on the contents and presentation in this report. 


\section{REFERENCES}

1. M. Diaz, 2019, DSFM Regulatory Conference, "Advanced Fuels Update on the Front End of the Fuel Cycle,” https://www.nrc.gov/docs/ML1925/ML19255F598.pdf

2. F. Pimental et al., 2019, "The Economic Benefits and Challenges with Utilizing Increased Enrichment and Fuel Burnup for Light-Water Reactors," Nuclear Energy Institute.

3. W. Marshall et al., 2015, Technical Basis for Peak Reactivity Burnup Credit for BWR Spent Nuclear Fuel in Storage and Transportation Systems, NUREG/CR-7194.

4. W. A. Wieselquist, R. A. Lefebvre, and M. A. Jessee, Eds., SCALE Code System, ORNL/TM2005/39, Version 6.2.4, Oak Ridge National Laboratory, Oak Ridge, TN (2020).

5. K. Way and E. P. Wigner, The Rate of Decay of Fission Products, Phys. Rev. 73, 1318, 1948.

6. S Glasstone, Nuclear Reactor Engineering $\quad$ Princeton, N.J. Van Nostrand [1967]

7. N. E. Todreas and M. S. Kazimi, 1990, Nuclear Systems I Thermal Hydraulic Fundamentals. Taylor \& Francis Group, LLC, New York, US Nuclear Regulatory Commission 2000.

8. Regulatory Guide 1.183: Alternative Radiological Source Terms for Evaluating Design Basis Accidents at Nuclear Power Reactors.

9. I. C. Gauld and J. C. Ryman, 2000, Nuclide Importance to Criticality Safety, Decay Heating, and Source Terms Related to Transport and Interim Storage of High-Burnup LWR Fuel, NUREG/CR6700 .

10. Nuclear Regulatory Commission, 2014, ML14113A088, LaSalle, Units 1 \& 2, Updated Final Safety Analysis Report, Revision 20, Chapter 4.0, Reactor. http://www.nrc.gov/docs/ML0813/ML081330057.pdf

11. W. J. Marshall et. al., Technical Basis for Peak Reactivity Burnup Credit for BWR Spent Nuclear Fuel in Storage and Transportation Systems, NUREG/CR-7194 (ORNL/TM- 2014/240), prepared for the US Nuclear Regulatory Commission by Oak Ridge National Laboratory, Oak Ridge, TN (2015). https://www.nrc.gov/docs/ML1509/ML15097A186.pdf

12. LaSalle, Units $1 \& 2$, Submittal of Updated Final Safety Analysis Report (UFSAR), Revision 20, Chapter 4, ML14113A088, April 2014. https:/www.nrc.gov/docs/ML1411/ML14113A088.pdf

13. D.J. Kelly, "Depletion of a BWR Lattice Using the RACER Continuous energy Monte Carlo Code ", Proc Int. Conf. on Math and Comp. Reactor Physics, and Env, Analysis, Portland, Oregon, USA, 1995,

14. M. L. Fensin. Optimum Boiling Water Reactor Fuel Design Strategies to Enhance Reactor Shutdown by the Standby Liquid Control System, Master's Thesis, University of Florida (2004).

15. R. Hall et. al., "Isotopic and Fuel Lattice Parameter Trends in Extended Enrichment and Higher Burnup LWR Fuel Vol. 1: PWR Fuel”, ORNL/TM-202/1833 


\section{APPENDIX A. EFFECT OF CROSS SECTION LIBRARY}

A separate analysis was performed to identify any effect in the reactivity, DTC, and MVC based on the cross-section library. The purpose of this comparison is to provide some qualitative insight into the impact of the 56-group cross section approximation used throughout this volume. The 10\% lattice was depleted using SCALE 56-group ENDF/B-VII.1 cross sections and SCALE 252-group ENDF/B-VII.1 cross sections. Figure A.3. shows the difference in the reactivity for the dominant (DOM) and vanished (VAN) region lattices up to $80 \mathrm{GWd} / \mathrm{MTU}$. This figure shows that the 56-group library consistently predicts greater reactivity for much of the depletion, with the exception being in the vanished lattice at 75+ GWd/MTU. Overall, the differences are small compared to the $\mathrm{k}_{\text {inf }}$ changes observed between lattice types, void fractions and enrichments seen in Figure 6.

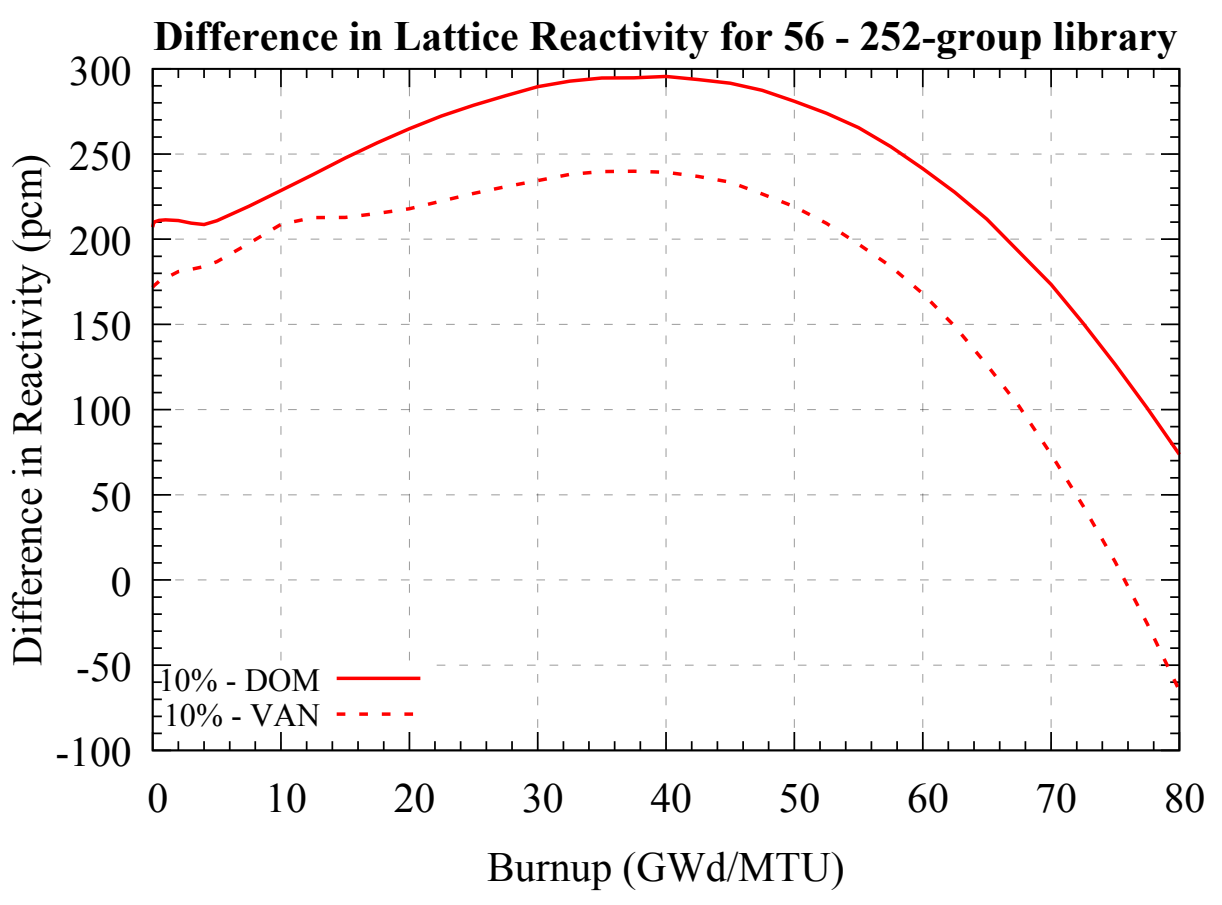

Figure 27. Difference in reactivity between the 252 and 56 g cross section libraries for the $\mathbf{1 0 \%}$ limit dominant and vanished lattices.

Additionally, the DTC (Figure A.4.) and MVC (Figure A.5.) show consistent trends at higher burnups between the dominant and vanished lattices and the 56- and 252-group cross section libraries. Initially, the DTC for the 56-group library is greater until the lattice reaches $\sim 20$ $\mathrm{GWd} / \mathrm{MTU}$, at which point the DTCs for the 56- and 252-group intersect. Again, this is simply to provide some level of reassurance that there is little impact of cross section library approximation upon the conclusions reached in this volume. 
Fuel Temp. Coefficient of Reactivity for 56 - 252-group lib.

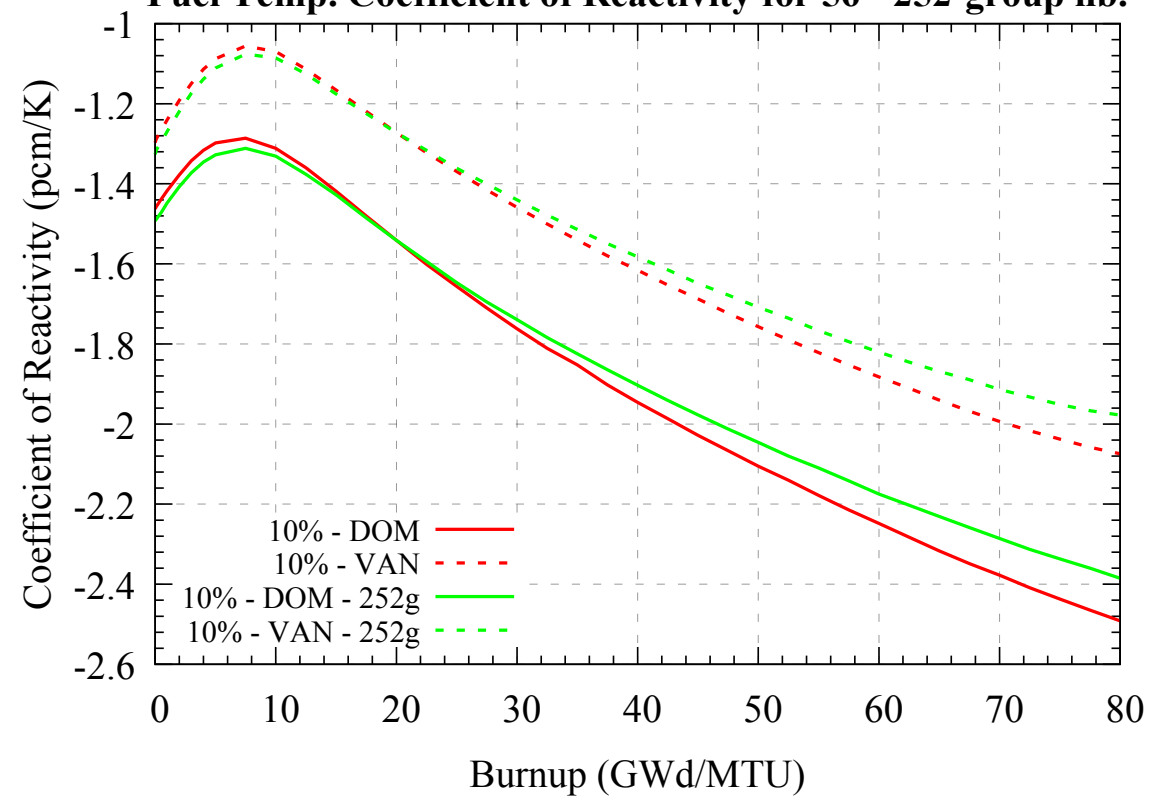

Figure 28. Comparison of the Doppler temperature coefficient (DTC) for the 252 and $56 \mathrm{~g}$ cross section libraries for the $\mathbf{1 0 \%}$ limit dominant and vanished lattices.

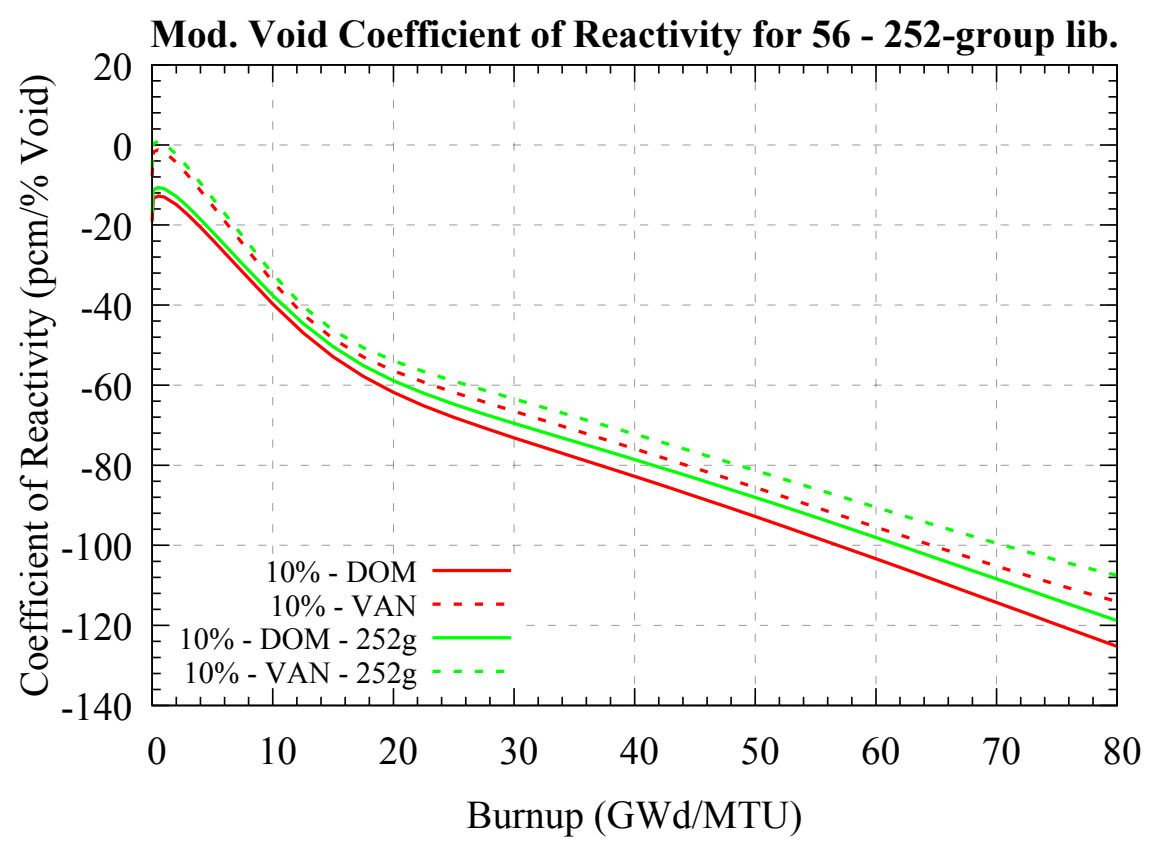

Figure 29. Comparison of the moderator void coefficient (MVC) for the 252 and $56 \mathrm{~g}$ cross section libraries for the $10 \%$ limit dominant and vanished lattices. 


\section{APPENDIX B. ARCHIVE FILE CONTENT}

The input and output names (in association with their respective directory names) for the lattice models used in this report are self-explanatory. Organization of the directories and related subdirectories are provided in Table B-1. The naming convention for each lattice model is also provided in Table B-2. A list of spreadsheets with the associated tables and figures in this document are listed in Table B-3

Table B.1. Main directory structure of input and output repository

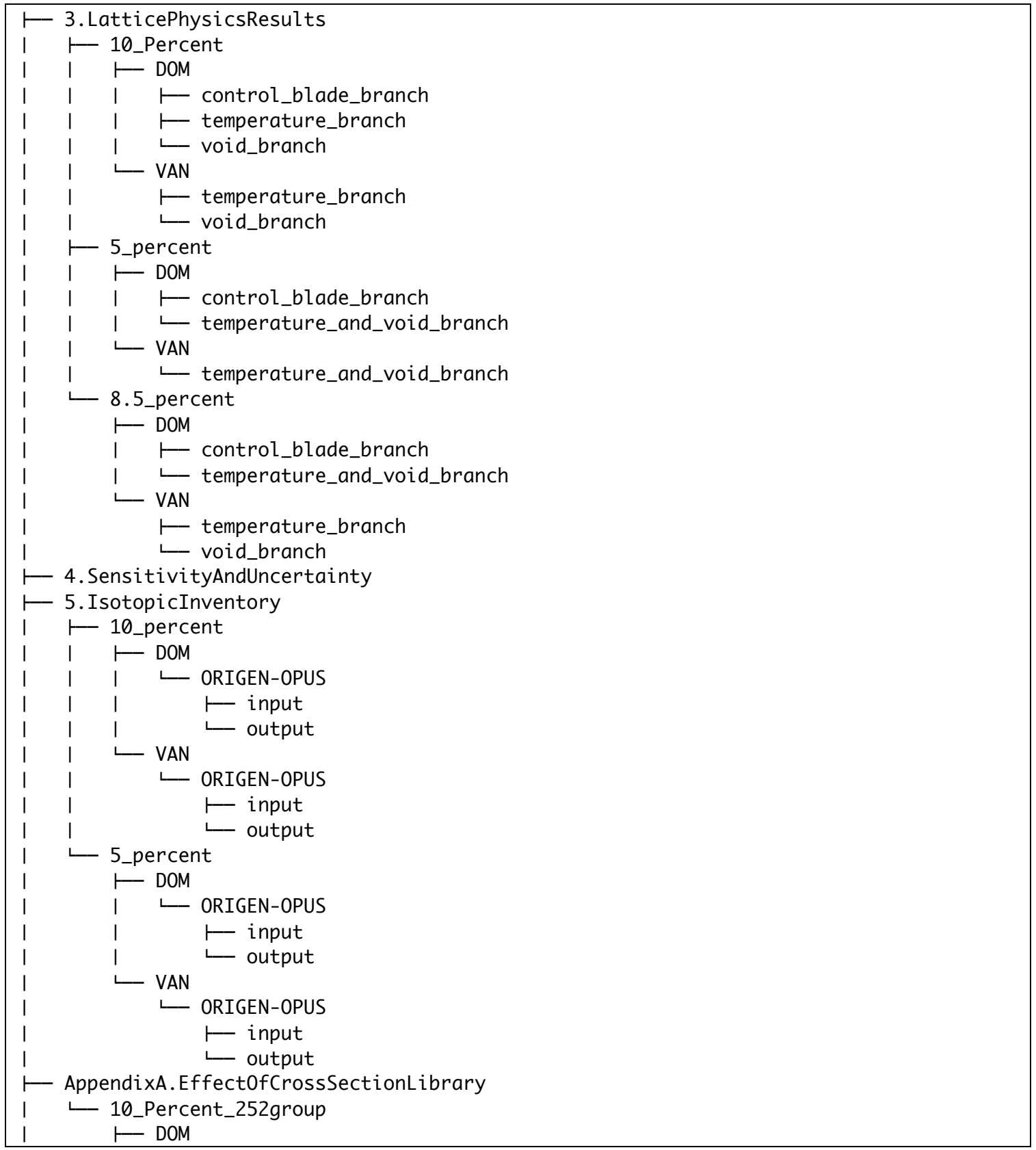




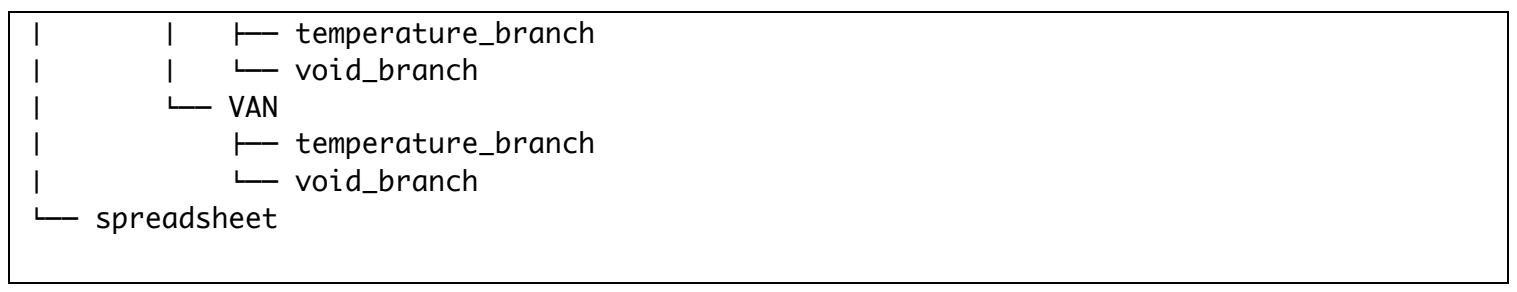

Table B.2. Input model naming convention used in this report

\begin{tabular}{|l|l|}
\hline Filename & Description \\
\hline GE14_5v40.inp & $\begin{array}{l}\text { GE-14 Dominant region lattice with 5\%max-4.5av } \\
\text { enrichment at 40\% void fraction }\end{array}$ \\
\hline GE14_5v10.inp & $\begin{array}{l}\text { GE-14 Dominant region lattice with 5\%max-4.5av } \\
\text { enrichment at } 10 \% \text { void fraction }\end{array}$ \\
\hline GE14_5v40_van.inp & $\begin{array}{l}\text { GE-14 Vanished region lattice with 5\%max-4.5av } \\
\text { enrichment at 40\% void fraction }\end{array}$ \\
\hline GE14_8.5v40.inp & $\begin{array}{l}\text { GE-14 Dominant region lattice with } 8.5 \% \text { max- } \\
6.5 \text { av enrichment at 40\% void fraction }\end{array}$ \\
\hline GE14_8.5v40_van.inp & $\begin{array}{l}\text { GE-14 Vanished region lattice with 8.5\%max- } \\
5.92 \text { av enrichment at 40\% void fraction }\end{array}$ \\
\hline GE14_8v40.inp* & $\begin{array}{l}\text { GE-14 Dominant region lattice with } 10 \% \text { max- } \\
7.4 \text { av enrichment at 40\% void fraction }\end{array}$ \\
\hline $\begin{array}{l}* 10 \% \text { maximum-7.4 \% average enrichment cases were originally named to be consistent with PWR maximum } \\
\text { enrichment cases. }\end{array}$
\end{tabular}

Table B.3. Spreadsheets and corresponding sections

\begin{tabular}{|l|l|l|c|}
\hline Figure & Spreadsheet & Sheet & Section \\
\hline Figure 4 & fluxratios.xlsx & plots & 3.1 \\
\hline Figure 5 & 1_Group_Flux.xlsx & Sheet1 & 3.1 \\
\hline $\begin{array}{l}\text { Figure 6, Figure 7, } \\
\text { Figure 8, Figure 9 }\end{array}$ & multiplication_factor.xlsx & plot & 3.2 \\
\hline Figure 10, Figure 11 & crosssection-abs.xlsx & flux_group1, flux_group2 & 3.3 .1 \\
\hline Figure 12, Figure 13 & crosssection-fiss.xlsx & $\begin{array}{l}\text { fission_macro_group1, } \\
\text { fission_macro_group2 }\end{array}$ & 3.3 .1 \\
\hline Figure 14 & beta_eff.xlsx & beta_eff & 3.3 .2 \\
\hline Figure 4 & static_responses.1.stddev.8e.xlsx & Sheet3 & 4.2 \\
\hline Figure 15 & uncertaintyKeff.v40.xlsx & Sheet1 & 4.2 \\
\hline $\begin{array}{l}\text { Figure 17, Figure 18, } \\
\text { Figure 19, Figure 20, } \\
\text { Figure 22, Figure 23, } \\
\text { Figure 24 }\end{array}$ & decay_heat_and_activity.xlsx & Decay_Heat3, Activity2 & $5.1,5.2$ \\
\hline Figure 25, Figure 21 & inreactor_inventories.xlsm & & \\
\hline Figure 26 & spontaneousFission.xlsx & Sheet1 & \\
\hline Table 31 & isotopes252vs56.xlsm & 56-enr & 5.2 \\
\hline
\end{tabular}

